\title{
Lusioersily
}

\section{Theoretical analysis on efficiency factor of direct expansion PV/T module for heat pump application}

Yao, J., Chen, E., Dai, Y., \& Huang, M. (2020). Theoretical analysis on efficiency factor of direct expansion PV/T module for heat pump application. Solar Energy, 206, 677-694. https://doi.org/10.1016/j.solener.2020.04.053

Link to publication record in Ulster University Research Portal

Published in:
Solar Energy

Publication Status:

Published (in print/issue): 31/08/2020

DOI:

https://doi.org/10.1016/j.solener.2020.04.053

\section{Document Version}

Author Accepted version

\section{General rights}

Copyright for the publications made accessible via Ulster University's Research Portal is retained by the author(s) and / or other copyright owners and it is a condition of accessing these publications that users recognise and abide by the legal requirements associated with these rights.

\section{Take down policy}

The Research Portal is Ulster University's institutional repository that provides access to Ulster's research outputs. Every effort has been made to ensure that content in the Research Portal does not infringe any person's rights, or applicable UK laws. If you discover content in the Research Portal that you believe breaches copyright or violates any law, please contact pure-support@ulster.ac.uk. 


\title{
Theoretical analysis on efficiency factor of direct expansion PVT module for heat pump application
}

\author{
Jian YAO $^{\text {a, b }}$, Erjian CHEN ${ }^{\text {a, b }}$, Yanjun DAI *, a, b, Mingjun HUANG $^{\text {c }}$ \\ ${ }^{\text {a }}$ Institute of Refrigeration and Cryogenics, Shanghai Jiao Tong University, Shanghai 200240, China \\ ${ }^{\mathrm{b}}$ Engineering Research Center of Solar Energy and Refrigeration, MOE, China \\ ${ }^{\mathrm{c}}$ Centre for Sustainable Technologies, School of the Built Environment, University of Ulster, Newtownabbey, \\ Northern Ireland, BT37 0QB, UK \\ *: Corresponding author: E-mail address: yjdai@ @jtu.edu.cn (Yanjun DAI); Tel.: +86-21-34204358; fax: \\ $+86-21-34206814$
}

\begin{abstract}
Direct expansion solar assisted PVT (photovoltaic/thermal) heat pump is a combination of PVT technology and heat pump technology, which can improve the comprehensive conversion efficiency of solar energy, and it is suitable for solar heating applications. In this paper, the efficiency factor of direct expansion PVT module employing roll-bond panel has been theoretically derived, modified, and validated by experimental results. Moreover, the efficiency factor could be used to design, evaluate, and optimize the thermal performance of direct expansion solar assisted heat pump systems. In addition, parameter analysis of four evaporator unit types has been conducted, and the recommendation values of each parameter have also been presented. The simulation results show that the roll-bond evaporator (fluid channel width: $10 \mathrm{~mm}$ ) with hexagon and rectangle patterns have better temperature distribution uniformity than grid and linear types, and their temperature differences are both $0.038{ }^{\circ} \mathrm{C}$ while their dimensionless pressure losses are 0.109 and 0.230 , respectively. To specifically design different kinds of PVT collector/evaporator or direct expansion evaporators, a novel design method for roll-bond evaporator is proposed, and a combination of hexagon and grid types is recommended for PVT module. Moreover, the recommendation fluid channel width of the roll-bond panel is $8 \mathrm{~mm}$ to $13 \mathrm{~mm}$ while the scaling ratio is 0.8 to 1.2 . The modified efficiency factors are $0.521,0.564,0.549$, and 0.342 of hexagon, grid, rectangle, and linear types when the fluid channel width is $10 \mathrm{~mm}$, respectively.
\end{abstract}

Keywords: Solar energy; Direct expansion; PVT; Efficiency factor; Roll-bond panel; Channel design method

\section{Introduction}

The total amount of energy consumption is continuously climbing around the world, which has brought energy and environmental crisis (Caetano et al., 2017; Pietrosemoli and Rodríguez-Monroy, 2019). The development and utilization of renewable energy have become an effective solution. Compared with other renewable energy, solar energy has become the first choice and research hotspot due to its ubiquity, abundance, and sustainability (Keček et al., 2019; Kuik et al., 2019; Tsai, 2015). The solar energy utilization method could be mainly divided into two categories: photothermal and photovoltaic.

For solar thermal utilization, different solar collectors (Mellor et al., 2018) and heat transfer 
fluids like water, air, nanofluid, and refrigerant (Kamel et al., 2015) have been proposed and studied. Direct expansion solar assisted heat pump system using refrigerant as a thermal collect medium was first proposed by Sporn and Ambrose (Sporn and Ambrose, 1955) in 1955. Moreover, it is now developed and researched much more due to its high efficiency, energy-saving, stability, and environmental friendly (Mohanraj et al., 2018) and widely used for solar heating applications. In recent years, numerous researchers have conducted different studies about the direct expansion solar assisted heat pump systems. Sun et al. (Sun et al., 2015) conducted a comparison between the air source heat pump water heater (ASHPWH) and the direct expansion solar assisted heat pump water heater (DX-SAHPWH) under various operating conditions. They found that the DX-SAHPWH system takes both solar and ambient air as heat source under clear day conditions and its COP is about 1.5 times of ASHPWH. Huang et al. (Huang et al., 2016) investigated the frosting characteristics and heating performance of direct expansion solar assisted heat pump for space heating under frosting conditions. They demonstrated that solar irradiation could effectively prevent or retard frosting and improve the heating performance of the DX-SAHP system as well. Stojanović and Akander (Stojanović and Akander, 2010) used a direct-expansion heat pump for independent building heating and domestic hot water supply. In their system, the collector area is $42.5 \mathrm{~m}^{2}$ and the heat pump power is $8.4 \mathrm{~kW}$, and they measured that the actual indoor temperature is no less than $20^{\circ} \mathrm{C}$ during the testing period.

For photovoltaic utilization, $\mathrm{PV}$ panels are the primary method to transfer solar radiation into electricity directly, and it's reported that PV panels will provide $11 \%$ of global electricity by 2050 (Paolo Frankl, 2010). Nevertheless, the electrical efficiency is decreased significantly with the increase of the PV cells' temperature (Huide et al., 2017). The PVT (photovoltaic/thermal) technology coupled PV modules with thermal collectors was first proposed by Wolf et al. (Wolf, 1976) in 1976 to reduce PV cells' temperature and improve electrical efficiency. According to the merits mentioned above of refrigerant as a thermal collect medium, the direct expansion solar assisted PVT heat pump has been proposed and studied recently. Several research groups have investigated different kinds of direct expansion solar assisted PVT heat pump systems for the past few years.

Zhou et al. (Zhou et al., 2019) experimentally studied a roll-bond PVT heat pump system during summer, and they found that the average value of heating power and system heating COP are $4.7 \mathrm{~kW}$ and 6.16, respectively. Del Amo et al. (Del Amo et al., 2019) investigated the feasibility of the solar PVT heat pump through experiments. In their study, the highest COP of the system can reach 4.62 while the PV module provides $67.6 \%$ of the power demand, and the payback period is six years. Cai et al. (Cai et al., 2017) proposed a dynamic model of direct expansion PVT-air dual-source heat pump water heater system and conducted its performance characterization through simulation. Their results reveal that the system can operate with an average COP above 2.0 under an ambient temperature of $10^{\circ} \mathrm{C}$ and solar irradiation of $100 \mathrm{~W} / \mathrm{m}^{2}$. Yao et al. (Yao et al., 2020) proposed a solar assisted PVT heat pump system coupled with build-in PCM heat storage. Their simulation results show that a $20 \mathrm{~m}^{2}$ PVT panel module can output $21.4 \%$ of the electricity to the power grid when the solar radiation intensity is $600 \mathrm{~W} / \mathrm{m}^{2}$ and meet the heat demand of a $100 \mathrm{~m}^{2}$ room while maintain the operation of the system and its corresponding COP is 5.79. A novel hybrid PVT-air dual-source heat pump system is proposed by Zhang et al. (Zhang et al., 2019) and their simulation results indicated that the electrical energy output could increase $14.7 \%$ compared with a conventional PV panel. Chauhan et al. (Chauhan et al., 2019) 
theoretically evaluated and designed the PVT module and FPC collectors through entropy generation aspect. In their study, the maximum temperature reduction is $18{ }^{\circ} \mathrm{C}$ through the proposed design, and its corresponding improvement of electrical efficiency is $8.6 \%$. Zhou et al. (Zhou et al., 2020) numerically simulated a direct expansion evaporator based on a micro-channel PVT and conducted experiments to verify the numerical model. The experimental average electrical, thermal, and overall efficiencies of the PVT module are $13.1 \%, 56.6 \%$, and $69.7 \%$, respectively, while the system COP is 4.7 .

The efficiency factor is an important parameter to reflect the heat transfer capacity of solar collectors and features of the physical characteristics of thermal collectors (Zhang et al., 2012). Moreover, the efficiency factor could be used to theoretically evaluate and optimize the solar collector instead of conducted numerous experiments. As shown in Fig. 1, the researches about flat-plate solar collectors started in the early 1900s, and various investigations have conducted (Bliss, 1959; Hc and Bb, 1942; Hottel and Whillier, 1955; Saffarian et al., 2020; Wolf, 1976). The efficiency factor of water or air based PVT module has been reported by Hottle et al. ( $\mathrm{Hc}$ and Bb, 1942), Whillier et al. (Hottel and Whillier, 1955) and Bliss (Bliss, 1959). However, the efficiency factor of PVT as collector/evaporator of heat pump has not been reported, and the optimization on roll-bond evaporator design is also rarely studied. Therefore, in this paper, theoretical derivation and parameter analysis on the efficiency factor of the direct expansion PVT module have been conducted. Firstly, the direct expansion solar assisted PVT heat pump system composition, and a detailed description of the PVT collector/evaporator are introduced. Secondly, a mathematical model is used to derive the modified efficiency factor as well as the heat removal factor of four evaporator unit types. Then the theoretical efficiency factor is verified by experimental results. Finally, parameter analysis of the direct expansion PVT module employing roll-bond evaporator has been investigated. The objective of this paper is to propose the efficiency factor expression of PVT collector/evaporator and provide a novel design method for the roll-bond evaporator.

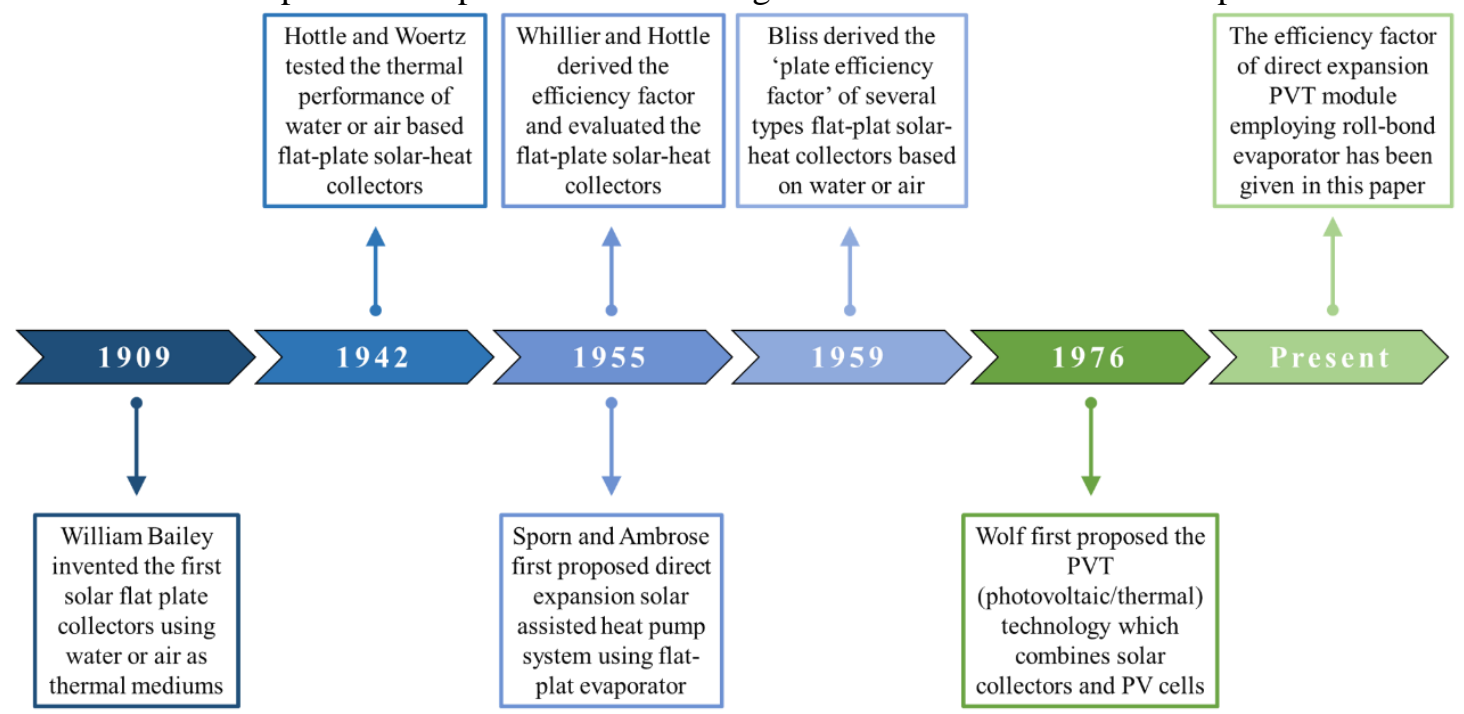

Fig. 1. The development history of flat-plate solar collectors.

\section{System description}

\subsection{Composition of solar assisted PVT heat pump}


Typical direct expansion solar assisted heat pump system is consists of evaporator, compressor, condenser, and throttle valve. The PVT collector/evaporator is an essential component of the direct expansion solar assisted heat pump system, which is shown in Fig. 2(a). Compared to conventional solar assisted heat pump system which could only produce thermal energy, the PVT module could produce both electrical and thermal energy as shown in Fig. 2(b). Moreover, the combination of photovoltaic and photothermal technology could use the cooling fluid to extract waste heat from PV cells. In the meantime, the temperature of PV cells would be regulated, and therefore the electrical efficiency would increase simultaneously. The thermal efficiency of the PVT collector/evaporator is an important parameter which would directly influence both the electrical efficiency and heat pump efficiency.

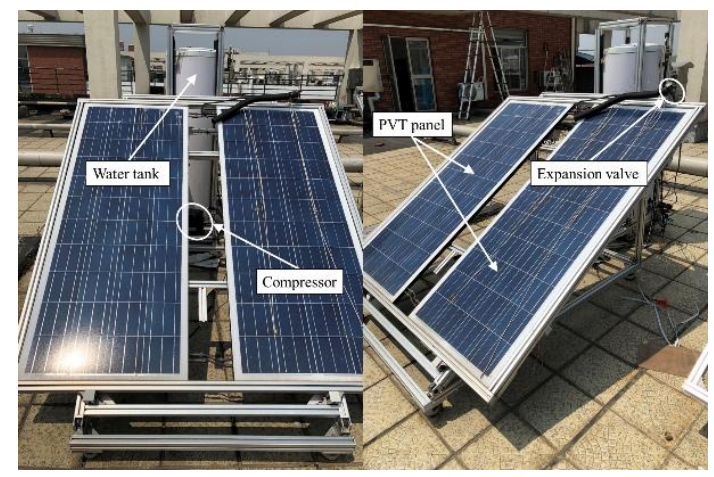

(a)

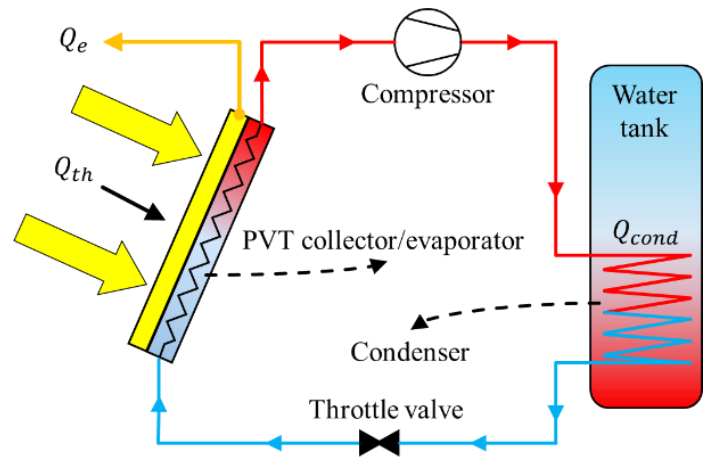

(b)

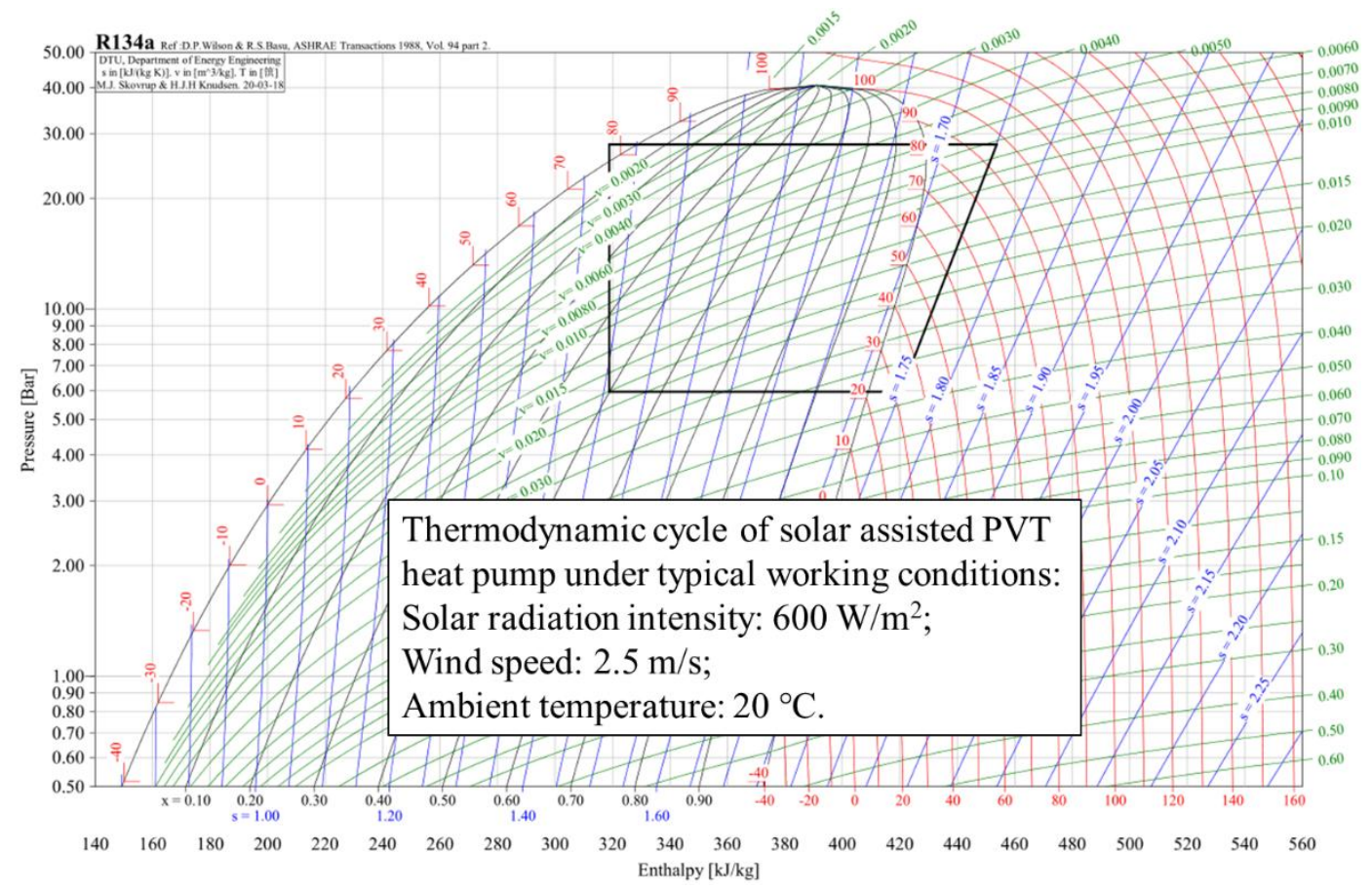

(c)

Fig. 2. (a) Solar assisted PVT heat pump system. (b) Thermodynamic cycle of direct expansion solar assisted PVT heat pump system. (c) Pressure-enthalpy diagram of solar assisted PVT heat pump thermodynamic cycle.

Fig. 2(c) shows the pressure-enthalpy diagram of solar assisted PVT heat pump thermodynamic cycle under typical working conditions: solar radiation intensity is $600 \mathrm{~W} / \mathrm{m}^{2}$; 
wind speed is $2.5 \mathrm{~m} / \mathrm{s}$, and ambient temperature is $20^{\circ} \mathrm{C}$. The refrigerant type is $\mathrm{R} 134 \mathrm{a}$ and in this case, the evaporating temperature is around $22^{\circ} \mathrm{C}$ and the condensing temperature is about $80{ }^{\circ} \mathrm{C}$

In addition, this paper focus on the theoretical analysis of the efficiency factor of direct expansion PVT module. On the other hand, the mathematical models of each part including PVT module, compressor, condenser, and throttle valve of solar assisted PVT heat pump have been established in the authors' previous work (Yao et al., 2020). In this regard, the performance analysis of the solar assisted PVT heat pump could be conducted using the mathematical models. Thus, the main points of section 3 are the theoretical derivation on efficiency factor of direct expansion PVT module and the exergy analysis. It needs to be emphasized that the expressions of the efficiency factor in section 3 are used in the mathematical model of PVT module to further simulate the system performance.

\subsection{Description of direct expansion PVT module employing roll-bond panel}

The front side of the PVT collector/evaporator is shown in Fig. 3(a) and the roll-bond panel which augmented in PVT module is shown in Fig. 3(b). The roll-bond panel is made of aluminum, and the fluid channel which painted by graphite powder is processed by high-pressure nitrogen. The channel pattern which is consists of hexagon and grid evaporator unit types has been optimized to balance the temperature distribution of the PV panel and pressure drop. As shown in Fig. 3(c), the heat loss from PVT panel to ambient is consist of two processes: (1) heat loss from PV cells to PV-glazing cover; (b) heat loss from PV-glazing cover to ambient.

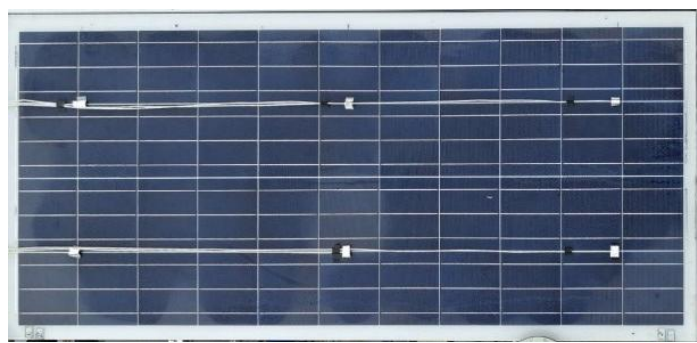

(a)

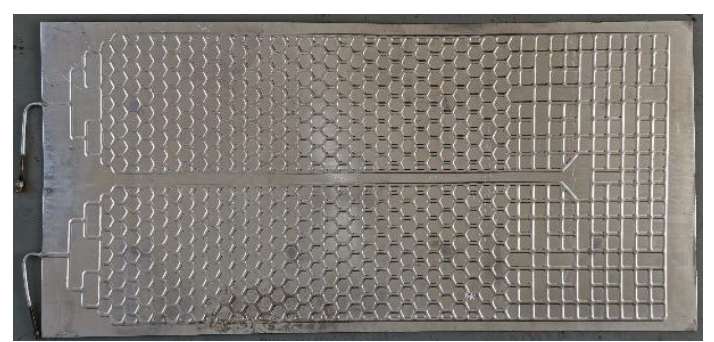

(b)

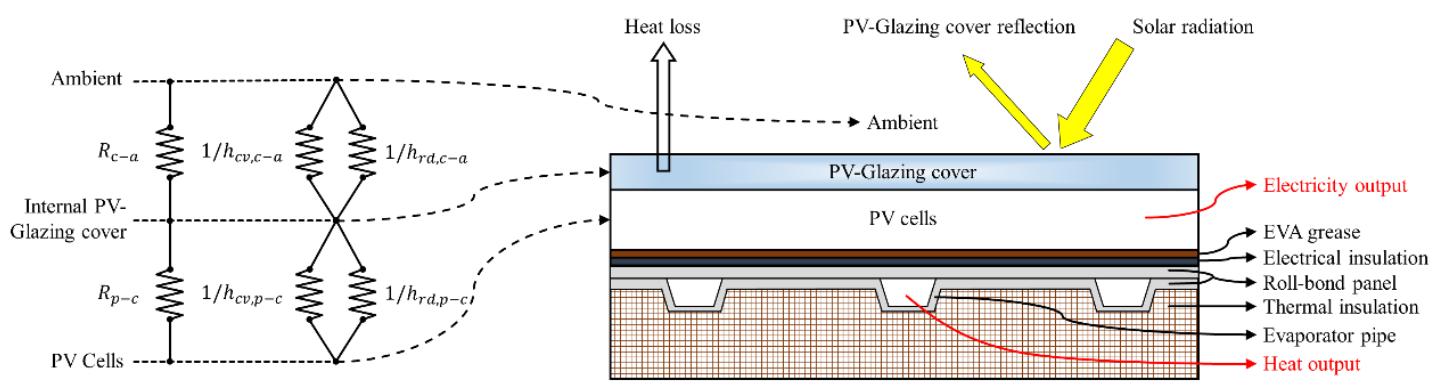

(c) 
Table. 1. Characteristic parameters of different PVT layers.

\begin{tabular}{llll}
\hline Parameters & Nomenclature & Value & Unit \\
\hline Thickness of PV-glazing cover & $\delta_{g, p v}$ & 1 & $\mathrm{~mm}$ \\
Emissivity of PV-glazing cover & $\varepsilon_{c}$ & 0.84 & {$[-]$} \\
Transmissivity of PV-glazing cover & $\tau_{g, p v}$ & 0.9 & {$[-]$} \\
Thickness of PV cells & $\delta_{p v}$ & 0.3 & $\mathrm{~mm}$ \\
Emissivity of PV cells & $\varepsilon_{p}$ & 0.96 & {$[-]$} \\
Absorptance of PV cells & $a_{p}$ & 0.85 & {$[-]$} \\
Thermal conductivity of PV cells & $\kappa_{p}$ & 203 & $\mathrm{~W} /\left(\mathrm{m} \cdot{ }^{\circ} \mathrm{C}\right)$ \\
Absorptance of PV baseboard & $a_{b}$ & 0.8 & {$[-]$} \\
Thickness of EVA (Ethylene Vinyl Acetate) grease & $\delta_{E V A}$ & 0.5 & $\mathrm{~mm}$ \\
Thermal conductivity of EVA grease & $\kappa_{E V A}$ & 0.311 & $\mathrm{~W} /\left(\mathrm{m} \cdot{ }^{\circ} \mathrm{C}\right)$ \\
Thickness of electrical insulation & $\delta_{e i}$ & 0.5 & $\mathrm{~mm}$ \\
Thermal conductivity of electrical insulation & $\kappa_{e i}$ & 0.15 & $\mathrm{~W} /\left(\mathrm{m} \cdot{ }^{\circ} \mathrm{C}\right)$ \\
Electrical insulation material & {$[-]$} & $T e d l a r$ & {$[-]$} \\
Packing factor & $\beta_{p}$ & 1 & {$[-]$} \\
Thermal conductivity of roll-bond panel & $\kappa_{r b}$ & 151 & $\mathrm{~W} /\left(\mathrm{m} \cdot{ }^{\circ} \mathrm{C}\right)$ \\
Thickness of roll-bond panel pipe & $\delta_{r b}$ & 0.9 & $\mathrm{~mm}$ \\
Area of PVT module & $A$ & 2 & $\mathrm{~m}{ }^{2}$ \\
Width of PVT module & $W_{e v a}$ & 1 & $\mathrm{~m}$ \\
Length of PVT module & $L_{e v a}$ & 2 & $\mathrm{~m}$ \\
Refrigerant type & $r e f$ & $\mathrm{R} 134 \mathrm{a}$ & {$[-]$} \\
\hline
\end{tabular}

\section{Efficiency factor and heat removal factor}

The thermal efficiency is an important parameter to evaluate the thermal performance of solar collectors, especially in direct expansion PVT module which could reflect the heat extract capacity of the thermal collectors. In general, the instantaneous heat gain by PVT collector/evaporator can be expressed as (Duffie et al., 1994):

$$
Q_{u}{ }^{\prime}=A \cdot\left[(\tau \alpha) \cdot I \cdot\left(1-\eta_{\mathrm{e}}\right)-U_{L} \cdot\left(T_{b}-T_{a}\right)\right]
$$

However, it is difficult to determine the value of the average inner surface temperature of the collector pipe $\left(T_{b}\right)$, but the refrigerant temperature $\left(T_{w}\right)$ in direct expansion evaporator is easier to determine due to the isothermal process of evaporating. Thus, $T_{b}$ could be replaced by $T_{w}$ and the heat gain by PVT collector/evaporator can be expressed as (Chauhan et al., 2018):

$$
Q_{u}{ }^{\prime}=A \cdot F^{\prime} \cdot\left[(\tau \alpha) \cdot I \cdot\left(1-\eta_{\mathrm{e}}\right)-U_{L} \cdot\left(T_{w}-T_{a}\right)\right]
$$

where $F^{\prime}$ is the efficiency factor which represents the ratio of actual useful energy gain and useful gain if the collector inner surface is at the local fluid temperature.

If the average inner surface temperature of the collector pipe $\left(T_{b}\right)$ replaced by inlet temperature of refrigerant $\left(T_{i}\right)$, the heat gain by PVT collector/evaporator can be expressed as (Chauhan et al., 2018):

$$
Q_{u}{ }^{\prime}=A \cdot F_{R} \cdot\left[(\tau \alpha) \cdot I \cdot\left(1-\eta_{\mathrm{e}}\right)-U_{L} \cdot\left(T_{i}-T_{a}\right)\right]
$$


where $F_{R}$ is the heat removal factor which represents the ratio of actual useful energy gain and useful gain if the collector inner surface is equal to the temperature of inlet fluid.

In general, the efficiency factor $F^{\prime}$ is an index to evaluate how good the heat transfer is between the thermal collector and the heat transfer fluid, while the heat removal factor is a measure of the solar collector performance as a heat exchanger as it can be interpreted as the ratio of actual heat transfer and the maximum possible heat transfer. Moreover, both factors could reflect the physical construction features, thermal performance, and operating parameters of different kinds of thermal collectors. Consequently, the efficiency factor and heat removal factor could be used to simulate the performance of the direct expansion evaporator or PVT module which employing roll-bond panel in solar assisted heat pump system instead of conduct numerous experiments to get the thermal performance indices. Furthermore, it would be used in the design and optimization of direct expansion PVT module and solar assisted heat pump system. In this section, the derivation on efficiency factor and heat removal factor of both direct expansion evaporator and direct expansion PVT module would be presented in detail.

\subsection{Physical model}

As shown in Fig. 3(c), a direct expansion PVT module employing the roll-bond panel has a multilayer structure. The physical and heat transfer model of $W \times L$ PVT and direct expansion evaporator units have shown in Fig. 4. The only difference in efficiency factor between the PVT module and direct expansion evaporator is the expression of the heat loss coefficient. Thus, the derivation method of efficiency factor and the heat removal factor are the same of these two models.

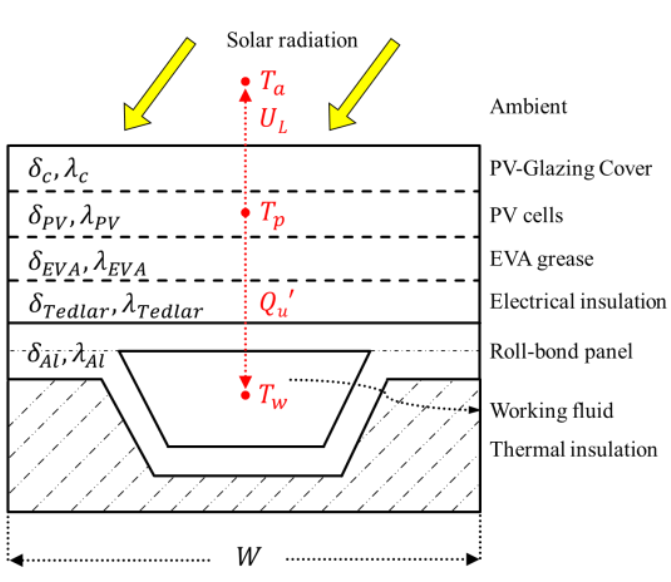

(a)

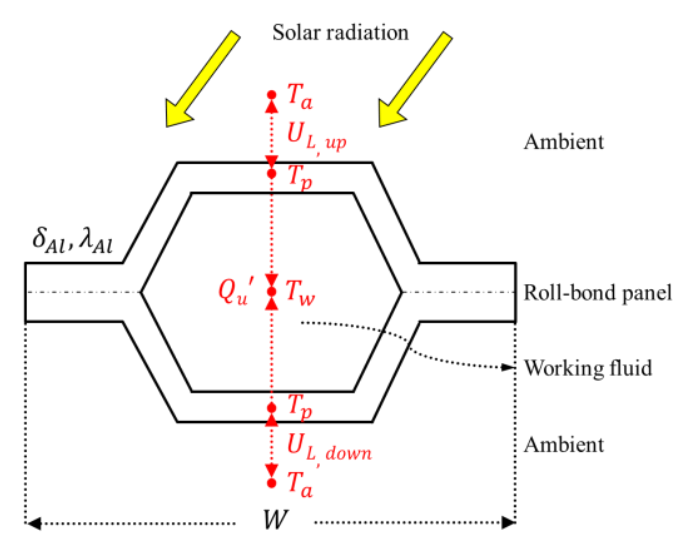

(b)

Fig. 4. (a) Physical and heat transfer model of a PVT unit. (b) Physical and heat transfer model of a direct expansion evaporator unit.

The channel pattern of the roll-bond panel has presented in Fig. 3(b). This panel is consist of different types of evaporator unit which have shown in Fig. 5. The evaporator unit's width is $W$ (35 mm) and length is $L(60 \mathrm{~mm})$, the detailed size has also shown in Fig. 5. The theoretical derivation of the efficiency factor and the heat removal factor is based on these four types of units. 

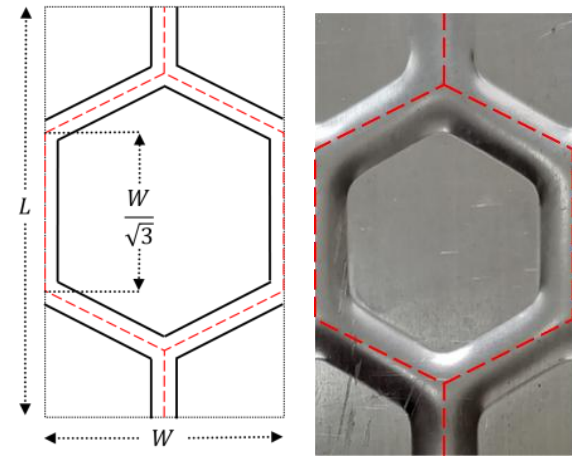

(a) Hexagon type
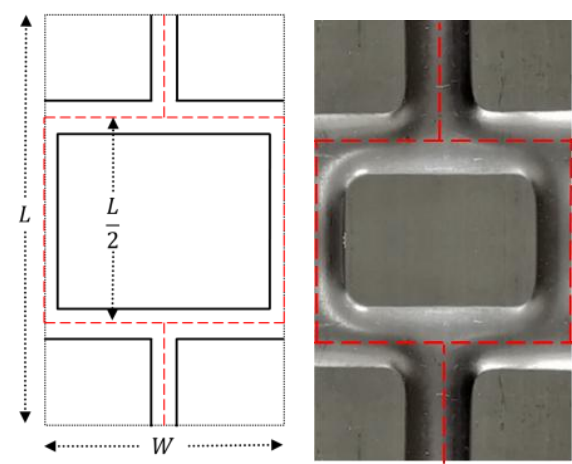

(c) Rectangle type
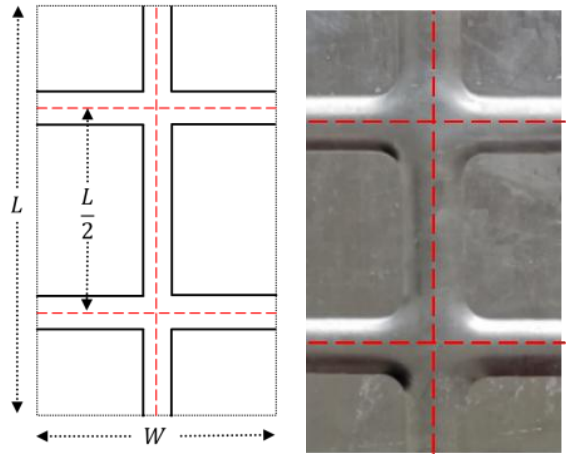

(b) Grid type

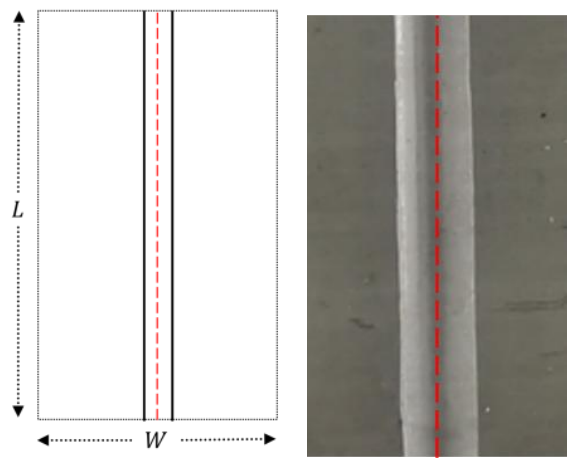

(d) Linear type

Fig. 5. Different types of evaporator units in the roll-bond panel.

\subsection{Efficiency factor}

In steady-state, the performance of a PVT module which employing roll-bond panel can be described by an energy balance indicating the distribution of the solar energy into useful energy gain, electrical energy gain, and thermal losses. Different types of roll-bond panels have been listed in Fig. 5 and take the hexagon type unit of the PVT module as an example.

For a $W \times L$ hexagon PVT unit, the useful energy gain can be expressed as:

$$
\begin{aligned}
& Q_{u}{ }^{\prime}=\left(W \cdot L-12 \cdot \frac{D}{2} \cdot \frac{W}{\sqrt{3}}\right) \cdot F \cdot\left[(\tau \alpha) \cdot I \cdot\left(1-\eta_{\mathrm{e}}\right)-U_{L} \cdot\left(T_{p}-T_{a}\right)\right] \\
& +12 \cdot \frac{D}{2} \cdot \frac{W}{\sqrt{3}} \cdot\left[(\tau \alpha) \cdot I \cdot\left(1-\eta_{\mathrm{e}}\right)-U_{L} \cdot\left(T_{p}-T_{a}\right)\right]
\end{aligned}
$$

where $W$ and $L$ are the width and length of the PVT collector/evaporator unit, respectively; $D$ is the equivalent width of the fluid channel; $F$ is the fin efficiency which can be expressed by (Duffie et al., 1994):

$$
F=\frac{\tanh \left(U_{b}\right)}{U_{b}}
$$

where $U_{b}$ is a dimensionless parameter which can be defined as (Duffie et al., 1994):

$$
U_{b}=\frac{W \cdot L-2 \sqrt{3} \cdot W \cdot D}{2 L} \cdot \sqrt{\frac{U_{L}}{\lambda_{A l} \cdot\left(2 \cdot \delta_{A l}\right)+\lambda_{\text {Tedlar }} \cdot \delta_{\text {Tedlar }}+\lambda_{E V A} \cdot \delta_{E V A}}}
$$


Meanwhile, the useful energy gain by Eq. (4) must be transferred to the fluid, which can be expressed as:

$$
Q_{u}{ }^{\prime}=12 \cdot \frac{1}{2} \cdot \frac{W}{\sqrt{3}} \cdot \frac{T_{p}-T_{w}}{\frac{1}{D} \cdot\left(\frac{\delta_{\text {EVA }}}{\lambda_{\text {EVA }}}+\frac{\delta_{\text {Tedlar }}}{\lambda_{\text {Tedlar }}}+\frac{\delta_{A l}}{\lambda_{A l}}\right)+\frac{1}{h_{e q} \cdot \pi \cdot D}}
$$

where $\delta_{E V A}, \delta_{\text {Tedlar }}$ and $\delta_{A l}$ are the thickness of EVA grease, electrical insulation and roll-bond panel, respectively; $\lambda_{E V A}, \lambda_{\text {Tedlar }}$ and $\lambda_{A l}$ are the thermal conductivity of EVA grease, electrical insulation and roll-bond panel, respectively; $h_{e q}$ is the equivalent heat transfer coefficient between the collector pipe and fluid.

Solving Eq. (7) for the expression of $T_{p}$ :

$$
T_{p}=T_{w}+\frac{\sqrt{3}}{6} \cdot \frac{Q_{u}^{\prime}}{W}\left[\frac{1}{D} \cdot\left(\frac{\delta_{E V A}}{\lambda_{E V A}}+\frac{\delta_{\text {Tedlar }}}{\lambda_{\text {Tedlar }}}+\frac{\delta_{A l}}{\lambda_{A l}}\right)+\frac{1}{h_{e q} \cdot \pi \cdot D}\right]
$$

Then submit $T_{p}$ into Eq. (4) to get the expression of $Q_{u}$ ' which is equal to Eq. (2):

$Q_{u}{ }^{\prime}=[(W \cdot L-2 \sqrt{3} \cdot W \cdot D) \cdot F+2 \sqrt{3} \cdot W \cdot D] \cdot\left\{(\tau \alpha) \cdot \mathrm{I} \cdot\left(1-\eta_{\mathrm{e}}\right)-\mathrm{U}_{\mathrm{L}} \cdot\left[\frac{\sqrt{3}}{6} \cdot \frac{Q_{u}{ }^{\prime}}{W}\left[\frac{1}{D} \cdot\left(\frac{\delta_{E V A}}{\lambda_{E V A}}+\frac{\delta_{\text {Tedlar }}}{\lambda_{\text {Tedlar }}}+\frac{\delta_{A l}}{\lambda_{A l}}\right)+\frac{1}{h_{e q} \cdot \pi \cdot D}\right]+T_{w}-T_{a}\right]\right\}$ $=A \cdot F^{\prime} \cdot\left[(\tau \alpha) \cdot I \cdot\left(1-\eta_{\mathrm{e}}\right)-U_{L} \cdot\left(T_{w}-T_{a}\right)\right]$

Compare these two expressions in Eq. (9) and then the efficiency factor can be expressed as:

$$
F^{\prime}=\frac{1 / U_{L}}{W \cdot L \cdot\left\{\frac{1}{U_{L} \cdot[(W \cdot L-2 \sqrt{3} \cdot W \cdot D) \cdot F+2 \sqrt{3} \cdot W \cdot D]}+\frac{\sqrt{3}}{6 \cdot W} \cdot\left[\frac{1}{D} \cdot\left(\frac{\delta_{E V A}}{\lambda_{E V A}}+\frac{\delta_{\text {Tedlar }}}{\lambda_{\text {Tedlar }}}+\frac{\delta_{A l}}{\lambda_{A l}}\right)+\frac{1}{h_{e q} \cdot \pi \cdot D}\right]\right\}}
$$

As shown in Fig. 4(a), the overall heat loss coefficient $\left(U_{L}\right)$ is consists of two processes: (1) heat loss from PV cells to PV-glazing cover; (2) heat loss from PV-glazing cover to ambient. The overall heat loss coefficient can be calculated by (Kuang et al., 2003; P. Hartnett and M. Rohsenow, 1973):

where $h_{c d, p-c}$ and $h_{r d, p-c}$ are the conductive and radiative heat transfer coefficient between PV cells and PV-glazing cover; $h_{c v, c-a}$ and $h_{r d, c-a}$ are the convective and radiative heat transfer coefficient between PV-glazing cover and ambient. 
For direct expansion evaporator using in the solar assisted heat pump, the overall heat loss coefficient can be calculated by:

$$
U_{L}=U_{L, u p}+U_{L, \text { down }}
$$

$$
U_{L, u p}=h_{c v, A l-a}+h_{r d, A l-a}
$$

$$
U_{L, d o w n}=h_{c v, A l-a}+h_{r d, A l-g}
$$

251

252

253

254

255

256

257

258

where $h_{c v, A l-a}$ and $h_{r d, A l-a}$ are the convective and radiative heat transfer coefficient between the roll-bond panel and ambient; $h_{r d, A l-g}$ is the radiative heat transfer coefficient between roll-bond panel and ground.

For other types of PVT collector/evaporator unit as well as direct expansion evaporator unit which employing roll-bond panel, the same method is adopted to obtain the theoretical expressions of efficiency factor. A summary of PVT and direct expansion evaporator efficiency factor is presented in Table. 2. 
Table. 2. A summary of PVT and direct expansion evaporator efficiency factor.

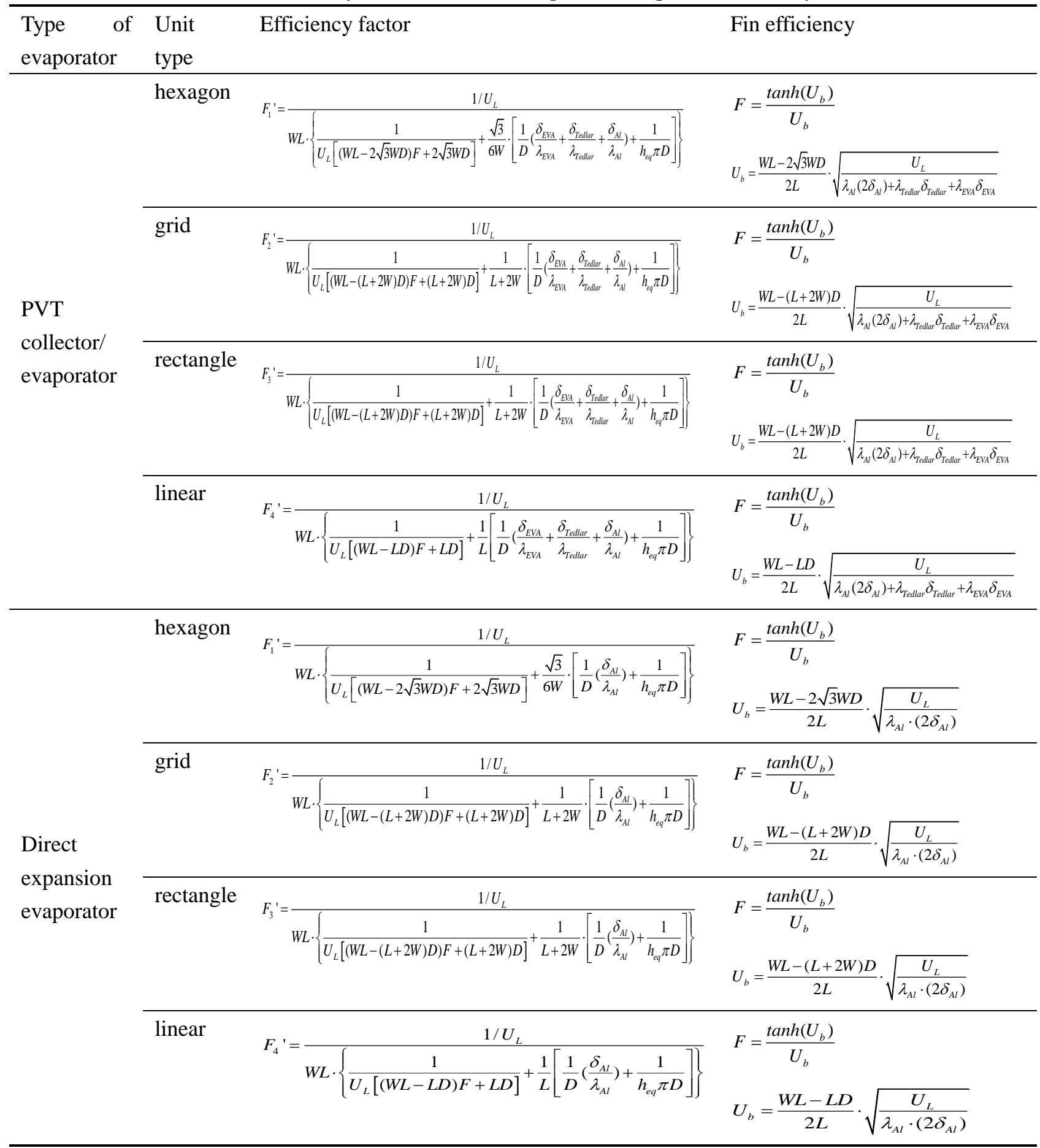

$261 \quad 3.3$ Dimensionless pressure loss coefficient modification

Although the efficiency factor expressions of different types of evaporator units have been given, the direct expansion solar collector is not the same as water or air based solar collector. The refrigerant flows in the evaporator will cause a pressure drop which means it would transfer a certain percentage of kinetic energy to heat. Moreover, it would reduce the heat extract capacity of the fluid from the thermal collector and increase the energy consumption of the compressor. To 
evaluate the influence of pressure drop on efficiency factor, a mathematical model using the CFD (Computational Fluid Dynamics) model has been proposed, and the CFD model of PVT collector/evaporator unit including BLOCK and GRID layouts has shown in Fig. 6.

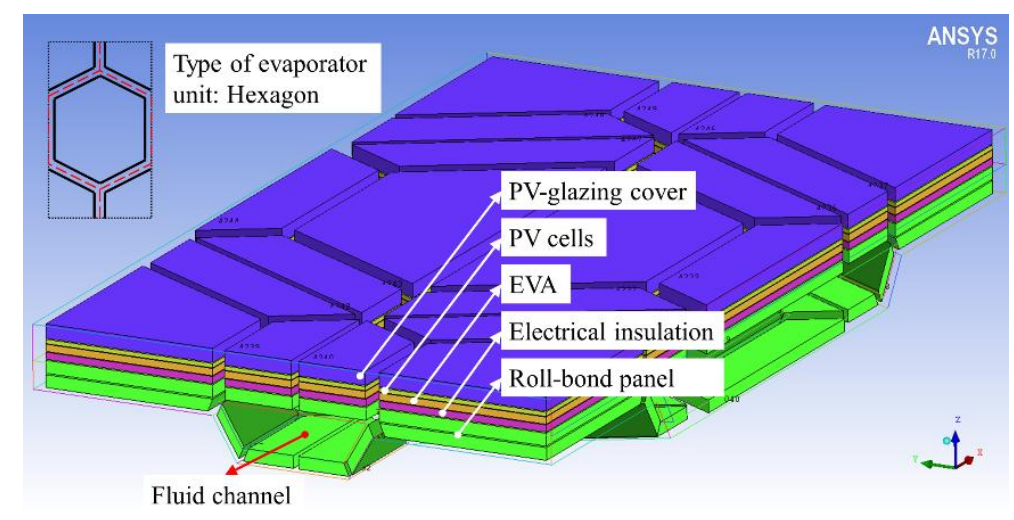

(a)

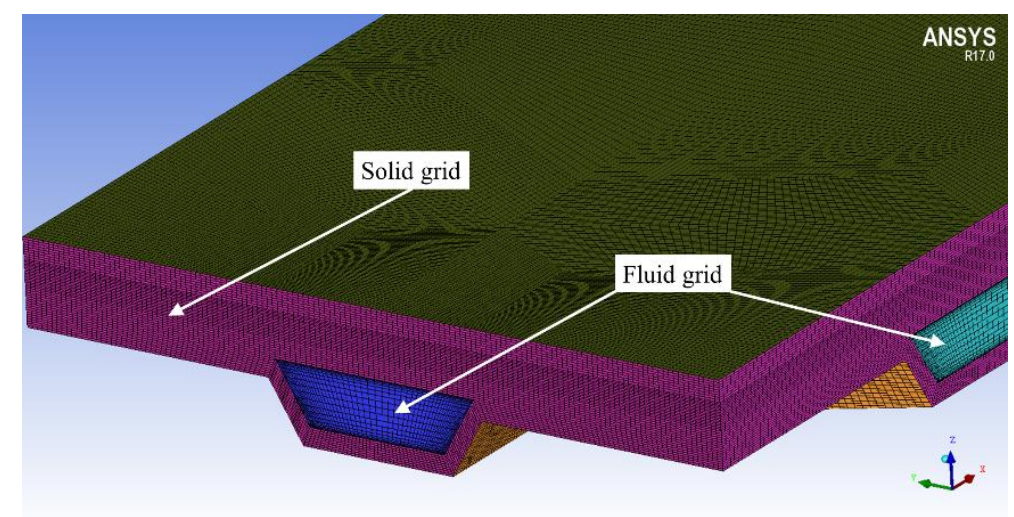

(b)

Fig. 6. (a) The BLOCK layers of solid part for hexagon PVT collector/evaporator unit. (b) The GRID distribution of solid and fluid part for hexagon PVT collector/evaporator unit.

A dimensionless pressure loss coefficient has been added to modify the original expression of the efficiency factor, which can be defined as:

$$
F_{\text {mod }}{ }^{\prime}=\left[1-f\left(P^{\prime}\right) \cdot P^{\prime}\right] \cdot F^{\prime}
$$

$$
P^{\prime}=\frac{P_{\text {loss }}}{P_{\text {ave }}}=\frac{P_{\text {eva }, \text { in }}-P_{\text {eva }, \text { out }}}{1 / 2 \cdot\left(P_{\text {eva }, \text { in }}+P_{\text {eva }, \text { out }}\right)}
$$

where the $P^{\prime}$ is the dimensionless pressure loss; $P_{\text {loss }}$ and $P_{\text {ave }}$ are the pressure loss and average pressure in the evaporator; $P_{\text {eva,in }}$ and $P_{\text {eva,out }}$ are the inlet pressure and outlet pressure of the evaporator; $f\left(P^{\prime}\right)$ is a function of $P^{\prime}$ which is fitting by the CFD model. Through this CFD model, the dimensionless pressure loss could be obtained. Moreover, the difference between unmodified efficiency factor and modified efficiency factor could be used to derivate the function $f\left(P^{\prime}\right)$ expressions of each type unit. The fitting data and function expression of each type of unit are listed in Table. 3 while the simulation pressure is $0.5 \mathrm{Mpa}$. 
Table. 3. Fitting data calculated by the CFD model.

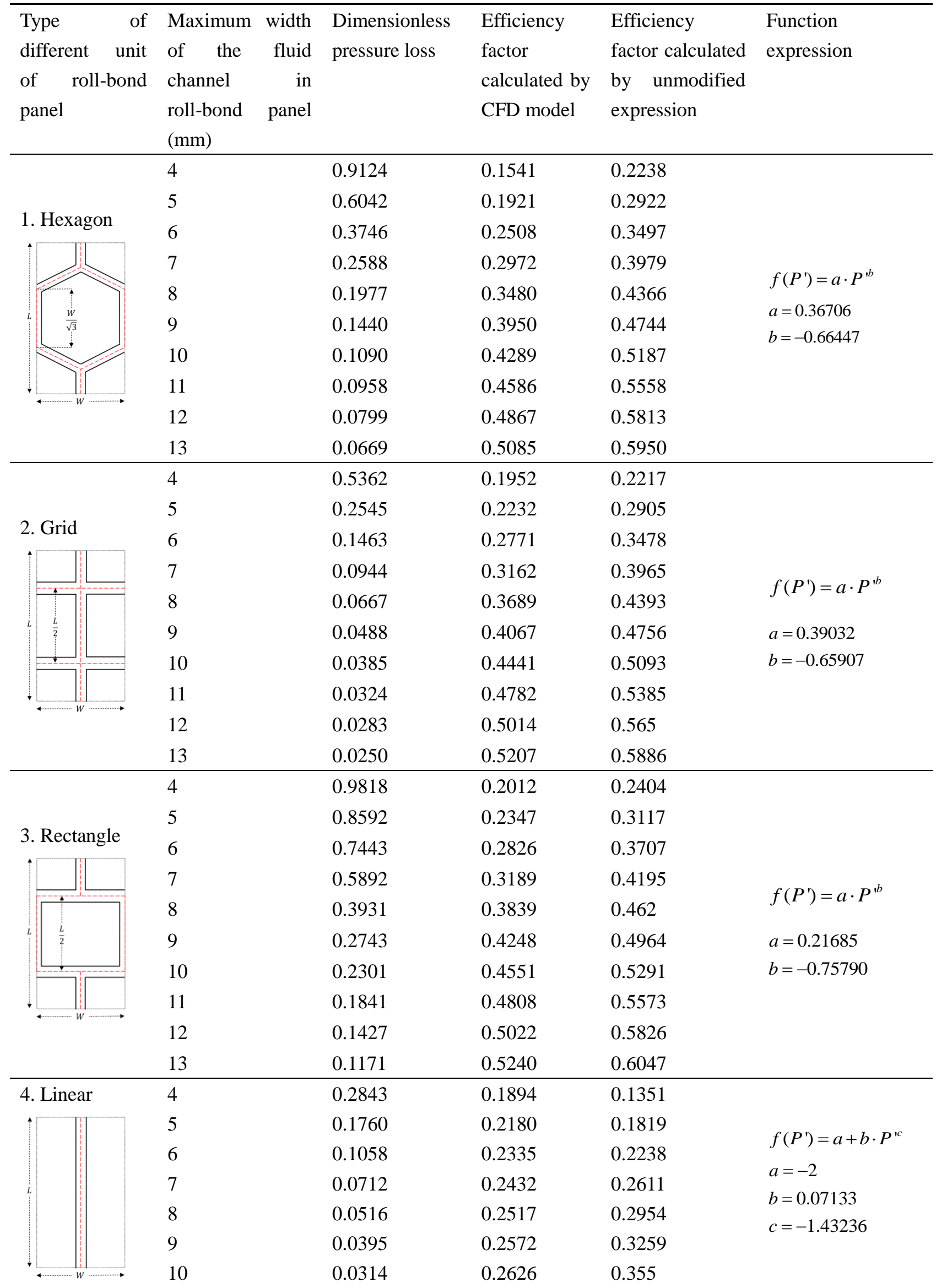




\begin{tabular}{llll}
11 & 0.0257 & 0.2670 & 0.381 \\
12 & 0.0217 & 0.2707 & 0.4052 \\
13 & 0.0186 & 0.2739 & 0.4277 \\
\hline
\end{tabular}

286

287

288

289

290

291

292

293

294

295

296

297

298

299

300

301

302

303

304

305

306

The modified expression of the efficiency factor of different unit types are listed as follows:

Hexagon:

$$
F_{\text {mod }, 1}{ }^{\prime}=\left[1-\left(0.36706 \cdot P^{1^{-0.06447}}\right) \cdot P^{\prime}\right] \cdot F_{1}{ }^{\prime}
$$

Grid:

$$
F_{\text {mod }, 2}{ }^{\prime}=\left[1-\left(0.39032 \cdot P^{1-0.65907}\right) \cdot P^{\prime}\right] \cdot F_{2}{ }^{\prime}
$$

Rectangle:

$$
F_{\text {mod }, 3}{ }^{\prime}=\left[1-\left(0.21685 \cdot P^{-0.7579}\right) \cdot P^{\prime}\right] \cdot F_{3}{ }^{\prime}
$$

Linear:

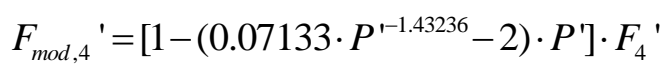

where subscript 1 to 4 represents hexagon, grid, rectangle, and linear type of roll-bond panel unit.

As shown in Fig. 3(b), different direct expansion evaporators may consist of several types of units (combination of hexagon, grid, rectangle, and linear). Thus, the whole panel's efficiency factor can be defined as:

$$
F_{\text {mod }}{ }^{\prime}=\sum_{1}^{n} \frac{S_{n}}{S_{\text {Tot }}} \cdot F_{\text {mod, },}{ }^{\prime}
$$

where the $S_{n}$ and $S_{\text {Tot }}$ are the area of different types of units and area of the whole panel, respectively.

\subsection{Heat removal factor}

The energy balance on the fluid element is shown in Fig. 7. Refer to Eq. (3), the heat removal factor represents the ratio of actual useful energy gain and useful gain if the collector inner surface is equal to the temperature of inlet fluid. Thus, the definition of heat removal factor $F_{R}$ can be expressed as:

$$
F_{R}=\frac{\dot{m} \cdot\left(\chi_{\text {out }}-\chi_{\text {in }}\right) \cdot \Delta H_{r e f}}{W \cdot L \cdot\left[(\tau \alpha) \cdot I \cdot\left(1-\eta_{\mathrm{e}}\right)-U_{L} \cdot\left(T_{\text {in }}-T_{a}\right)\right]}
$$

where $\dot{m}$ is the mass flow rate of refrigerant; $\chi_{\text {in }}$ and $\chi_{\text {out }}$ are the degree of dryness of inlet and outlet refrigerant flow; $\Delta H_{r e f}$ is the latent heat of refrigerant.

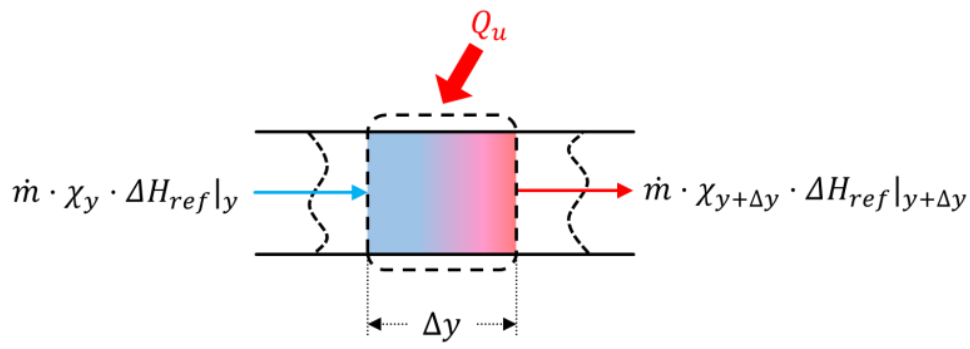

Fig. 7. Energy balance on the fluid element. 
The thermal energy gain by refrigerant of a length $\Delta y$ can be calculated by:

$$
Q_{u}=\left.\dot{m} \cdot \chi_{y+\Delta y} \cdot \Delta H_{r e f}\right|_{y+\Delta y}-\left.\dot{m} \cdot \chi_{y} \cdot \Delta H_{r e f}\right|_{y}
$$

Meanwhile, the thermal energy gain by the thermal collector can be expressed as:

$$
Q_{u}=W \cdot \Delta y \cdot F^{\prime} \cdot\left[(\tau \alpha) \cdot I \cdot\left(1-\eta_{\mathrm{e}}\right)-U_{L} \cdot\left(T_{i n}-T_{a}\right)\right]
$$

where the $F^{\prime}$ and $U_{L}$ are assumed independent of position. Then Eq. (27) is equal to Eq. (28) and this following equation could be obtained:

$$
\dot{m} \cdot \Delta H_{r e f} \cdot \frac{\chi_{y+\Delta y}-\chi_{y}}{\Delta y}=W \cdot F^{\prime} \cdot\left[(\tau \alpha) \cdot I \cdot\left(1-\eta_{\mathrm{e}}\right)-U_{L} \cdot\left(T_{i n}-T_{a}\right)\right]
$$

When $\Delta \mathrm{y}$ approximates to zero, $\chi_{y+\Delta y}-\chi_{y}$ could be replaced by $d \chi, \Delta y$ could be replaced by $d y$ and integrate the formula. Then the following equation could be obtained:

$$
\begin{gathered}
\int_{\text {in }}^{\text {out }} \dot{m} \cdot \Delta H_{r e f} \cdot d \chi=\int_{\text {in }}^{\text {out }} W \cdot F^{\prime} \cdot\left[(\tau \alpha) \cdot I \cdot\left(1-\eta_{\mathrm{e}}\right)-U_{L} \cdot\left(T_{\text {in }}-T_{a}\right)\right] \cdot d y \\
\dot{m} \cdot \Delta H_{r e f} \cdot\left(\chi_{\text {out }}-\chi_{\text {in }}\right)=W \cdot F^{\prime} \cdot\left[(\tau \alpha) \cdot I \cdot\left(1-\eta_{\mathrm{e}}\right)-U_{L} \cdot\left(T_{\text {in }}-T_{a}\right)\right] \cdot L
\end{gathered}
$$

Then submitting $\dot{m} \cdot \Delta H_{\text {ref }} \cdot\left(\chi_{\text {out }}-\chi_{\text {in }}\right)$ into the definition Eq. (26), the heat removal factor can be expressed as:

$$
F_{R}=\frac{\dot{m} \cdot\left(\chi_{\text {out }}-\chi_{\text {in }}\right) \cdot \Delta H_{r e f}}{W \cdot L \cdot\left[(\tau \alpha) \cdot I \cdot\left(1-\eta_{\mathrm{e}}\right)-U_{L} \cdot\left(T_{\text {in }}-T_{a}\right)\right]}=\frac{W \cdot F^{\prime} \cdot\left[(\tau \alpha) \cdot I \cdot\left(1-\eta_{\mathrm{e}}\right)-U_{L} \cdot\left(T_{\text {in }}-T_{a}\right)\right] \cdot L}{W \cdot L \cdot\left[(\tau \alpha) \cdot I \cdot\left(1-\eta_{\mathrm{e}}\right)-U_{L} \cdot\left(T_{\text {in }}-T_{a}\right)\right]}=F^{\prime}
$$

As shown in Eq. (32), the heat removal factor is equal to the efficiency factor for direct expansion evaporator due to the isothermal evaporating process. Thus, only the parameter analysis of the efficiency factor would be conducted in the next few sections.

\subsection{Exergy analysis}

Fig. 8 shows the exergy flow diagram of the PVT module. Considering the PVT module as a single control volume and assuming a steady-state condition, the exergy balance can be expressed as follows:

$$
\sum E x_{\text {in }}=\sum E x_{\text {out }}+\sum E x_{\text {loss }}
$$

where the $E x_{i n}, E x_{\text {out }}$, and $E x_{\text {loss }}$ refer to exergy rate of input, output, and losses, respectively. The total exergy input is consists of two parts: input exergy of the sun $\left(E x_{\text {sun }}\right)$ and input exergy of the refrigerant $\left(E x_{\text {ref,in }}\right)$. The total exergy output is consists of two parts: output electrical exergy $\left(E x_{e}\right)$ and output exergy of the refrigerant $\left(E x_{\text {ref out }}\right)$. The equations could be expressed as:

$$
\begin{gathered}
\sum E x_{\text {in }}=E x_{\text {sun }}+E x_{\text {ref }, \text { in }} \\
\sum E x_{\text {out }}=E x_{e}+E x_{\text {ref }, \text { out }} \\
E x_{\text {sun }}+E x_{\text {ref }, \text { in }}=E x_{e}+E x_{\text {ref }, \text { out }}+E x_{\text {loss }}
\end{gathered}
$$

The input exergy of the sun ( $\left.E x_{\text {sun }}\right)$ could be calculated by (Park et al., 2014): 


$$
E x_{\text {sun }}=A \cdot I \cdot\left(1-\frac{T_{a}}{T_{\text {sun }}}\right)
$$

where the $A$ is the area of PVT module; $I$ is the solar radiation intensity; $T_{a}$ and $T_{\text {sun }}$ are the temperature of the ambient and the sun, respectively. The exergy of the refrigerant which is equal to the thermal exergy $\left(E x_{t h}\right)$ could be calculated as:

$$
E x_{\text {th }}=E x_{\text {ref }, \text { out }}-E x_{\text {ref }, \text { in }}=m_{\text {ref }} \cdot\left(\psi_{\text {out }}-\psi_{\text {in }}\right)
$$

where $m_{\text {ref }}$ is the mass flow rate of the refrigerant; $\Psi_{\text {out }}$ and $\Psi_{\text {in }}$ are the stream exergy per unit mass which could be calculated as:

$$
\begin{gathered}
\psi_{\text {out }}=\left(h_{\text {out }}-h_{a}\right)-T_{a} \cdot\left(s_{\text {out }}-s_{a}\right) \\
\psi_{\text {in }}=\left(h_{\text {in }}-h_{a}\right)-T_{a} \cdot\left(s_{\text {in }}-s_{a}\right)
\end{gathered}
$$

where $h$ and $s$ are the enthalpy and entropy values. Because the electrical energy is a useful available work, the exergy of the PV cells is equal to the electrical power (Chow et al., 2009):

$$
E x_{e}=Q_{e}=A \cdot I \cdot \tau_{c} \cdot \alpha_{p} \cdot \beta_{p} \cdot \eta_{e}
$$

where $\tau_{c}$ is the transmittances of the PV-glazing cover; $a_{p}$ is the absorption ratio of the PV cells; $\beta_{p}$ is the packing factor of PV panels; $\eta_{e}$ is the PV cells electrical efficiency which can be calculated by (Huide et al., 2017):

$$
\eta_{e}=\eta_{r c} \cdot\left[1-\beta_{p v} \cdot\left(T_{p}-T_{r c}\right)\right]
$$

$\eta_{r c}$ is the reference photovoltaic efficiency value of PV cells at $T_{r c}=298 \mathrm{~K}, \eta_{r c}=0.18 ; \beta_{p v}$ is the temperature coefficient ( $1 / \mathrm{K}$ ) of PV cell efficiency, $\beta_{p v}=0.0045$ (Huide et al., 2017).

Therefore, the electrical and thermal exergy efficiencies could be expressed as:

$$
\begin{gathered}
\varepsilon_{e}=\frac{E x_{e}}{E x_{\text {sun }}}=\frac{Q_{e}}{E x_{\text {sun }}} \\
\varepsilon_{\text {th }}=\frac{E x_{\text {th }}}{E x_{\text {sun }}}=\frac{m_{\text {ref }} \cdot\left[\left(h_{\text {out }}-h_{\text {in }}\right)-T_{a} \cdot\left(s_{\text {out }}-s_{\text {in }}\right)\right]}{E x_{\text {sun }}}
\end{gathered}
$$

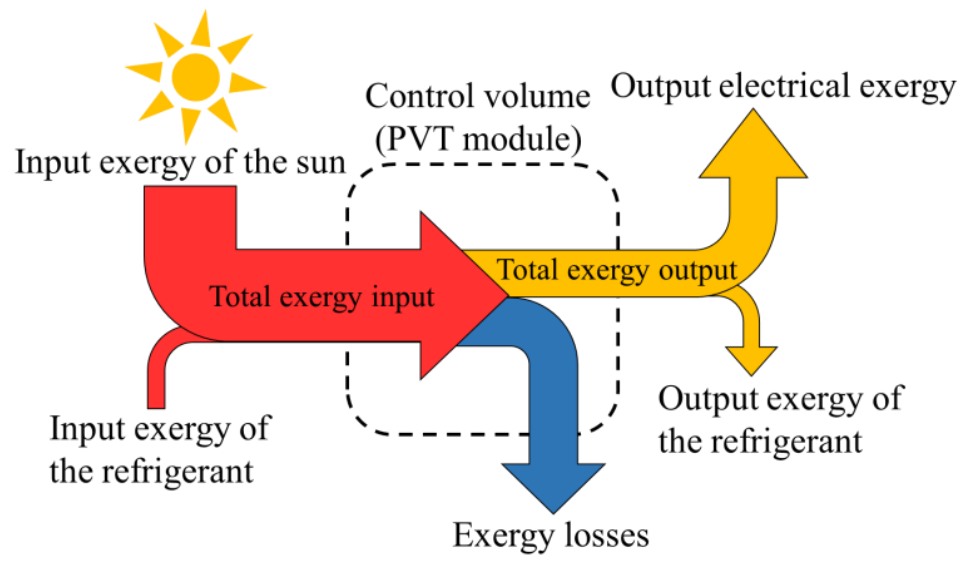

Fig. 8. Exergy flow diagram of the PVT module. 
To ensure the reliability of the proposed mathematic model of efficiency factor, the simulation results should be compared with experimental results. In this section, the experimental results of 20 days have been used to verify the accuracy of the theoretical efficiency factor. Kong et al. (Kong et al., 2018a; Kong et al., 2018b) have conducted a direct expansion solar assisted heat pump system experimentally during summer, autumn, and winter. In their study, a $200 \mathrm{~L}$ water tank and a $2.1 \mathrm{~m}^{2}$ linear type direct expansion evaporator (maximum flow channel is $10 \mathrm{~mm}$ ) have been adopted in their system. The experimental parameters from the literatures have listed in Table. 4. The main point of this paper is the theoretical analysis of the efficiency factor. However, the mathematical model of direct expansion solar assisted heat pump system should be established to simulate the system performance and verify the efficiency factor. As mentioned in section 2.1, the mathematical model of direct expansion solar assisted heat pump has been established in the authors' previous work (Yao et al., 2020), therefore, the content of the mathematical model has not

Table. 4. Experimental parameters (Kong et al., 2018a; Kong et al., 2018b).

\begin{tabular}{llll}
\hline \multicolumn{1}{c}{ Parameters } & Nomenclature & Value & Unit \\
\hline Type of the evaporator & {$[-]$} & Linear & {$[-]$} \\
Area of the evaporator & $A$ & 2.1 & $\mathrm{~m}^{2}$ \\
Width of the evaporator & $W_{\text {eva }}$ & 1.0 & $\mathrm{~m}$ \\
Length of the evaporator & $L_{\text {eva }}$ & 2.1 & $\mathrm{~m}$ \\
Maximum width of the fluid channel & $D_{\max }$ & 10 & $\mathrm{~mm}$ \\
Thickness of the fluid channel & $\delta_{\text {channel }}$ & 2.8 & $\mathrm{~mm}$ \\
Thickness of the evaporator & $\delta_{A l}$ & 1.5 & $\mathrm{~mm}$ \\
Material of the evaporator & {$[-]$} & Aluminum & {$[-]$} \\
Refrigerant type & $r e f$ & $\mathrm{R} 134 \mathrm{a}$ & {$[-]$} \\
Volume of water tank & $V_{\text {tank }}$ & 200 & $\mathrm{~L}$ \\
\hline
\end{tabular}

The detailed comparison results of the COP (coefficient of performance) and the efficiency factor have been listed in Table. 5. 20 days of experimental results have been compared with simulated results. In addition, the experimental efficiency factor could be obtained as follows: the total heat transfer rate of the evaporator could be calculated through the COP and the thermal energy stored in the water tank. Then, the heat transfer rate between the evaporator and the ambient could be calculated by the wind speed and panel/ambient temperature as well as the heat absorption rate from solar irradiation of the evaporator. Finally, the experimental efficiency factor could be obtained by the solar radiation intensity, the area of the evaporator, and the heat absorption rate from solar irradiation of the evaporator. The experimental efficiency factor is considered equal to the ratio of the heat absorption rate per square meter $\left(\mathrm{W} / \mathrm{m}^{2}\right)$ of the evaporator and the solar radiation intensity $\left(\mathrm{W} / \mathrm{m}^{2}\right)$.

\footnotetext{
The experimental COP and simulated COP vary from 3.2 to 6.0 under different conditions,
} 
and a higher COP could be obtained under high solar radiation intensity, high ambient temperature, and low wind speed. The maximum experimental COP (5.68) is reached in 2017/07/26, while the simulated COP is 5.92, and its relative error is $4.2 \%$. The minimum COP (3.45) occurs in $2017 / 12 / 17$ when the solar irradiation is low $\left(233 \mathrm{~W} / \mathrm{m}^{2}\right)$, meanwhile, the simulated COP is 3.22 and the relative error is $-6.54 \%$. The average relative error of COP is $4.12 \%$, while the maximum relative error is $-8.12 \%$ which occurs in $2017 / 12 / 29$. On the other hand, the minimum experimental efficiency factor is obtained as 0.4856 due to a high wind speed while the simulation result is 0.5083 , and its relative error is $4.68 \%$. The peak value of the experimental efficiency factor is 0.6932 while the simulated efficiency factor is 0.6534 , and the relative error is $-5.74 \%$. The maximum relative error of the efficiency factor is obtained in $2017 / 11 / 27$ which is $7.46 \%$ while the average relative error of these 20 days results is $3.45 \%$.

Table. 5. Experimental and simulation results of the COP and the efficiency factor.

\begin{tabular}{|c|c|c|c|c|c|c|c|c|c|c|c|}
\hline $\begin{array}{l}\text { Date } \\
\text { (year/month } \\
\text { /day) }\end{array}$ & $\begin{array}{l}\text { Ambient } \\
\text { temperat } \\
\text { ure }\left({ }^{\circ} \mathrm{C}\right)\end{array}$ & $\begin{array}{l}\text { Solar } \\
\text { radiation } \\
\text { intensity } \\
\left(\mathrm{W} / \mathrm{m}^{2}\right)\end{array}$ & $\begin{array}{l}\text { Wind } \\
\text { speed } \\
(\mathrm{m} / \mathrm{s})\end{array}$ & $\begin{array}{l}\text { Temperature } \\
\text { difference } \\
\text { of water } \\
\operatorname{tank}\left({ }^{\circ} \mathrm{C}\right)\end{array}$ & $\begin{array}{l}\text { Operation } \\
\text { time (s) }\end{array}$ & $\begin{array}{l}\text { Experi } \\
\text { mental } \\
\text { COP }\end{array}$ & $\begin{array}{l}\text { Simul } \\
\text { ated } \\
\text { COP }\end{array}$ & $\begin{array}{l}\text { Relative } \\
\text { error of } \\
\operatorname{COP}(\%)\end{array}$ & $\begin{array}{l}\text { Experim } \\
\text { ental } \\
\text { efficienc } \\
\text { y factor }\end{array}$ & $\begin{array}{l}\text { Simulated } \\
\text { efficiency } \\
\text { factor }\end{array}$ & $\begin{array}{l}\text { Relative } \\
\text { error of } \\
\text { efficiency } \\
\text { factor }(\%)\end{array}$ \\
\hline $2017 / 7 / 10$ & 33.3 & 633 & 1.8 & 16.9 & 7320 & 5.59 & 5.28 & -5.52 & 0.6480 & 0.6467 & -0.20 \\
\hline $2017 / 7 / 11$ & 33.5 & 660 & 1.7 & 26.9 & 10740 & 4.43 & 4.50 & 1.62 & 0.6642 & 0.6497 & -2.18 \\
\hline $2017 / 7 / 12$ & 32.2 & 519 & 1.7 & 26.5 & 10500 & 4.41 & 4.33 & -1.72 & 0.6916 & 0.6497 & -6.06 \\
\hline $2017 / 7 / 13$ & 34.0 & 634 & 1.8 & 28.2 & 10260 & 4.85 & 4.77 & -1.62 & 0.6731 & 0.6466 & -3.93 \\
\hline $2017 / 7 / 15$ & 28.1 & 632 & 1.5 & 27.7 & 10560 & 4.55 & 4.61 & 1.38 & 0.6550 & 0.6559 & 0.14 \\
\hline $2017 / 7 / 18$ & 33.9 & 258 & 1.2 & 26.0 & 12540 & 3.78 & 3.70 & -2.20 & 0.6810 & 0.6652 & -2.33 \\
\hline $2017 / 7 / 22$ & 33.1 & 415 & 1.4 & 27.8 & 11280 & 4.34 & 4.09 & -5.70 & 0.6794 & 0.6589 & -3.02 \\
\hline $2017 / 7 / 26$ & 33.7 & 659 & 1.3 & 27.3 & 13560 & 5.68 & 5.92 & 4.20 & 0.6161 & 0.6620 & 7.45 \\
\hline $2017 / 8 / 15$ & 32.7 & 619 & 1.5 & 28.7 & 8040 & 3.63 & 3.88 & 6.84 & 0.6508 & 0.6558 & 0.77 \\
\hline $2017 / 8 / 25$ & 33.3 & 630 & 1.4 & 28.0 & 8700 & 3.71 & 3.89 & 4.92 & 0.6452 & 0.6589 & 2.13 \\
\hline $2017 / 10 / 31$ & 19.6 & 658 & 2.8 & 38.4 & 22980 & 4.61 & 4.82 & 4.64 & 0.5791 & 0.6184 & 6.79 \\
\hline $2017 / 11 / 2$ & 25.0 & 559 & 4.6 & 37.0 & 21360 & 5.09 & 5.16 & 1.42 & 0.5605 & 0.5726 & 2.16 \\
\hline $2017 / 11 / 11$ & 15.2 & 683 & 4.7 & 40.0 & 22260 & 4.54 & 4.25 & -6.28 & 0.5488 & 0.5705 & 3.95 \\
\hline $2017 / 11 / 14$ & 17.3 & 653 & 4.0 & 34.8 & 21420 & 4.46 & 4.36 & -2.21 & 0.5482 & 0.5873 & 7.13 \\
\hline $2017 / 11 / 27$ & 13.2 & 578 & 3.5 & 39.2 & 23700 & 4.23 & 3.95 & -6.56 & 0.5583 & 0.5999 & 7.46 \\
\hline $2017 / 12 / 2$ & 11.9 & 414 & 7.7 & 32.7 & 19800 & 4.33 & 4.02 & -7.21 & 0.4856 & 0.5083 & 4.68 \\
\hline $2017 / 12 / 7$ & 10.8 & 487 & 8.9 & 31.5 & 19500 & 4.93 & 4.90 & -0.57 & 0.4871 & 0.4871 & 0.00 \\
\hline $2017 / 12 / 17$ & 7.9 & 233 & 2.1 & 34.2 & 23640 & 3.45 & 3.22 & -6.54 & 0.6414 & 0.6385 & -0.46 \\
\hline $2017 / 12 / 28$ & 10.7 & 322 & 1.6 & 31.1 & 18900 & 3.88 & 3.76 & -3.16 & 0.6932 & 0.6534 & -5.74 \\
\hline $2017 / 12 / 29$ & 9.9 & 308 & 1.5 & 30.8 & 19920 & 5.37 & 4.93 & -8.12 & 0.6727 & 0.6565 & -2.42 \\
\hline
\end{tabular}

408

409

410

411

412

413

414
In addition, Fig. 9 shows the error analysis of COP and efficiency factor. The green dots represent the simulation results of COP and efficiency factor. Both the relative errors of COP and efficiency factor are within $\pm 10 \%$. Therefore, the proposed expressions of the efficiency factor are considered reliable. Moreover, the efficiency factor could be used to design, optimize, and evaluate the performance of different direct expansion evaporator which employing roll-bond panel. 


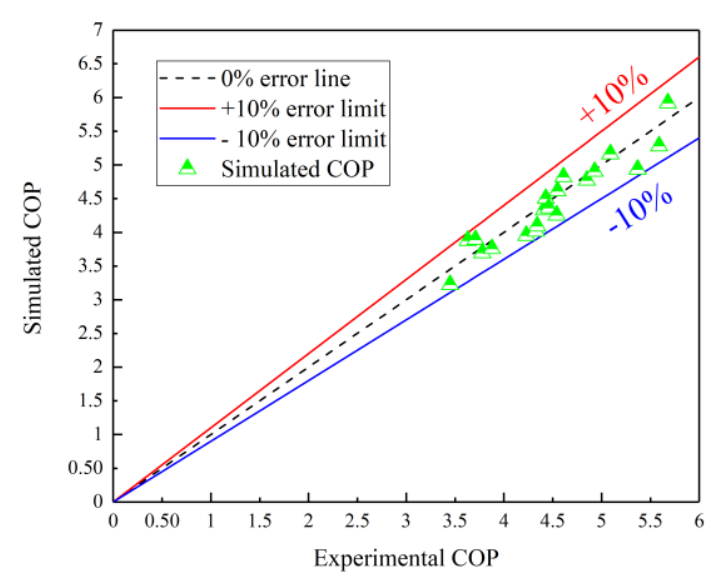

(a)

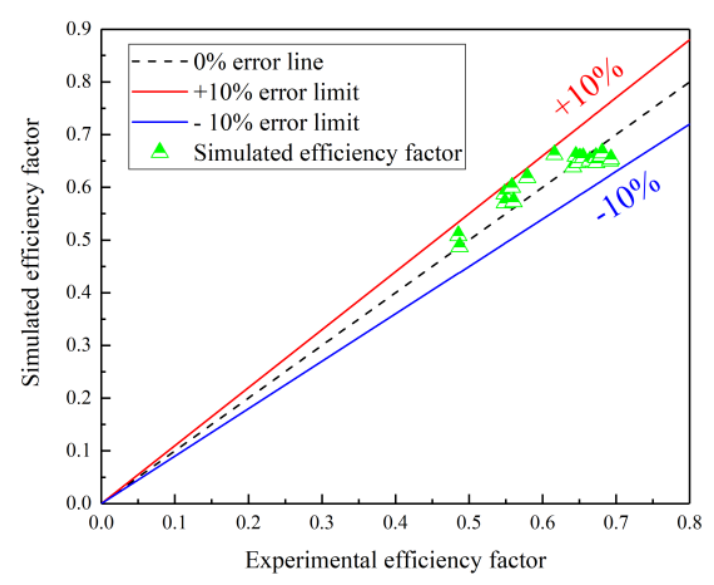

(b)

Fig. 9. Error analysis of (a) simulated COP and experimental COP. (b) simulated efficiency factor and experimental efficiency factor.

\section{Parameter analysis}

\subsection{Different pattern of the fluid channel}

The modified and unmodified efficiency factor and dimensionless pressure loss of four evaporator patterns have shown in Fig. 10, and in this case, the maximum fluid channel width of each type unit is $10 \mathrm{~mm}$. The analysis is conducted under wind speed is $2.5 \mathrm{~m} / \mathrm{s}$, ambient temperature is $25^{\circ} \mathrm{C}$, and PV cells' temperature is $40^{\circ} \mathrm{C}$. The rectangle type has the highest pressure loss due to the fluid channel pattern which would divide the mainstream into two opposite streams. The pressure loss of hexagon type is second caused by the same reason, while the grid and linear types have the lowest pressure loss. However, the separation of the refrigerant in the channel would make the temperature distribution more uniform, which is better for the performance and life of the PV cells. After modification of the dimensionless pressure loss coefficient, the grid type has the highest efficiency factor which means under the same conditions, this kind of evaporator would extract most waste heat from PV panels. The modified efficiency factors under these conditions are $0.521,0.564,0.549$, and 0.342 of hexagon, grid, rectangle, and linear unit types, respectively. Moreover, the rectangle and hexagon types have far better thermal performance than linear type because of a larger area of the fluid channel which means a larger heat transfer area. 


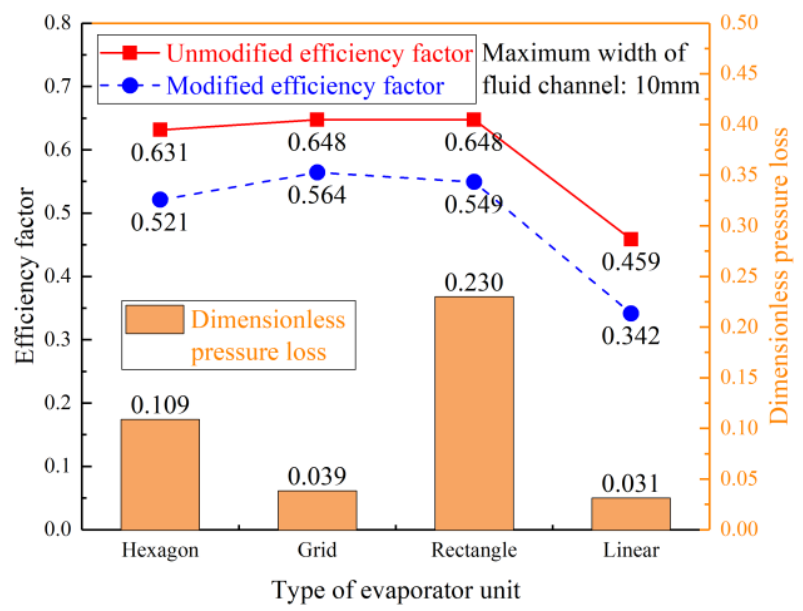

The temperature uniformity of PV cells is also an important index to evaluate the therma performance of PVT collector/evaporator. The working conditions are: solar radiation intensity is $750 \mathrm{~W} / \mathrm{m}^{2}$, wind speed is $2.5 \mathrm{~m} / \mathrm{s}$, the maximum fluid channel width of each type unit is $10 \mathrm{~mm}$. The temperature distributions of cross-section and the front surface of the PVT module have shown in Fig. 11. The fluid inlet is at downside and outlet is at upside while left and right are set as symmetry in Ansys Fluent 17.0. As shown in Fig. 11(a, c), the mainstream from inlet would be forcibly separated into two streams which would cause a significant pressure loss. In the grid and linear type channels, the mainstream would not be forcibly separated into several streams which leads to a lower pressure loss. As shown in Fig. 11(b), there are four fluid branches around the mainstream. Fluid in these branches almost has no velocity but helps to transfer heat from the roll-bond panel, and that is the reason why grid type has a higher thermal efficiency than linear type. Fig. 11(e h) shows the temperature distribution of PVT module front surface and its corresponding maximum temperature difference. The hexagon and rectangle types have a minimum temperature difference which is $0.038{ }^{\circ} \mathrm{C}$ while the linear type is $0.061{ }^{\circ} \mathrm{C}$ and the grid type is $0.135^{\circ} \mathrm{C}$. The hexagon and rectangle type has a better temperature uniformity due to the forced separation of fluid in the channel. However, the accumulation of pressure loss through each unit would cause a significant increase in system energy consumption. Temperature uniformity, thermal efficiency, energy consumption are the three most important indices of PVT collector/evaporator. Considering about above-mentioned indices, the combination of hexagon and grid type would be a better choice than other combinations.

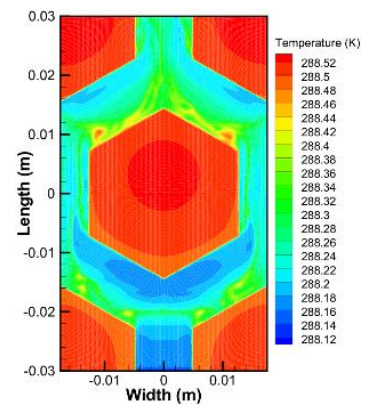

(a) Hexagon

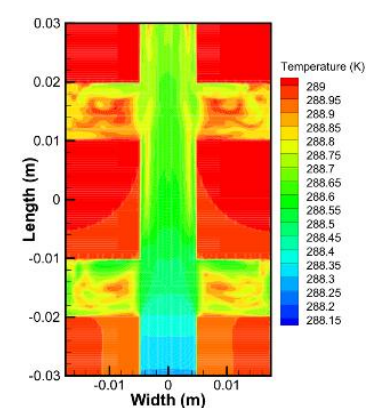

(b) Grid

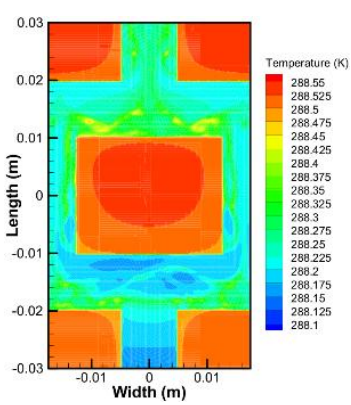

(c) Rectangle

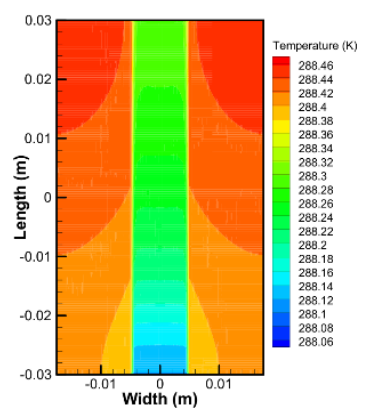

(d) Linear 


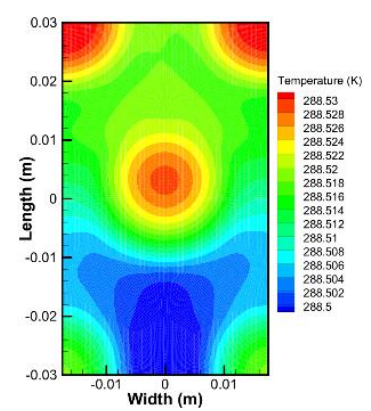

(e) Maximum

temperature

difference: $0.038^{\circ} \mathrm{C}$

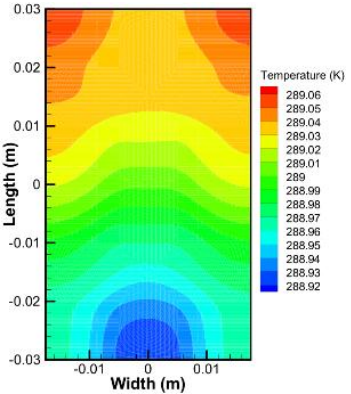

(f) Maximum

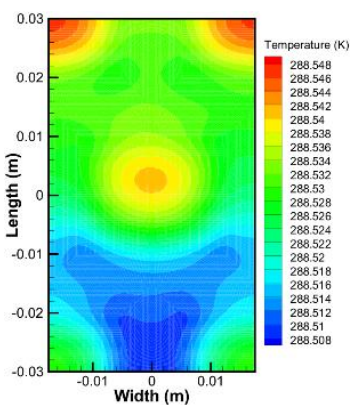

(g) Maximum temperature

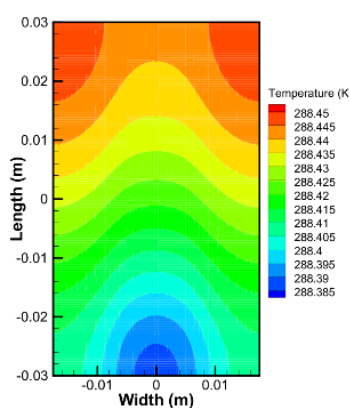

(h) Maximum

temperature difference: $0.061^{\circ} \mathrm{C}$
458

459

460

461

462

463

464

465

466

467

468

469

470

471

472

473

474

475

476

477

478

479

480

481

482

483

484

Fig. 11. (a $\sim \mathbf{d})$ Temperature distribution of cross-section view; $(\mathbf{e} \sim \mathbf{h})$ Temperature distribution of PVT front surface and maximum temperature difference.

Table. 6. Maximum temperature difference and electrical response of each type evaporator unit.

\begin{tabular}{lllll}
\hline Type of evaporator unit & Hexagon & Grid & Rectangle & Linear \\
\hline Maximum temperature difference $\left({ }^{\circ} \mathrm{C}\right)$ & 0.038 & 0.135 & 0.038 & 0.061 \\
Electrical efficiency $(\%)$ & 13.08 & 13.13 & 13.11 & 12.59 \\
Improvement of electrical efficiency $(\%)$ & 15.73 & 16.15 & 15.97 & 11.44 \\
Electrical power $(\mathrm{W})$ & 195.9 & 196.6 & 196.4 & 188.6 \\
\hline
\end{tabular}

Table. 6 presents the maximum temperature difference and electrical response of each type evaporator unit. Under given conditions, the electrical efficiency of a single PV module without thermal collector is $11.30 \%$ while its corresponding electrical power is $168.9 \mathrm{~W}$. Meanwhile, the electrical efficiencies of the hexagon, grid, rectangle, and linear types are $13.08 \%, 13.13 \%$, $13.11 \%$, and $12.59 \%$, respectively. The grid type has the most substantial improvement of electrical efficiency which is $16.15 \%$, while the linear type has the minimum improvement of electrical efficiency which is $11.44 \%$. Moreover, the electrical powers of the hexagon, grid, rectangle, and linear types are $195.9 \mathrm{~W}, 196.6 \mathrm{~W}, 196.4 \mathrm{~W}$, and $188.6 \mathrm{~W}$, respectively.

\subsection{Solar radiation intensity}

The adoption of different types of evaporators would influence the system performance of the direct expansion solar assisted heat pump. In this sub-section, the influence of solar radiation intensity on several system performance indices have been further studied under the working conditions: solar radiation intensity varies from $200 \mathrm{~W} / \mathrm{m}^{2}$ to $1000 \mathrm{~W} / \mathrm{m}^{2}$; wind speed is $2.5 \mathrm{~m} / \mathrm{s}$; ambient temperature is $20^{\circ} \mathrm{C}$; maximum width of the fluid channel is $10 \mathrm{~mm}$.

As shown in Fig. 12(a), different solar radiation intensity would affect the temperature uniformity of the PVT front surface. The maximum temperature differences of the PVT front surface of these four types would increase with the increase of the solar irradiation, which means a higher solar radiation intensity would reduce the temperature uniformity. The hexagon, rectangle, and linear types have almost the same maximum temperature differences when the solar radiation intensity is under $600 \mathrm{~W} / \mathrm{m}^{2}$, while the maximum temperature difference of grid type is much higher than that of the others. Under high solar irradiation conditions, the hexagon and rectangle types perform better at temperature uniformity. For instance, the maximum temperature 
differences of hexagon and rectangle types are $0.0588{ }^{\circ} \mathrm{C}$ and $0.0582{ }^{\circ} \mathrm{C}$ when solar radiation intensity is $1000 \mathrm{~W} / \mathrm{m}^{2}$, respectively, while the maximum temperature differences of grid and linear types are $0.2018{ }^{\circ} \mathrm{C}$ and $0.1174{ }^{\circ} \mathrm{C}$, respectively.

Fig. 12(b d) presents the variation curves of the COP, the mass flow rate of refrigerant, and the compressor power with the variation of solar radiation intensity. A high system COP could be obtained as well as the mass flow rate of refrigerant under high solar radiation intensity. Moreover, the heat pump system using grid type evaporator has better performance than others, for instance, the grid type system has the highest $\mathrm{COP}(6.67)$ when solar radiation intensity is $1000 \mathrm{~W} / \mathrm{m}^{2}$ while the COPs of rectangle, hexagon, and linear type systems are 6.46, 5.85, and 4.67, respectively. In the meantime, the mass flow rates of refrigerant of grid, rectangle, hexagon, and linear type systems are $5.9 \mathrm{~g} / \mathrm{s}, 5.8 \mathrm{~g} / \mathrm{s}, 6.5 \mathrm{~g} / \mathrm{s}$, and $8.1 \mathrm{~g} / \mathrm{s}$, respectively. As shown in Fig. 12(d), the variations curves of the compressor powers of different systems have the same variation trend, the compressor power increase at first when solar radiation intensity is below $600 \mathrm{~W} / \mathrm{m}^{2}$ and then decrease when the solar radiation intensity exceeds $600 \mathrm{~W} / \mathrm{m}^{2}$. That is because the mass flow rate of refrigerant is low under low solar irradiation conditions, therefore, the compression process would not consume much electricity and lead to a lower compressor power. The evaporating temperature and pressure would increase with the increase of solar irradiation and then lead to a lower compression ratio and finally cause a lower compressor power.
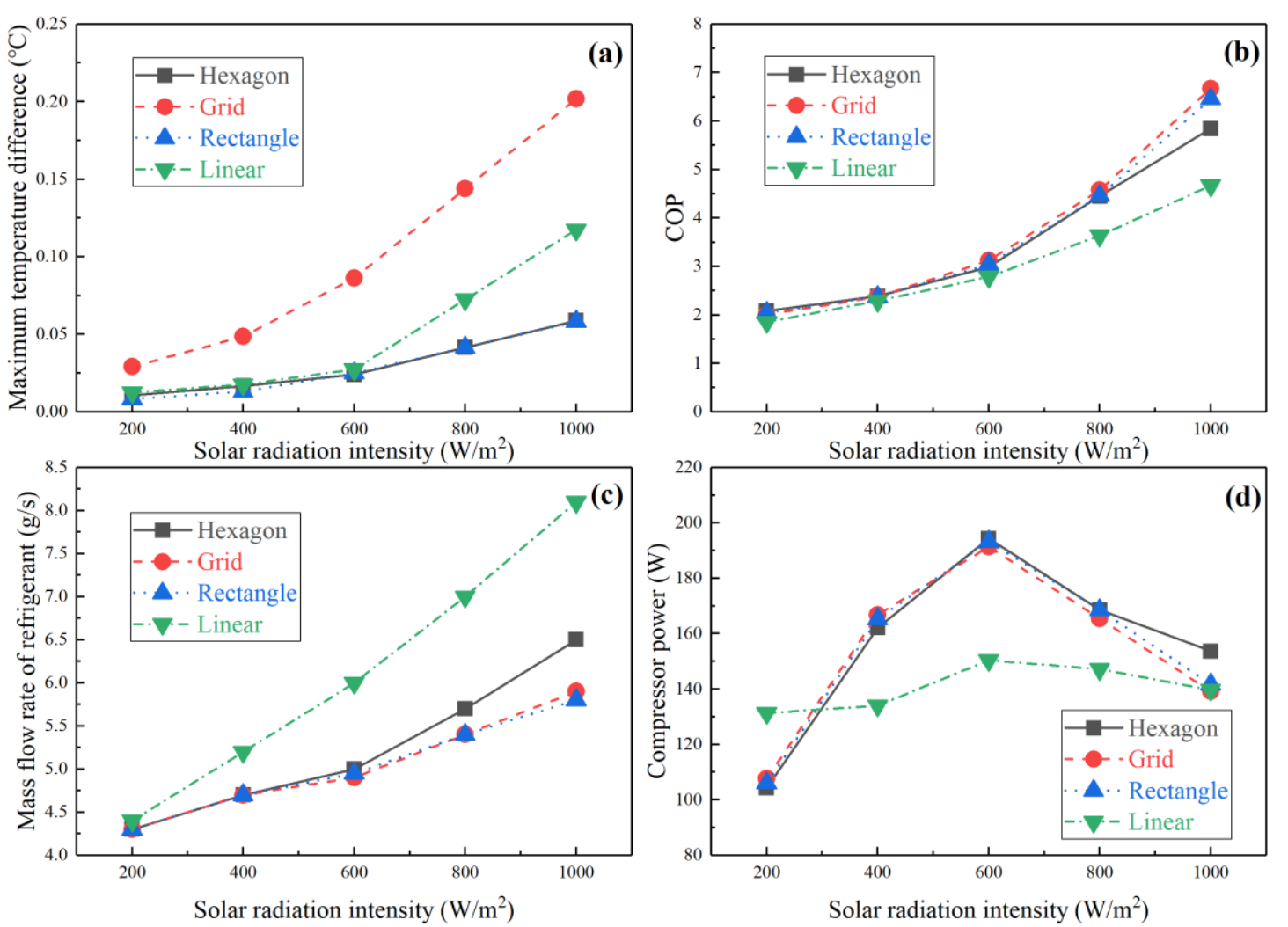

Fig. 12. Influence of solar radiation intensity on (a) maximum temperature difference. (b) COP. (c) mass flow rate of refrigerant. (d) compressor power.

The adoption of solar collector/evaporator would decrease the PV cells' temperature, however, different types of evaporators have different abilities to reduce the PV cells' temperature and improve electrical efficiency. In this regard, the PV cells' temperature and electrical efficiency 
of these four systems are compared with a single PV system. The PV cells' temperatures of a single PV system are $31.8^{\circ} \mathrm{C}, 43.8^{\circ} \mathrm{C}, 55.7^{\circ} \mathrm{C}, 67.9^{\circ} \mathrm{C}$, and $80.4{ }^{\circ} \mathrm{C}$ when solar radiation intensities are $200 \mathrm{~W} / \mathrm{m}^{2}, 400 \mathrm{~W} / \mathrm{m}^{2}, 600 \mathrm{~W} / \mathrm{m}^{2}, 800 \mathrm{~W} / \mathrm{m}^{2}$, and $1000 \mathrm{~W} / \mathrm{m}^{2}$, respectively. Meanwhile, the electrical efficiencies of a single PV system are $13.35 \%, 12.61 \%, 11.87 \%, 11.11 \%$, and $10.34 \%$, respectively.

As shown in Fig. 13(a, b), the linear type evaporator has the worst ability to reduce the PV cells' temperature, and it has the lowest improvement of electrical efficiency, while the others have almost the same performance. For instance, the linear type system reduces $28.2^{\circ} \mathrm{C}$ of the PV cells' temperature and improve $16.8 \%$ of the electrical efficiency compare with a single PV system when the solar radiation intensity is $1000 \mathrm{~W} / \mathrm{m}^{2}$. In the meantime, the temperature drops of grid, rectangle, and hexagon type systems are $39.7^{\circ} \mathrm{C}, 39.3^{\circ} \mathrm{C}$, and $38.8^{\circ} \mathrm{C}$, respectively. Meanwhile, the improvements in electrical efficiency of grid, rectangle, and hexagon type systems are $23.8 \%$, $23.5 \%$, and $23.2 \%$, respectively. Furthermore, the electrical powers of the grid, rectangle, hexagon, and linear type systems are $255.9 \mathrm{~W}, 255.4 \mathrm{~W}, 254.8 \mathrm{~W}$, and $241.7 \mathrm{~W}$, respectively.
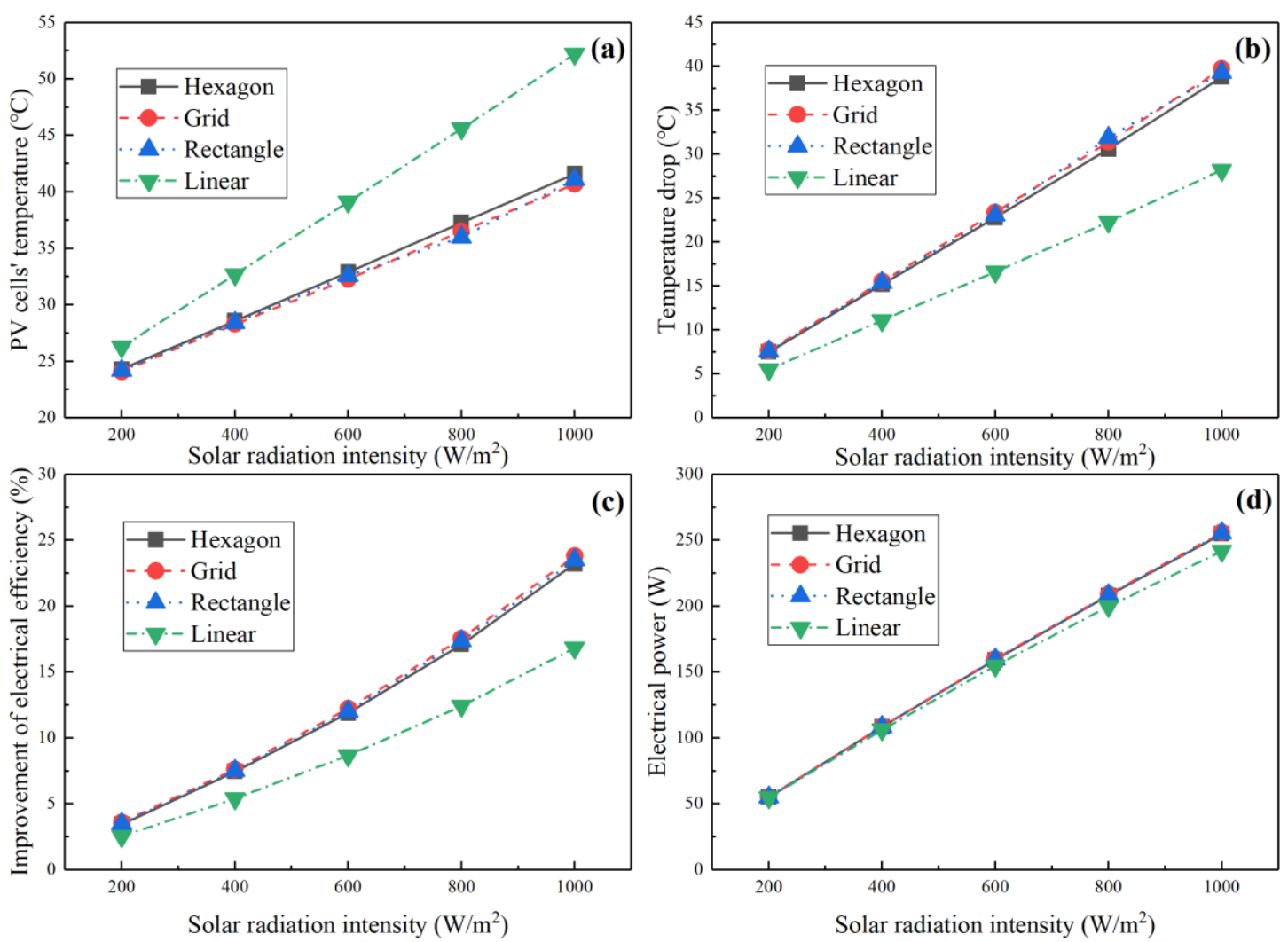

Fig. 13. Influence of solar radiation intensity on (a) PV cells' temperature. (b) temperature drop.

(c) improvement of electrical efficiency. (d) electrical power.

Fig. 14(a) shows the variation curves of electrical exergy efficiency and electrical efficiency with the solar radiation intensity. The electrical exergy efficiency as well as electrical efficiency both decrease linearly with the increase of solar irradiation, and the linear type PVT system has the lowest electrical exergy efficiency and electrical efficiency compare with other systems. For instance, the electrical exergy efficiency of the linear type system is $12.73 \%$ when solar radiation intensity is $1000 \mathrm{~W} / \mathrm{m}^{2}$ while the electrical exergy efficiencies of grid, rectangle, and hexagon type systems are $13.48 \%, 13.45 \%$, and $13.42 \%$. As shown in Fig. 14(b), the system using grid type 
evaporator has the highest thermal exergy efficiency and leads to the highest COP, while the system using linear type evaporator has the lowest thermal exergy efficiency under different solar irradiation conditions.

Fig. 14(c) presents the influence of solar radiation intensity on the efficiency factor, and the efficiency factors of all four types of evaporators decreases smoothly with the increase of solar irradiation. The same conclusion could be drawn as sub-section 5.1 that the grid type evaporator has the highest efficiency factor, and the rectangle type evaporator is the second highest, then is the hexagon type evaporator, while the linear type evaporator has the lowest efficiency factor.

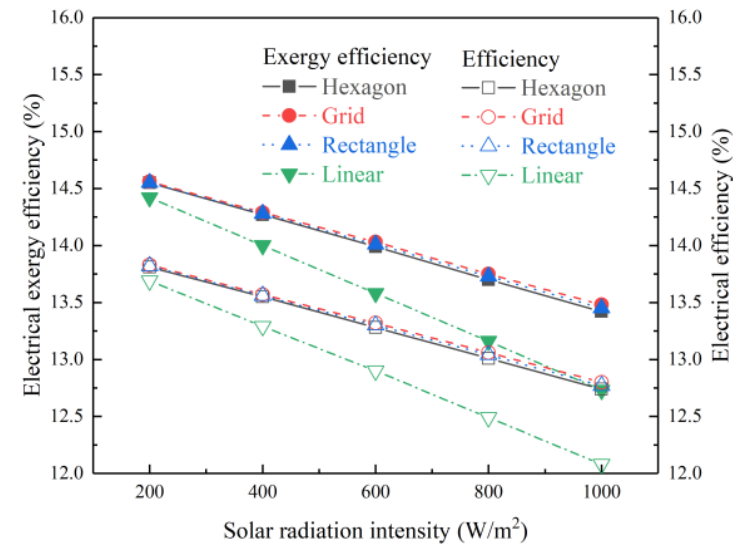

(a)

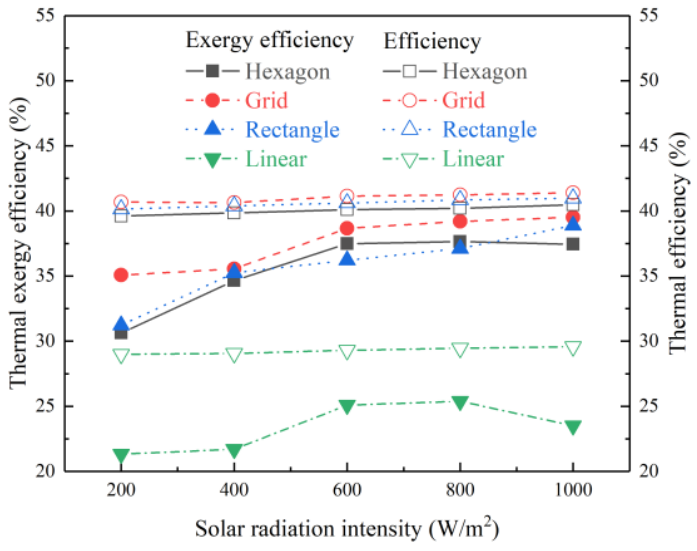

(b)

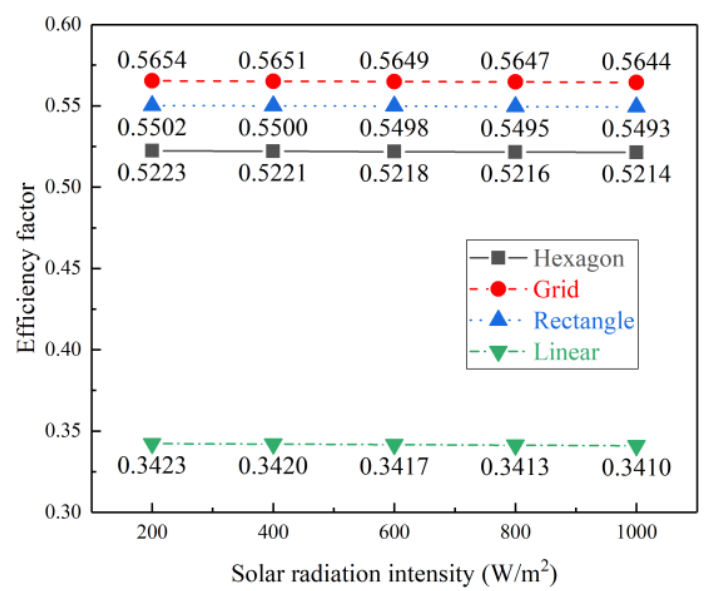

(c)

\subsection{Width of the fluid channel}

The influence of fluid channel width on modified and unmodified efficiency factor and dimensionless pressure loss is shown in Fig. 15. The analysis is conducted under wind speed is 2.5 $\mathrm{m} / \mathrm{s}$, ambient temperature is $25^{\circ} \mathrm{C}$, and $\mathrm{PV}$ cells' temperature is $40^{\circ} \mathrm{C}$. The maximum width of the fluid channels varies from $4 \mathrm{~mm}$ to $13 \mathrm{~mm}$ of each type of evaporator unit. If the width is less than $4 \mathrm{~mm}$, the roll-bond panel is useless and meaningless as a thermal collector due to a significant pressure loss, which would cause a high compressor power and reduce the mass flow rate of refrigerant, and finally lead to a poor thermal performance of the evaporator. If the width is wider 
than $13 \mathrm{~mm}$, the roll-bond panel would not be able to withstand the high-pressure refrigerant without destruction. As shown in Fig. 15(a), the efficiency factor increases rapidly from the beginning and smoothly at the end. The linear type has the highest modified efficiency factor than the other three types when the fluid width is $4 \mathrm{~mm}$ due to the minimum dimensionless pressure loss coefficient. However, the modified efficiency factors of the other three types exceed linear type when the width is wider than $6 \mathrm{~mm}$. Moreover, the modified efficiency factor of the grid type is almost two times of linear type when the fluid channel width is $13 \mathrm{~mm}$. The modified efficiency factors at $13 \mathrm{~mm}$ of hexagon, grid, rectangle, and linear type are 182.5\%,170.5\%,131.3\%, and $21.5 \%$ higher than at $4 \mathrm{~mm}$, respectively. A wider width of the fluid channel is better for the PVT collector/evaporator theoretically due to a higher efficiency factor. Nevertheless, a wider width of the fluid channel means more charge of refrigerant in the solar assisted heat pump system, which would cause a higher initial cost due to a larger volume of fluid in the roll-bond evaporator.

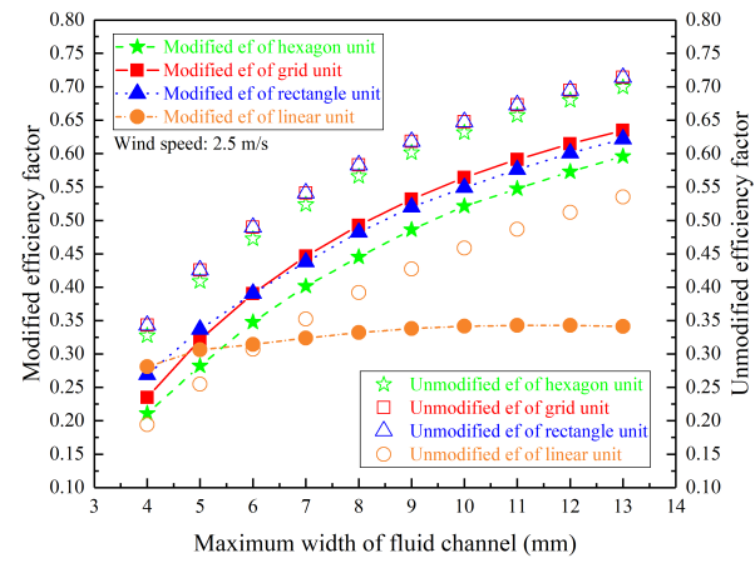

(a)

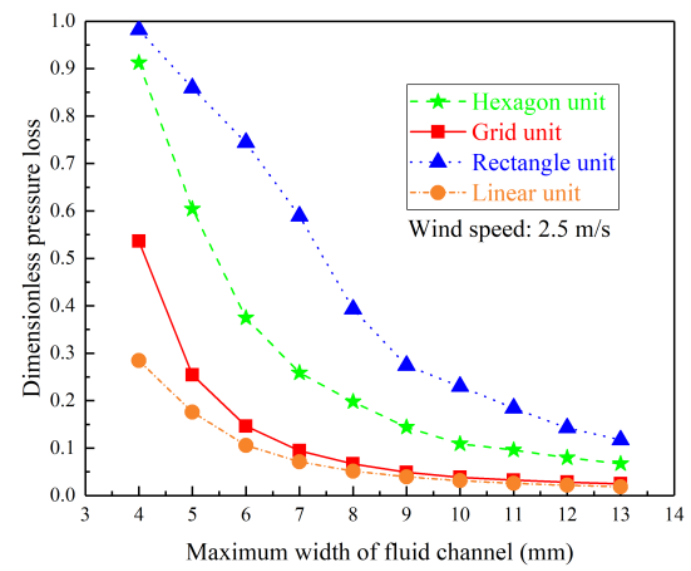

(b)

Fig. 15. Influence of width of the fluid channel on (a) modified and unmodified efficiency factor;

(b) dimensionless pressure loss coefficient.

As shown in Fig. 15(b), different types of evaporator units have the same trend of dimensionless pressure loss. The rectangle type has the highest pressure drop, and hexagon type is the second while the grid type is almost half of it, and the linear type is the last. The pressure drop decreases rapidly from the beginning and smoothly at the end, which has the opposite trend with the efficiency factor. The dimensionless pressure drop at $13 \mathrm{~mm}$ of hexagon, grid, rectangle, and linear type is $7.33 \%, 4.65 \%, 11.92 \%$, and $6.54 \%$ of it at $4 \mathrm{~mm}$. Thus, the fluid channel is not the wider, the better through the above discussion, it has to consider pressure loss, efficiency factor, and initial cost. Due to the significant reduction of pressure loss when fluid channel width increases, the recommendation of fluid channel width is in the range of $8 \mathrm{~mm}$ to $13 \mathrm{~mm}$. If the channel width exceeds $13 \mathrm{~mm}$, the roll-bond panel could not withstand the high-pressure refrigerant during the evaporating process.

\subsection{Area scaling ratio of PVT collector/evaporator unit}

The influence of area scaling ratio which varies from 0.5 to 1.5 on the modified efficiency factor of four types units is shown in Fig. 16. The analysis is conducted under PV cells' temperature is $40^{\circ} \mathrm{C}$ ambient temperature is $25^{\circ} \mathrm{C}$, the maximum width of the fluid channel is 10 $\mathrm{mm}$, and wind speed is $2.5 \mathrm{~m} / \mathrm{s}$. The illustration of the scaling ratio is shown in the downside of 
Fig. 16 which means the length and width of the unit multiple scaling ratio varies from 0.5 to 1.5 while the channel pattern and fluid channel width remain the same. This parameter would reflect the arrangement density of each unit in the same area roll-bond panel. These four variation curves share the same trend which is almost linearly decreased when the scaling ratio increases. The smaller the evaporator unit, the more refrigerant charge of the evaporator which would multiply the initial cost. The maximum modified efficiency factors are obtained when the scaling ratio is 0.5 , which are $0.639,0.685,0.667$, and 0.468 of hexagon, grid, rectangle, and linear type, respectively. Moreover, the modified efficiency factors when scaling ratio is 0.5 are $45.3 \%, 42.9 \%$, $42.9 \%$, and $74.4 \%$ higher than it when scaling ratio is 1.5 of hexagon, grid, rectangle, and linear type, respectively. The modified efficiency factor of the linear type unit would be affected by the scaling ratio most due to the simplest pattern. From the other aspect, the smaller the unit, the worse the pressure withstand capacity, and under a high solar radiation intensity, smaller unit is more vulnerable to break by the high-pressure refrigerant during the evaporating process. Therefore, pressure withstands capacity, efficiency factor, and initial cost should be considered to define the best scaling ratio of an evaporator unit, and the recommendation scaling ration is 0.8 to 1.2 due to the reasons mentioned above.

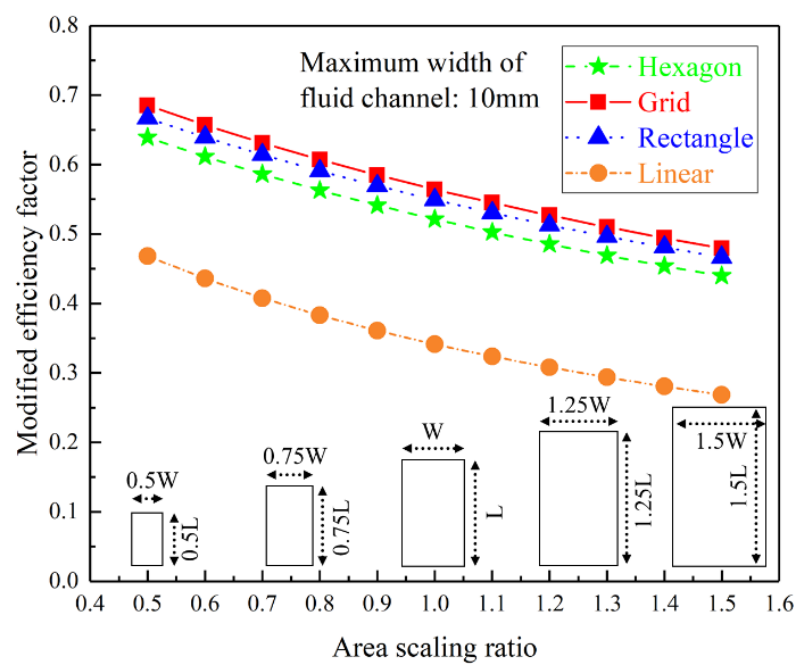

Fig. 16. Influence of area scaling ratio on modified efficiency factor of four types units.

\subsection{Combination of different evaporator unit types}

According to the above discussions, there are six combinations of four unit types have shown in Fig. 17. The hexagon and rectangle types have the best temperature distribution uniformity while these two types have higher pressure loss, which means a higher energy consumption of the compressor. On the opposite, the grid and linear type have the lowest pressure loss but have a worse temperature distribution uniformity. Therefore, a novel combination method has been proposed: the combination of different unit types would be a solution to balance temperature distribution uniformity and pressure loss. Form combination (a) to (f), the pressure loss would decrease as well as temperature distribution uniformity. Thus, the combination choice is not the same for different usage. For instance, if the roll-bond evaporator is used for a direct expansion evaporator solar assisted heat pump system, the temperature distribution uniformity is not the first concern. Thus, the grid type or combination (f) would be the best choice due to a higher efficiency 
factor and a lower compressor energy consumption, which would lead to a higher system COP (coefficient of performance). If the roll-bond evaporator is encapsulated in the PVT module, consider the temperature distribution uniformity to be a higher priority than the pressure loss. Because the temperature distribution uniformity would significantly affect the electrical efficiency and life of the PV cells. Moreover, a more uniformity temperature would increase the stability of the PV cells' current output, which is good for the MPPT solar control device. Thus, combination (b) and (c) would be a better choice for the PVT module considering temperature uniformity than other combinations. To be noted, this novel design method could also be used for different types of PV panels. That is because different kinds of PV panels made by different materials like monocrystalline silicon or polycrystalline silicon and their positions where produce heat are different. Therefore, the evaporator pattern encapsulated in PVT module could be specifically designed and customized for different kinds of PV panels through this design method.

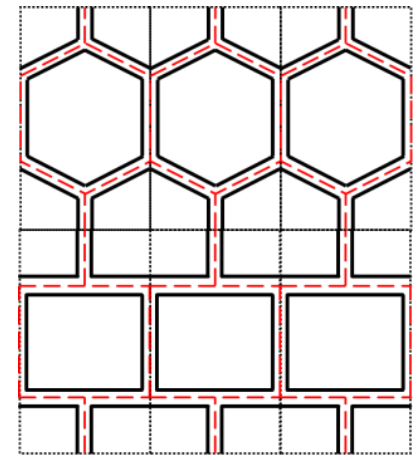

(a) Hexagon-Rectangle

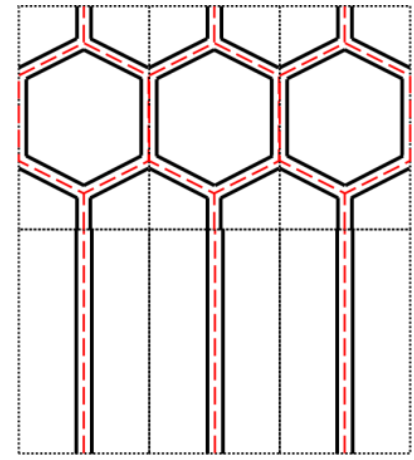

(d) Hexagon-Linear

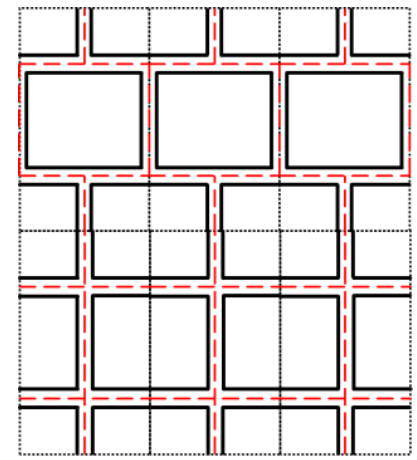

(b) Rectangle-Grid

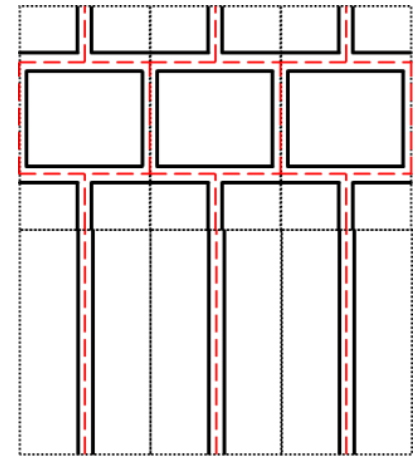

(e) Rectangle-Linear

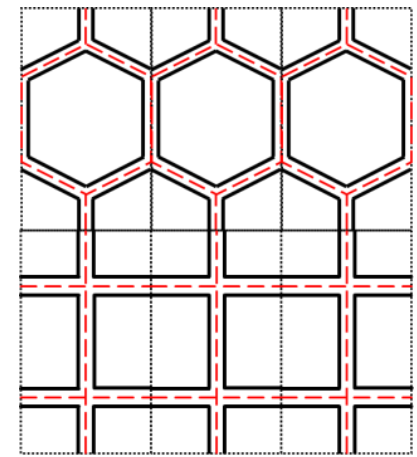

(c) Hexagon-Grid

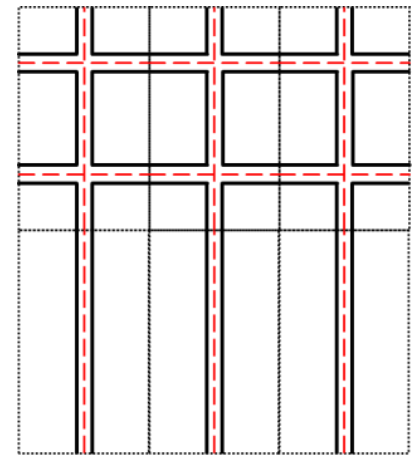

(f) Grid-Linear

Fig. 17. (a f) Different combinations of four unit types.

\section{Conclusions}

Theoretical analysis on the efficiency factor of direct expansion PVT module employing roll-bond collector/evaporator for heat pump application has been conducted in this paper. Aiming to evaluate and design different patterns of roll-bond evaporator which encapsulated in the PVT module, the characteristics of four evaporator unit types have been studied and verified. The main conclusions can be drawn as follows:

(1) Different theoretical efficiency factor expressions of hexagon, grid, rectangle, and linear type units of both PVT module and direct expansion evaporator have given in Table. 2. Moreover, to evaluate the influence of pressure loss on efficiency factor, a mathematical model using the 
CFD model is proposed to modify the efficiency factor which has shown in section 3.3.

(2) Hexagon and rectangle types have better temperature distribution uniformity but higher pressure loss while grid and linear types are the opposite. The dimensionless pressure losses are $0.109,0.039,0.230$ and 0.031 of hexagon, grid, rectangle and linear unit types when the fluid channel width is $10 \mathrm{~mm}$, respectively, while the PV cells' maximum temperature differences are $0.038^{\circ} \mathrm{C}, 0.135^{\circ} \mathrm{C}, 0.038^{\circ} \mathrm{C}$ and $0.061{ }^{\circ} \mathrm{C}$, respectively.

(3) A higher solar radiation intensity would decrease the temperature uniformity of PVT front surface due to a higher temperature difference. The grid type evaporator perform better at reducing the PV cells' temperature (reduce $23.4{ }^{\circ} \mathrm{C}$ when solar irradiation is $600 \mathrm{~W} / \mathrm{m}^{2}$ ) and its corresponding improvement of electrical efficiency is $12.2 \%$ which is $11.9 \%$ for hexagon type, $12.0 \%$ for rectangle type, and $8.7 \%$ for linear type.

(4) The recommendation fluid channel width of the roll-bond panel is $8 \mathrm{~mm}$ to $13 \mathrm{~mm}$, while the recommendation scaling ratio is 0.8 to 1.2 . The modified efficiency factors are $0.521,0.564$, 0.549 , and 0.342 of hexagon, grid, rectangle, and linear types when fluid channel width is $10 \mathrm{~mm}$, respectively.

(5) A novel design method is proposed to specifically design for different kinds of PV panels or direct expansion evaporators. Combinations of the hexagon and grid types or rectangle and grid types are recommended for PVT collector/evaporator, while the combination of grid and linear types or whole grid types are recommended for direct expansion evaporator.

The efficiency factor could be used to analyze and optimize the direct expansion solar collector/evaporator and to simulate the performance of solar assisted heat pump systems. However, the expressions of the modified efficiency of other evaporator patterns could be further studied.

\section{Acknowledgments}

This research work is funded by the International Research Cooperation Program of Shanghai (Grant No. 18160710500).

\section{Nomenclature:}

\section{Symbols}

$A$

W

$L$

$F^{\prime}$

$F_{\text {mod }}$

$F_{R}$

$F$

$\Delta H$

$h$

$S$

$U$

$D$

$T$ area $\left(\mathrm{m}^{2}\right)$

width of roll-bond panel collector/evaporator unit $(\mathrm{m})$

length of roll-bond panel collector/evaporator unit $(\mathrm{m})$

unmodified efficiency factor (-)

modified efficiency factor $(-)$

heat removal factor (-)

fin efficiency (-)

latent heat $(\mathrm{kJ} / \mathrm{kg})$

heat transfer coefficient $\left(\mathrm{W} / \mathrm{m}^{2} \cdot{ }^{\circ} \mathrm{C}\right) /$ enthalpy $(\mathrm{J} / \mathrm{kg})$

entropy $\left(\mathrm{J} / \mathrm{kg} \cdot{ }^{\circ} \mathrm{C}\right)$

heat loss coefficient $\left(\mathrm{W} / \mathrm{m}^{2} \cdot{ }^{\circ} \mathrm{C}\right)$

equivalent width of the fluid channel (m)

temperature $(\mathrm{K})$ 


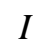

$Q$

$v$

$m$

$P^{\prime}$

$P$

Ex

667

668 Greek symbols

$\delta$

$\tau$

$a$

$\beta$

$\varepsilon$

$\kappa$

$\sigma$

$\eta$

$\chi$

$\Psi$

669

670 Subscripts

$\begin{array}{ll}p & \text { PV cells } \\ e & \text { electrical } \\ c & \text { PV-glazing cover }\end{array}$

EVA

eva

ref

cv

$c d$

$r d$

Al

a

$L$

$u$

Tot

$n$

$e q$

in

out

sun solar radiation intensity $\left(\mathrm{W} / \mathrm{m}^{2}\right)$

heat transfer rate $(\mathrm{W})$

wind speed $(\mathrm{m} / \mathrm{s})$

mass flowrate $(\mathrm{kg} / \mathrm{s})$

dimensionless pressure loss (-)

pressure $(\mathrm{Pa})$

exergy rate (W)

thickness (m)

transmittance (-)

absorption ratios (-)

packing factor (-)

emissivity (-) / exergy efficiency (-)

thermal conductivity $\left(\mathrm{W} / \mathrm{m} \cdot{ }^{\circ} \mathrm{C}\right)$

Stefan-Boltzmann constant (-)

efficiency (-)

dryness (-)

stream exergy per unit mass (W/kg)

EVA (Ethylene Vinyl Acetate) grease

evaporator

refrigerant

convection

conduction

radiation

aluminum roll-bond panel pipe

ambient

lost

useful

total

number

equivalent

inlet

outlet

sun

References:

672 Bliss, R.W., 1959. The derivations of several "Plate-efficiency factors" useful in the design of flat-plate

673 solar heat collectors. Solar Energy 3(4), 55-64. 
Caetano, N.S., Mata, T.M., Martins, A.A., Felgueiras, M.C., 2017. New Trends in Energy Production and Utilization. Energy Procedia 107, 7-14.

Cai, J., Ji, J., Wang, Y., Zhou, F., Yu, B., 2017. A novel PVT-air dual source heat pump water heater system: Dynamic simulation and performance characterization. Energy Conversion and Management 148, 635-645.

Chauhan, A., Tyagi, V.V., Anand, S., 2018. Futuristic approach for thermal management in solar PVThermal systems with possible applications. Energy Conversion and Management 163, 314-354.

Chauhan, A., Tyagi, V.V., Anand, S., 2019. Minimum entropy generation and its validation against Hottel Whillier model for PVT and FPC collectors. Solar Energy 188, 143-157.

Chow, T.T., Pei, G., Fong, K.F., Lin, Z., Chan, A.L.S., Ji, J., 2009. Energy and exergy analysis of photovoltaic-thermal collector with and without glass cover. Applied Energy 86(3), 310-316.

Del Amo, A., Martínez-Gracia, A., Bayod-Rújula, A.A., Cañada, M., 2019. Performance analysis and experimental validation of a solar-assisted heat pump fed by photovoltaic-thermal collectors. Energy $169,1214-1223$.

Duffie, J., Beckman, W.A., Worek, W., 1994. Solar Engineering of Thermal Process. Journal of Solar Energy Engineering-transactions of The Asme - J SOL ENERGY ENG 116.

Hc, H., Bb, W., 1942. Performance of flat-plate solar-heat collectors. Trans. ASME (Am. Soc. Mech. Eng.); (United States) 64.

Hottel, H., Whillier, A., 1955. Evaluation of flat-plate solar collector performance. Trans. Conf. Use of Solar Energy; () 3 (Thermal Processes) Part 2.

Huang, W., Ji, J., Xu, N., Li, G., 2016. Frosting characteristics and heating performance of a direct-expansion solar-assisted heat pump for space heating under frosting conditions. Applied Energy 171, 656-666.

Huide, F., Xuxin, Z., Lei, M., Tao, Z., Qixing, W., Hongyuan, S., 2017. A comparative study on three types of solar utilization technologies for buildings: Photovoltaic, solar thermal and hybrid photovoltaic/thermal systems. Energy Conversion and Management 140, 1-13.

Kamel, R.S., Fung, A.S., Dash, P.R.H., 2015. Solar systems and their integration with heat pumps: A review. Energy and Buildings 87, 395-412.

Keček, D., Mikulić, D., Lovrinčević, Ž., 2019. Deployment of renewable energy: Economic effects on the Croatian economy. Energy Policy 126, 402-410.

Kong, X., Sun, P., Dong, S., Jiang, K., Li, Y., 2018a. Experimental performance analysis of a direct-expansion solar-assisted heat pump water heater with R134a in summer. International Journal of Refrigeration 91, 12-19.

Kong, X., Sun, P., Li, Y., Jiang, K., Dong, S., 2018b. Experimental studies of a variable capacity direct-expansion solar-assisted heat pump water heater in autumn and winter conditions. Solar Energy 170, 352-357.

Kuang, Y.H., Sumathy, K., Wang, R.Z., 2003. Study on a direct - expansion solar - assisted heat pump water heating system. International Journal of Energy Research 27, 531-548.

Kuik, O., Branger, F., Quirion, P., 2019. Competitive advantage in the renewable energy industry: Evidence from a gravity model. Renewable Energy 131, 472-481.

Mellor, A., Alonso Alvarez, D., Guarracino, I., Ramos, A., Riverola Lacasta, A., Ferre Llin, L., Murrell, A.J., Paul, D.J., Chemisana, D., Markides, C.N., Ekins-Daukes, N.J., 2018. Roadmap for the next-generation of hybrid photovoltaic-thermal solar energy collectors. Solar Energy 174, 386-398.

Mohanraj, M., Belyayev, Y., Jayaraj, S., Kaltayev, A., 2018. Research and developments on solar 
assisted compression heat pump systems - A comprehensive review (Part A: Modeling and modifications). Renewable and Sustainable Energy Reviews 83, 90-123.

P. Hartnett, J., M. Rohsenow, W., 1973. Handbook of Heat Transfer.

Paolo Frankl, S., 2010. Technology Roadmap: Solar Photovoltaic Energy.

Park, S.R., Pandey, A.K., Tyagi, V.V., Tyagi, S.K., 2014. Energy and exergy analysis of typical renewable energy systems. Renewable and Sustainable Energy Reviews 30, 105-123.

Pietrosemoli, L., Rodríguez-Monroy, C., 2019. The Venezuelan energy crisis: Renewable energies in the transition towards sustainability. Renewable and Sustainable Energy Reviews 105, 415-426.

Saffarian, M.R., Moravej, M., Doranehgard, M.H., 2020. Heat transfer enhancement in a flat plate solar collector with different flow path shapes using nanofluid. Renewable Energy 146, 2316-2329.

Sporn, P., Ambrose, E.R., 1955. The heat pump and solar energy proceedings of the world symposium on applied. Solar Energy 11, 1-5.

Stojanović, B., Akander, J., 2010. Build-up and long-term performance test of a full-scale solar-assisted heat pump system for residential heating in Nordic climatic conditions. Applied Thermal Engineering 30(2-3), 188-195.

Sun, X., Dai, Y., Novakovic, V., Wu, J., Wang, R., 2015. Performance Comparison of Direct Expansion Solar-assisted Heat Pump and Conventional Air Source Heat Pump for Domestic Hot Water. Energy Procedia 70, 394-401.

Tsai, H.-L., 2015. Modeling and validation of refrigerant-based PVT-assisted heat pump water heating (PVTA-HPWH) system. Solar Energy 122, 36-47.

Wolf, M., 1976. Performance analyses of combined heating and photovoltaic power systems for residences. Energy Conversion 16(1), 79-90.

Yao, J., Xu, H., Dai, Y., Huang, M., 2020. Performance analysis of solar assisted heat pump coupled with build-in PCM heat storage based on PVT panel. Solar Energy 197, 279-291.

Zhang, P., Rong, X., Yang, X., Zhang, D., 2019. Design and performance simulation of a novel hybrid PVT-air dual source heat pump system based on a three-fluid heat exchanger. Solar Energy 191, 505-517.

Zhang, X., Zhao, X., Smith, S., Xu, J., Yu, X., 2012. Review of R\&D progress and practical application of the solar photovoltaic/thermal (PVT) technologies. Renewable and Sustainable Energy Reviews 16(1), 599-617.

Zhou, C., Liang, R., Zhang, J., Riaz, A., 2019. Experimental study on the cogeneration performance of roll-bond-PVT heat pump system with single stage compression during summer. Applied Thermal Engineering 149, 249-261.

Zhou, J., Ma, X., Zhao, X., Yuan, Y., Yu, M., Li, J., 2020. Numerical simulation and experimental validation of a micro-channel PVT modules based direct-expansion solar heat pump system. Renewable Energy 145, 1992-2004. 


\title{
Theoretical analysis on efficiency factor of direct expansion PVT module for heat pump application
}

\author{
Jian YAO $^{\text {a, b }}$, Erjian CHEN ${ }^{\text {a, b }}$, Yanjun DAI *, a, b, Mingjun HUANG $^{\text {c }}$ \\ ${ }^{\text {a }}$ Institute of Refrigeration and Cryogenics, Shanghai Jiao Tong University, Shanghai 200240, China \\ ${ }^{\mathrm{b}}$ Engineering Research Center of Solar Energy and Refrigeration, MOE, China \\ ${ }^{\mathrm{c}}$ Centre for Sustainable Technologies, School of the Built Environment, University of Ulster, Newtownabbey, \\ Northern Ireland, BT37 0QB, UK \\ *: Corresponding author: E-mail address: yjdai@ @jtu.edu.cn (Yanjun DAI); Tel.: +86-21-34204358; fax: \\ $+86-21-34206814$
}

\begin{abstract}
Direct expansion solar assisted PVT (photovoltaic/thermal) heat pump is a combination of PVT technology and heat pump technology, which can improve the comprehensive conversion efficiency of solar energy, and it is suitable for solar heating applications. In this paper, the efficiency factor of direct expansion PVT module employing roll-bond panel has been theoretically derived, modified, and validated by experimental results. Moreover, the efficiency factor could be used to design, evaluate, and optimize the thermal performance of direct expansion solar assisted heat pump systems. In addition, parameter analysis of four evaporator unit types has been conducted, and the recommendation values of each parameter have also been presented. The simulation results show that the roll-bond evaporator (fluid channel width: $10 \mathrm{~mm}$ ) with hexagon and rectangle patterns have better temperature distribution uniformity than grid and linear types, and their temperature differences are both $0.038{ }^{\circ} \mathrm{C}$ while their dimensionless pressure losses are 0.109 and 0.230 , respectively. To specifically design different kinds of PVT collector/evaporator or direct expansion evaporators, a novel design method for roll-bond evaporator is proposed, and a combination of hexagon and grid types is recommended for PVT module. Moreover, the recommendation fluid channel width of the roll-bond panel is $8 \mathrm{~mm}$ to $13 \mathrm{~mm}$ while the scaling ratio is 0.8 to 1.2 . The modified efficiency factors are $0.521,0.564,0.549$, and 0.342 of hexagon, grid, rectangle, and linear types when the fluid channel width is $10 \mathrm{~mm}$, respectively.
\end{abstract}

Keywords: Solar energy; Direct expansion; PVT; Efficiency factor; Roll-bond panel; Channel design method

\section{Introduction}

The total amount of energy consumption is continuously climbing around the world, which has brought energy and environmental crisis (Caetano et al., 2017; Pietrosemoli and Rodríguez-Monroy, 2019). The development and utilization of renewable energy have become an effective solution. Compared with other renewable energy, solar energy has become the first choice and research hotspot due to its ubiquity, abundance, and sustainability (Keček et al., 2019; Kuik et al., 2019; Tsai, 2015). The solar energy utilization method could be mainly divided into two categories: photothermal and photovoltaic.

For solar thermal utilization, different solar collectors (Mellor et al., 2018) and heat transfer 
fluids like water, air, nanofluid, and refrigerant (Kamel et al., 2015) have been proposed and studied. Direct expansion solar assisted heat pump system using refrigerant as a thermal collect medium was first proposed by Sporn and Ambrose (Sporn and Ambrose, 1955) in 1955. Moreover, it is now developed and researched much more due to its high efficiency, energy-saving, stability, and environmental friendly (Mohanraj et al., 2018) and widely used for solar heating applications. In recent years, numerous researchers have conducted different studies about the direct expansion solar assisted heat pump systems. Sun et al. (Sun et al., 2015) conducted a comparison between the air source heat pump water heater (ASHPWH) and the direct expansion solar assisted heat pump water heater (DX-SAHPWH) under various operating conditions. They found that the DX-SAHPWH system takes both solar and ambient air as heat source under clear day conditions and its COP is about 1.5 times of ASHPWH. Huang et al. (Huang et al., 2016) investigated the frosting characteristics and heating performance of direct expansion solar assisted heat pump for space heating under frosting conditions. They demonstrated that solar irradiation could effectively prevent or retard frosting and improve the heating performance of the DX-SAHP system as well. Stojanović and Akander (Stojanović and Akander, 2010) used a direct-expansion heat pump for independent building heating and domestic hot water supply. In their system, the collector area is $42.5 \mathrm{~m}^{2}$ and the heat pump power is $8.4 \mathrm{~kW}$, and they measured that the actual indoor temperature is no less than $20^{\circ} \mathrm{C}$ during the testing period.

For photovoltaic utilization, $\mathrm{PV}$ panels are the primary method to transfer solar radiation into electricity directly, and it's reported that PV panels will provide $11 \%$ of global electricity by 2050 (Paolo Frankl, 2010). Nevertheless, the electrical efficiency is decreased significantly with the increase of the PV cells' temperature (Huide et al., 2017). The PVT (photovoltaic/thermal) technology coupled PV modules with thermal collectors was first proposed by Wolf et al. (Wolf, 1976) in 1976 to reduce PV cells' temperature and improve electrical efficiency. According to the merits mentioned above of refrigerant as a thermal collect medium, the direct expansion solar assisted PVT heat pump has been proposed and studied recently. Several research groups have investigated different kinds of direct expansion solar assisted PVT heat pump systems for the past few years.

Zhou et al. (Zhou et al., 2019) experimentally studied a roll-bond PVT heat pump system during summer, and they found that the average value of heating power and system heating COP are $4.7 \mathrm{~kW}$ and 6.16, respectively. Del Amo et al. (Del Amo et al., 2019) investigated the feasibility of the solar PVT heat pump through experiments. In their study, the highest COP of the system can reach 4.62 while the PV module provides $67.6 \%$ of the power demand, and the payback period is six years. Cai et al. (Cai et al., 2017) proposed a dynamic model of direct expansion PVT-air dual-source heat pump water heater system and conducted its performance characterization through simulation. Their results reveal that the system can operate with an average COP above 2.0 under an ambient temperature of $10^{\circ} \mathrm{C}$ and solar irradiation of $100 \mathrm{~W} / \mathrm{m}^{2}$. Yao et al. (Yao et al., 2020) proposed a solar assisted PVT heat pump system coupled with build-in PCM heat storage. Their simulation results show that a $20 \mathrm{~m}^{2}$ PVT panel module can output $21.4 \%$ of the electricity to the power grid when the solar radiation intensity is $600 \mathrm{~W} / \mathrm{m}^{2}$ and meet the heat demand of a $100 \mathrm{~m}^{2}$ room while maintain the operation of the system and its corresponding COP is 5.79. A novel hybrid PVT-air dual-source heat pump system is proposed by Zhang et al. (Zhang et al., 2019) and their simulation results indicated that the electrical energy output could increase $14.7 \%$ compared with a conventional PV panel. Chauhan et al. (Chauhan et al., 2019) 
theoretically evaluated and designed the PVT module and FPC collectors through entropy generation aspect. In their study, the maximum temperature reduction is $18{ }^{\circ} \mathrm{C}$ through the proposed design, and its corresponding improvement of electrical efficiency is $8.6 \%$. Zhou et al. (Zhou et al., 2020) numerically simulated a direct expansion evaporator based on a micro-channel PVT and conducted experiments to verify the numerical model. The experimental average electrical, thermal, and overall efficiencies of the PVT module are $13.1 \%, 56.6 \%$, and $69.7 \%$, respectively, while the system COP is 4.7 .

The efficiency factor is an important parameter to reflect the heat transfer capacity of solar collectors and features of the physical characteristics of thermal collectors (Zhang et al., 2012). Moreover, the efficiency factor could be used to theoretically evaluate and optimize the solar collector instead of conducted numerous experiments. As shown in Fig. 1, the researches about flat-plate solar collectors started in the early 1900s, and various investigations have conducted (Bliss, 1959; Hc and Bb, 1942; Hottel and Whillier, 1955; Saffarian et al., 2020; Wolf, 1976). The efficiency factor of water or air based PVT module has been reported by Hottle et al. ( $\mathrm{Hc}$ and Bb, 1942), Whillier et al. (Hottel and Whillier, 1955) and Bliss (Bliss, 1959). However, the efficiency factor of PVT as collector/evaporator of heat pump has not been reported, and the optimization on roll-bond evaporator design is also rarely studied. Therefore, in this paper, theoretical derivation and parameter analysis on the efficiency factor of the direct expansion PVT module have been conducted. Firstly, the direct expansion solar assisted PVT heat pump system composition, and a detailed description of the PVT collector/evaporator are introduced. Secondly, a mathematical model is used to derive the modified efficiency factor as well as the heat removal factor of four evaporator unit types. Then the theoretical efficiency factor is verified by experimental results. Finally, parameter analysis of the direct expansion PVT module employing roll-bond evaporator has been investigated. The objective of this paper is to propose the efficiency factor expression of PVT collector/evaporator and provide a novel design method for the roll-bond evaporator.

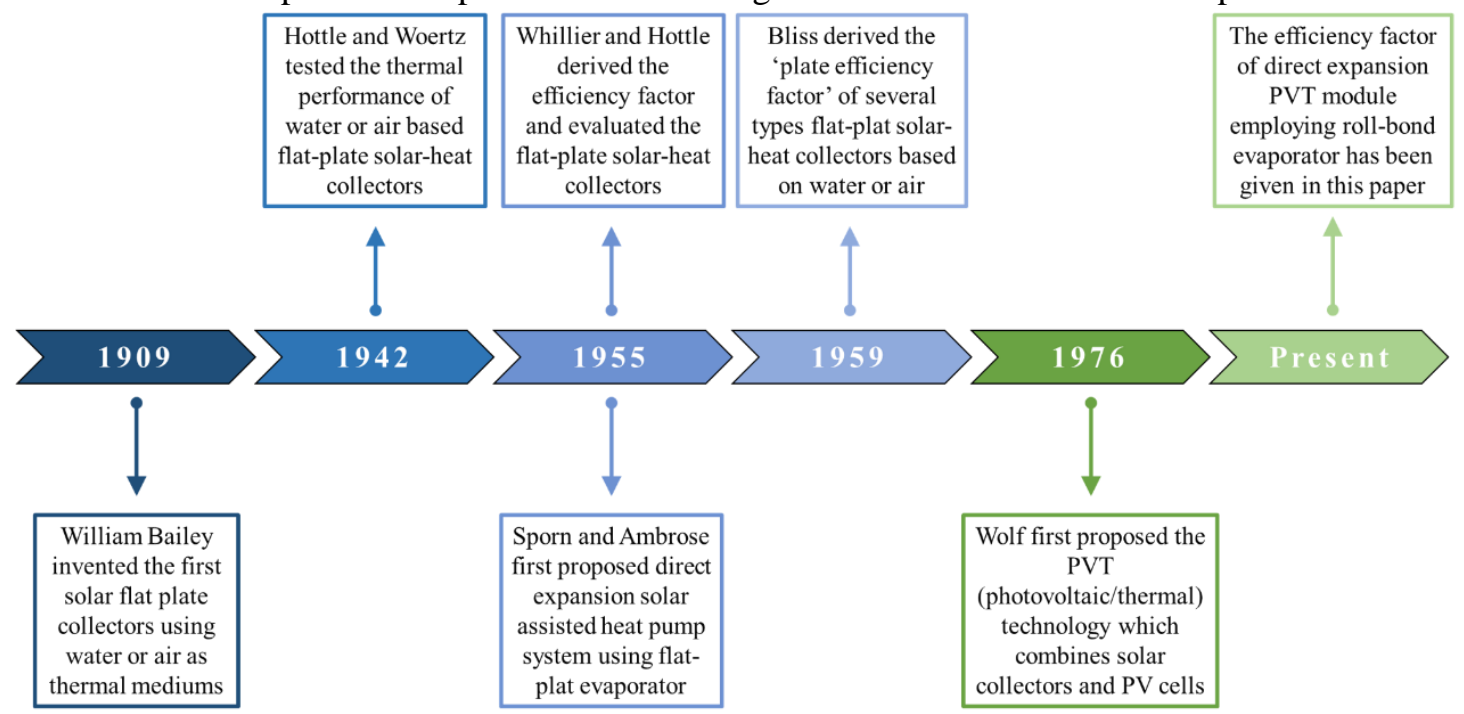

Fig. 1. The development history of flat-plate solar collectors.

\section{System description}

\subsection{Composition of solar assisted PVT heat pump}


Typical direct expansion solar assisted heat pump system is consists of evaporator, compressor, condenser, and throttle valve. The PVT collector/evaporator is an essential component of the direct expansion solar assisted heat pump system, which is shown in Fig. 2(a). Compared to conventional solar assisted heat pump system which could only produce thermal energy, the PVT module could produce both electrical and thermal energy as shown in Fig. 2(b). Moreover, the combination of photovoltaic and photothermal technology could use the cooling fluid to extract waste heat from PV cells. In the meantime, the temperature of PV cells would be regulated, and therefore the electrical efficiency would increase simultaneously. The thermal efficiency of the PVT collector/evaporator is an important parameter which would directly influence both the electrical efficiency and heat pump efficiency.

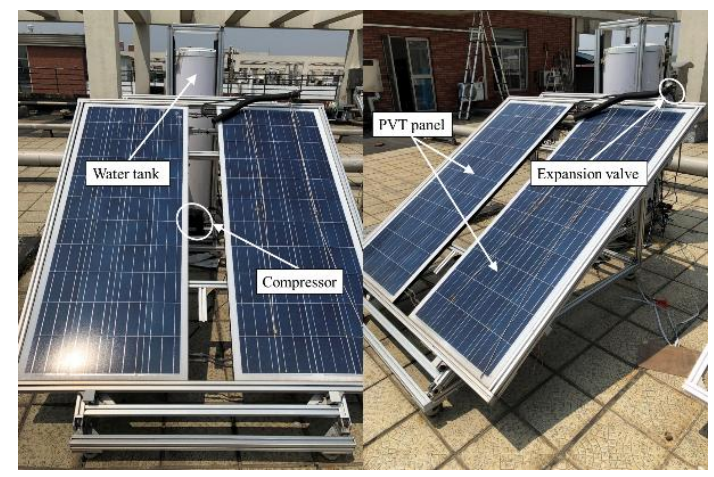

(a)

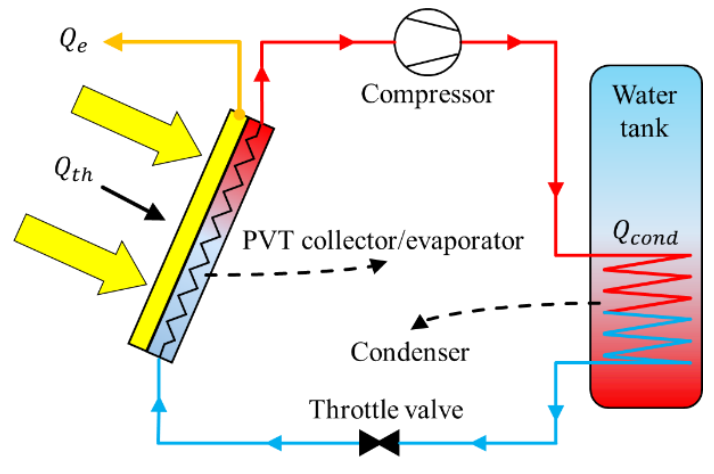

(b)

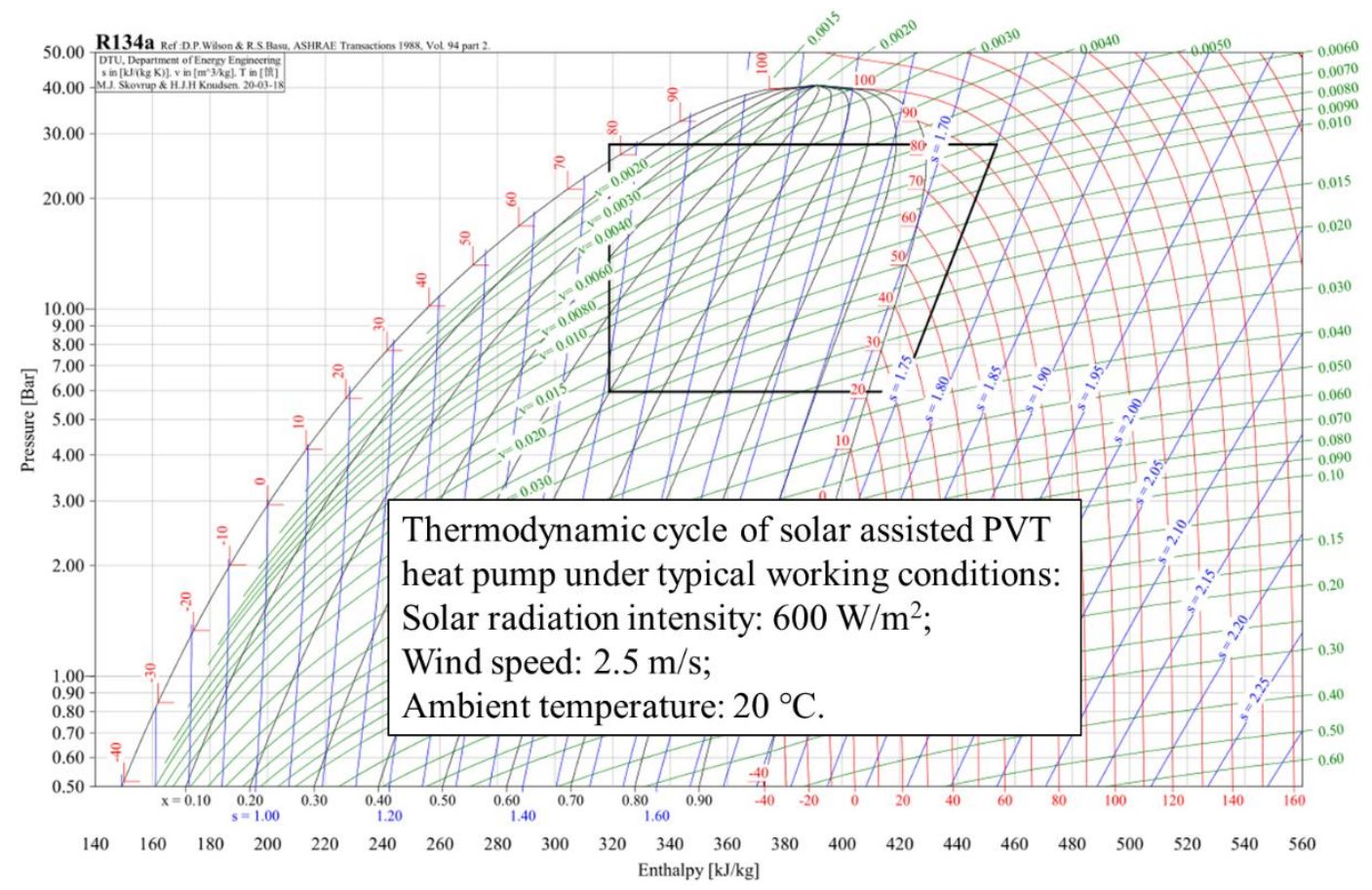

(c)

Fig. 2. (a) Solar assisted PVT heat pump system. (b) Thermodynamic cycle of direct expansion solar assisted PVT heat pump system. (c) Pressure-enthalpy diagram of solar assisted PVT heat pump thermodynamic cycle.

Fig. 2(c) shows the pressure-enthalpy diagram of solar assisted PVT heat pump thermodynamic cycle under typical working conditions: solar radiation intensity is $600 \mathrm{~W} / \mathrm{m}^{2}$; 
wind speed is $2.5 \mathrm{~m} / \mathrm{s}$, and ambient temperature is $20^{\circ} \mathrm{C}$. The refrigerant type is $\mathrm{R} 134 \mathrm{a}$ and in this case, the evaporating temperature is around $22^{\circ} \mathrm{C}$ and the condensing temperature is about $80{ }^{\circ} \mathrm{C}$

In addition, this paper focus on the theoretical analysis of the efficiency factor of direct expansion PVT module. On the other hand, the mathematical models of each part including PVT module, compressor, condenser, and throttle valve of solar assisted PVT heat pump have been established in the authors' previous work (Yao et al., 2020). In this regard, the performance analysis of the solar assisted PVT heat pump could be conducted using the mathematical models. Thus, the main points of section 3 are the theoretical derivation on efficiency factor of direct expansion PVT module and the exergy analysis. It needs to be emphasized that the expressions of the efficiency factor in section 3 are used in the mathematical model of PVT module to further simulate the system performance.

\subsection{Description of direct expansion PVT module employing roll-bond panel}

The front side of the PVT collector/evaporator is shown in Fig. 3(a) and the roll-bond panel which augmented in PVT module is shown in Fig. 3(b). The roll-bond panel is made of aluminum, and the fluid channel which painted by graphite powder is processed by high-pressure nitrogen. The channel pattern which is consists of hexagon and grid evaporator unit types has been optimized to balance the temperature distribution of the PV panel and pressure drop. As shown in Fig. 3(c), the heat loss from PVT panel to ambient is consist of two processes: (1) heat loss from PV cells to PV-glazing cover; (b) heat loss from PV-glazing cover to ambient.

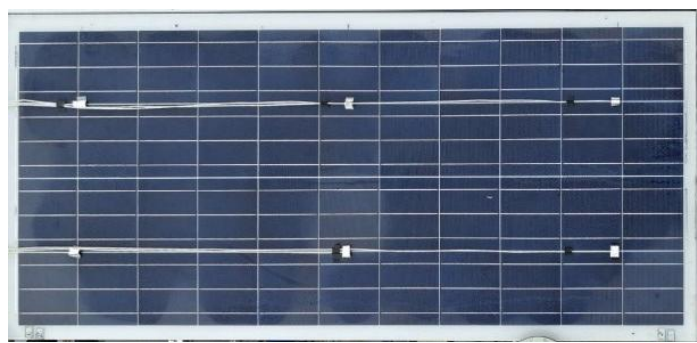

(a)

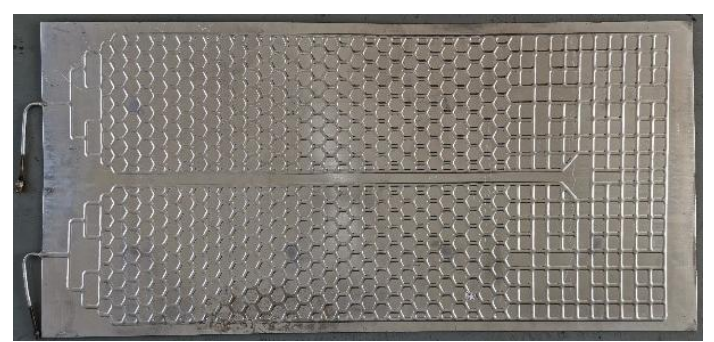

(b)

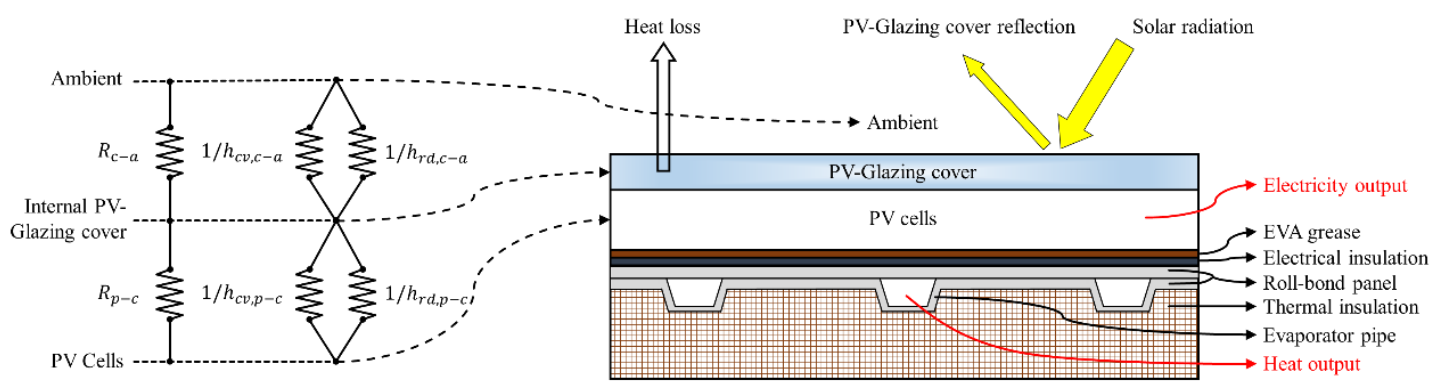

(c) 
Table. 1. Characteristic parameters of different PVT layers.

\begin{tabular}{llll}
\hline Parameters & Nomenclature & Value & Unit \\
\hline Thickness of PV-glazing cover & $\delta_{g, p v}$ & 1 & $\mathrm{~mm}$ \\
Emissivity of PV-glazing cover & $\varepsilon_{c}$ & 0.84 & {$[-]$} \\
Transmissivity of PV-glazing cover & $\tau_{g, p v}$ & 0.9 & {$[-]$} \\
Thickness of PV cells & $\delta_{p v}$ & 0.3 & $\mathrm{~mm}$ \\
Emissivity of PV cells & $\varepsilon_{p}$ & 0.96 & {$[-]$} \\
Absorptance of PV cells & $a_{p}$ & 0.85 & {$[-]$} \\
Thermal conductivity of PV cells & $\kappa_{p}$ & 203 & $\mathrm{~W} /\left(\mathrm{m} \cdot{ }^{\circ} \mathrm{C}\right)$ \\
Absorptance of PV baseboard & $a_{b}$ & 0.8 & {$[-]$} \\
Thickness of EVA (Ethylene Vinyl Acetate) grease & $\delta_{E V A}$ & 0.5 & $\mathrm{~mm}$ \\
Thermal conductivity of EVA grease & $\kappa_{E V A}$ & 0.311 & $\mathrm{~W} /\left(\mathrm{m} \cdot{ }^{\circ} \mathrm{C}\right)$ \\
Thickness of electrical insulation & $\delta_{e i}$ & 0.5 & $\mathrm{~mm}$ \\
Thermal conductivity of electrical insulation & $\kappa_{e i}$ & 0.15 & $\mathrm{~W} /\left(\mathrm{m} \cdot{ }^{\circ} \mathrm{C}\right)$ \\
Electrical insulation material & {$[-]$} & $T e d l a r$ & {$[-]$} \\
Packing factor & $\beta_{p}$ & 1 & {$[-]$} \\
Thermal conductivity of roll-bond panel & $\kappa_{r b}$ & 151 & $\mathrm{~W} /\left(\mathrm{m} \cdot{ }^{\circ} \mathrm{C}\right)$ \\
Thickness of roll-bond panel pipe & $\delta_{r b}$ & 0.9 & $\mathrm{~mm}$ \\
Area of PVT module & $A$ & 2 & $\mathrm{~m}{ }^{2}$ \\
Width of PVT module & $W_{e v a}$ & 1 & $\mathrm{~m}$ \\
Length of PVT module & $L_{e v a}$ & 2 & $\mathrm{~m}$ \\
Refrigerant type & $r e f$ & $\mathrm{R} 134 \mathrm{a}$ & {$[-]$} \\
\hline
\end{tabular}

\section{Efficiency factor and heat removal factor}

The thermal efficiency is an important parameter to evaluate the thermal performance of solar collectors, especially in direct expansion PVT module which could reflect the heat extract capacity of the thermal collectors. In general, the instantaneous heat gain by PVT collector/evaporator can be expressed as (Duffie et al., 1994):

$$
Q_{u}{ }^{\prime}=A \cdot\left[(\tau \alpha) \cdot I \cdot\left(1-\eta_{\mathrm{e}}\right)-U_{L} \cdot\left(T_{b}-T_{a}\right)\right]
$$

However, it is difficult to determine the value of the average inner surface temperature of the collector pipe $\left(T_{b}\right)$, but the refrigerant temperature $\left(T_{w}\right)$ in direct expansion evaporator is easier to determine due to the isothermal process of evaporating. Thus, $T_{b}$ could be replaced by $T_{w}$ and the heat gain by PVT collector/evaporator can be expressed as (Chauhan et al., 2018):

$$
Q_{u}{ }^{\prime}=A \cdot F^{\prime} \cdot\left[(\tau \alpha) \cdot I \cdot\left(1-\eta_{\mathrm{e}}\right)-U_{L} \cdot\left(T_{w}-T_{a}\right)\right]
$$

where $F^{\prime}$ is the efficiency factor which represents the ratio of actual useful energy gain and useful gain if the collector inner surface is at the local fluid temperature.

If the average inner surface temperature of the collector pipe $\left(T_{b}\right)$ replaced by inlet temperature of refrigerant $\left(T_{i}\right)$, the heat gain by PVT collector/evaporator can be expressed as (Chauhan et al., 2018):

$$
Q_{u}{ }^{\prime}=A \cdot F_{R} \cdot\left[(\tau \alpha) \cdot I \cdot\left(1-\eta_{\mathrm{e}}\right)-U_{L} \cdot\left(T_{i}-T_{a}\right)\right]
$$


where $F_{R}$ is the heat removal factor which represents the ratio of actual useful energy gain and useful gain if the collector inner surface is equal to the temperature of inlet fluid.

In general, the efficiency factor $F^{\prime}$ is an index to evaluate how good the heat transfer is between the thermal collector and the heat transfer fluid, while the heat removal factor is a measure of the solar collector performance as a heat exchanger as it can be interpreted as the ratio of actual heat transfer and the maximum possible heat transfer. Moreover, both factors could reflect the physical construction features, thermal performance, and operating parameters of different kinds of thermal collectors. Consequently, the efficiency factor and heat removal factor could be used to simulate the performance of the direct expansion evaporator or PVT module which employing roll-bond panel in solar assisted heat pump system instead of conduct numerous experiments to get the thermal performance indices. Furthermore, it would be used in the design and optimization of direct expansion PVT module and solar assisted heat pump system. In this section, the derivation on efficiency factor and heat removal factor of both direct expansion evaporator and direct expansion PVT module would be presented in detail.

\subsection{Physical model}

As shown in Fig. 3(c), a direct expansion PVT module employing the roll-bond panel has a multilayer structure. The physical and heat transfer model of $W \times L$ PVT and direct expansion evaporator units have shown in Fig. 4. The only difference in efficiency factor between the PVT module and direct expansion evaporator is the expression of the heat loss coefficient. Thus, the derivation method of efficiency factor and the heat removal factor are the same of these two models.

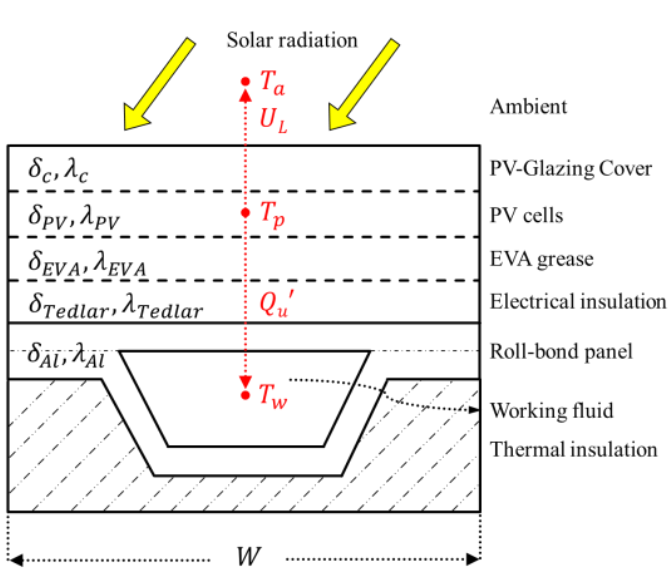

(a)

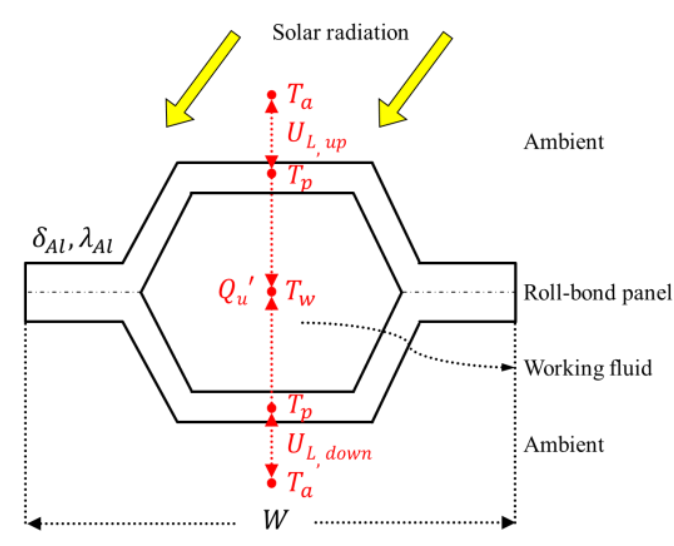

(b)

Fig. 4. (a) Physical and heat transfer model of a PVT unit. (b) Physical and heat transfer model of a direct expansion evaporator unit.

The channel pattern of the roll-bond panel has presented in Fig. 3(b). This panel is consist of different types of evaporator unit which have shown in Fig. 5. The evaporator unit's width is $W$ (35 mm) and length is $L(60 \mathrm{~mm})$, the detailed size has also shown in Fig. 5. The theoretical derivation of the efficiency factor and the heat removal factor is based on these four types of units. 

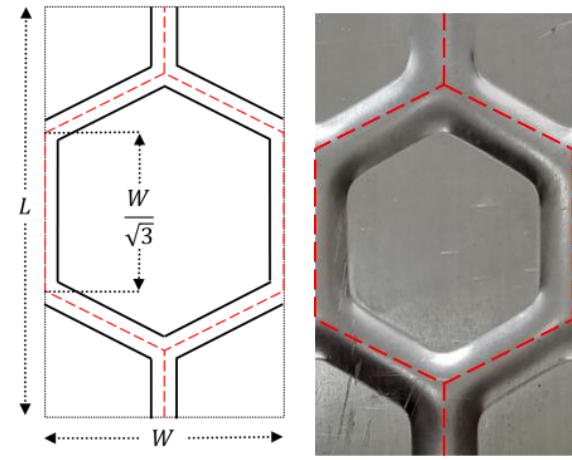

(a) Hexagon type
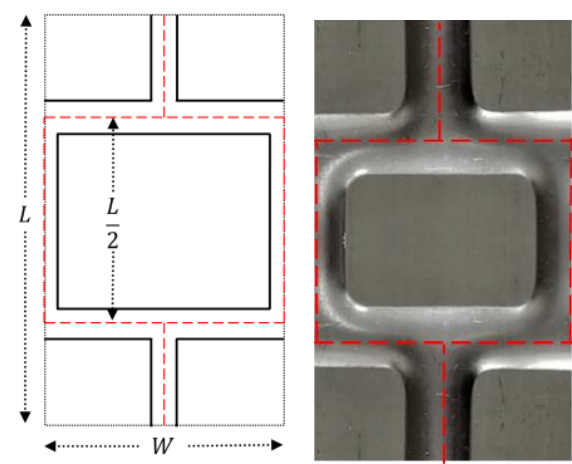

(c) Rectangle type
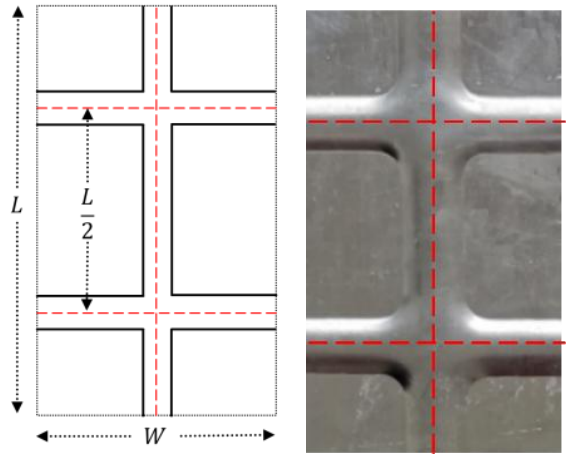

(b) Grid type

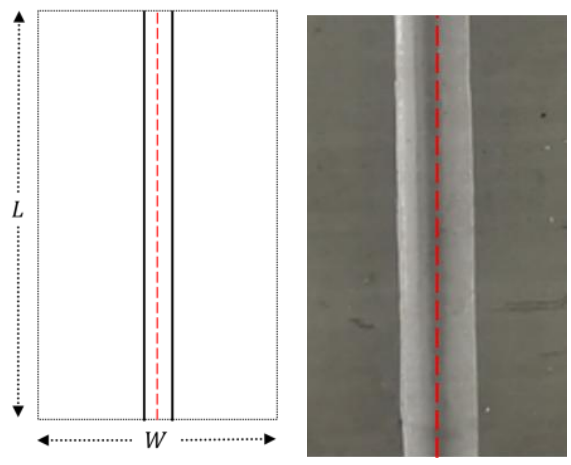

(d) Linear type

Fig. 5. Different types of evaporator units in the roll-bond panel.

\subsection{Efficiency factor}

In steady-state, the performance of a PVT module which employing roll-bond panel can be described by an energy balance indicating the distribution of the solar energy into useful energy gain, electrical energy gain, and thermal losses. Different types of roll-bond panels have been listed in Fig. 5 and take the hexagon type unit of the PVT module as an example.

For a $W \times L$ hexagon PVT unit, the useful energy gain can be expressed as:

$$
\begin{aligned}
& Q_{u}{ }^{\prime}=\left(W \cdot L-12 \cdot \frac{D}{2} \cdot \frac{W}{\sqrt{3}}\right) \cdot F \cdot\left[(\tau \alpha) \cdot I \cdot\left(1-\eta_{\mathrm{e}}\right)-U_{L} \cdot\left(T_{p}-T_{a}\right)\right] \\
& +12 \cdot \frac{D}{2} \cdot \frac{W}{\sqrt{3}} \cdot\left[(\tau \alpha) \cdot I \cdot\left(1-\eta_{\mathrm{e}}\right)-U_{L} \cdot\left(T_{p}-T_{a}\right)\right]
\end{aligned}
$$

where $W$ and $L$ are the width and length of the PVT collector/evaporator unit, respectively; $D$ is the equivalent width of the fluid channel; $F$ is the fin efficiency which can be expressed by (Duffie et al., 1994):

$$
F=\frac{\tanh \left(U_{b}\right)}{U_{b}}
$$

where $U_{b}$ is a dimensionless parameter which can be defined as (Duffie et al., 1994):

$$
U_{b}=\frac{W \cdot L-2 \sqrt{3} \cdot W \cdot D}{2 L} \cdot \sqrt{\frac{U_{L}}{\lambda_{A l} \cdot\left(2 \cdot \delta_{A l}\right)+\lambda_{\text {Tedlar }} \cdot \delta_{\text {Tedlar }}+\lambda_{E V A} \cdot \delta_{E V A}}}
$$


Meanwhile, the useful energy gain by Eq. (4) must be transferred to the fluid, which can be expressed as:

$$
Q_{u}{ }^{\prime}=12 \cdot \frac{1}{2} \cdot \frac{W}{\sqrt{3}} \cdot \frac{T_{p}-T_{w}}{\frac{1}{D} \cdot\left(\frac{\delta_{\text {EVA }}}{\lambda_{\text {EVA }}}+\frac{\delta_{\text {Tedlar }}}{\lambda_{\text {Tedlar }}}+\frac{\delta_{A l}}{\lambda_{A l}}\right)+\frac{1}{h_{e q} \cdot \pi \cdot D}}
$$

where $\delta_{E V A}, \delta_{\text {Tedlar }}$ and $\delta_{A l}$ are the thickness of EVA grease, electrical insulation and roll-bond panel, respectively; $\lambda_{E V A}, \lambda_{\text {Tedlar }}$ and $\lambda_{A l}$ are the thermal conductivity of EVA grease, electrical insulation and roll-bond panel, respectively; $h_{e q}$ is the equivalent heat transfer coefficient between the collector pipe and fluid.

Solving Eq. (7) for the expression of $T_{p}$ :

$$
T_{p}=T_{w}+\frac{\sqrt{3}}{6} \cdot \frac{Q_{u}^{\prime}}{W}\left[\frac{1}{D} \cdot\left(\frac{\delta_{E V A}}{\lambda_{E V A}}+\frac{\delta_{\text {Tedlar }}}{\lambda_{\text {Tedlar }}}+\frac{\delta_{A l}}{\lambda_{A l}}\right)+\frac{1}{h_{e q} \cdot \pi \cdot D}\right]
$$

Then submit $T_{p}$ into Eq. (4) to get the expression of $Q_{u}$ ' which is equal to Eq. (2):

$Q_{u}{ }^{\prime}=[(W \cdot L-2 \sqrt{3} \cdot W \cdot D) \cdot F+2 \sqrt{3} \cdot W \cdot D] \cdot\left\{(\tau \alpha) \cdot \mathrm{I} \cdot\left(1-\eta_{\mathrm{e}}\right)-\mathrm{U}_{\mathrm{L}} \cdot\left[\frac{\sqrt{3}}{6} \cdot \frac{Q_{u}{ }^{\prime}}{W}\left[\frac{1}{D} \cdot\left(\frac{\delta_{E V A}}{\lambda_{E V A}}+\frac{\delta_{\text {Tedlar }}}{\lambda_{\text {Tedlar }}}+\frac{\delta_{A l}}{\lambda_{A l}}\right)+\frac{1}{h_{e q} \cdot \pi \cdot D}\right]+T_{w}-T_{a}\right]\right\}$ $=A \cdot F^{\prime} \cdot\left[(\tau \alpha) \cdot I \cdot\left(1-\eta_{\mathrm{e}}\right)-U_{L} \cdot\left(T_{w}-T_{a}\right)\right]$

Compare these two expressions in Eq. (9) and then the efficiency factor can be expressed as:

$$
F^{\prime}=\frac{1 / U_{L}}{W \cdot L \cdot\left\{\frac{1}{U_{L} \cdot[(W \cdot L-2 \sqrt{3} \cdot W \cdot D) \cdot F+2 \sqrt{3} \cdot W \cdot D]}+\frac{\sqrt{3}}{6 \cdot W} \cdot\left[\frac{1}{D} \cdot\left(\frac{\delta_{E V A}}{\lambda_{E V A}}+\frac{\delta_{\text {Tedlar }}}{\lambda_{\text {Tedlar }}}+\frac{\delta_{A l}}{\lambda_{A l}}\right)+\frac{1}{h_{e q} \cdot \pi \cdot D}\right]\right\}}
$$

As shown in Fig. 4(a), the overall heat loss coefficient $\left(U_{L}\right)$ is consists of two processes: (1) heat loss from PV cells to PV-glazing cover; (2) heat loss from PV-glazing cover to ambient. The overall heat loss coefficient can be calculated by (Kuang et al., 2003; P. Hartnett and M. Rohsenow, 1973):

where $h_{c d, p-c}$ and $h_{r d, p-c}$ are the conductive and radiative heat transfer coefficient between PV cells and PV-glazing cover; $h_{c v, c-a}$ and $h_{r d, c-a}$ are the convective and radiative heat transfer coefficient between PV-glazing cover and ambient. 
For direct expansion evaporator using in the solar assisted heat pump, the overall heat loss coefficient can be calculated by:

$$
U_{L}=U_{L, u p}+U_{L, \text { down }}
$$

$$
U_{L, u p}=h_{c v, A l-a}+h_{r d, A l-a}
$$

$$
U_{L, d o w n}=h_{c v, A l-a}+h_{r d, A l-g}
$$

251

252

253

254

255

256

257

258

where $h_{c v, A l-a}$ and $h_{r d, A l-a}$ are the convective and radiative heat transfer coefficient between the roll-bond panel and ambient; $h_{r d, A l-g}$ is the radiative heat transfer coefficient between roll-bond panel and ground.

For other types of PVT collector/evaporator unit as well as direct expansion evaporator unit which employing roll-bond panel, the same method is adopted to obtain the theoretical expressions of efficiency factor. A summary of PVT and direct expansion evaporator efficiency factor is presented in Table. 2. 
Table. 2. A summary of PVT and direct expansion evaporator efficiency factor.

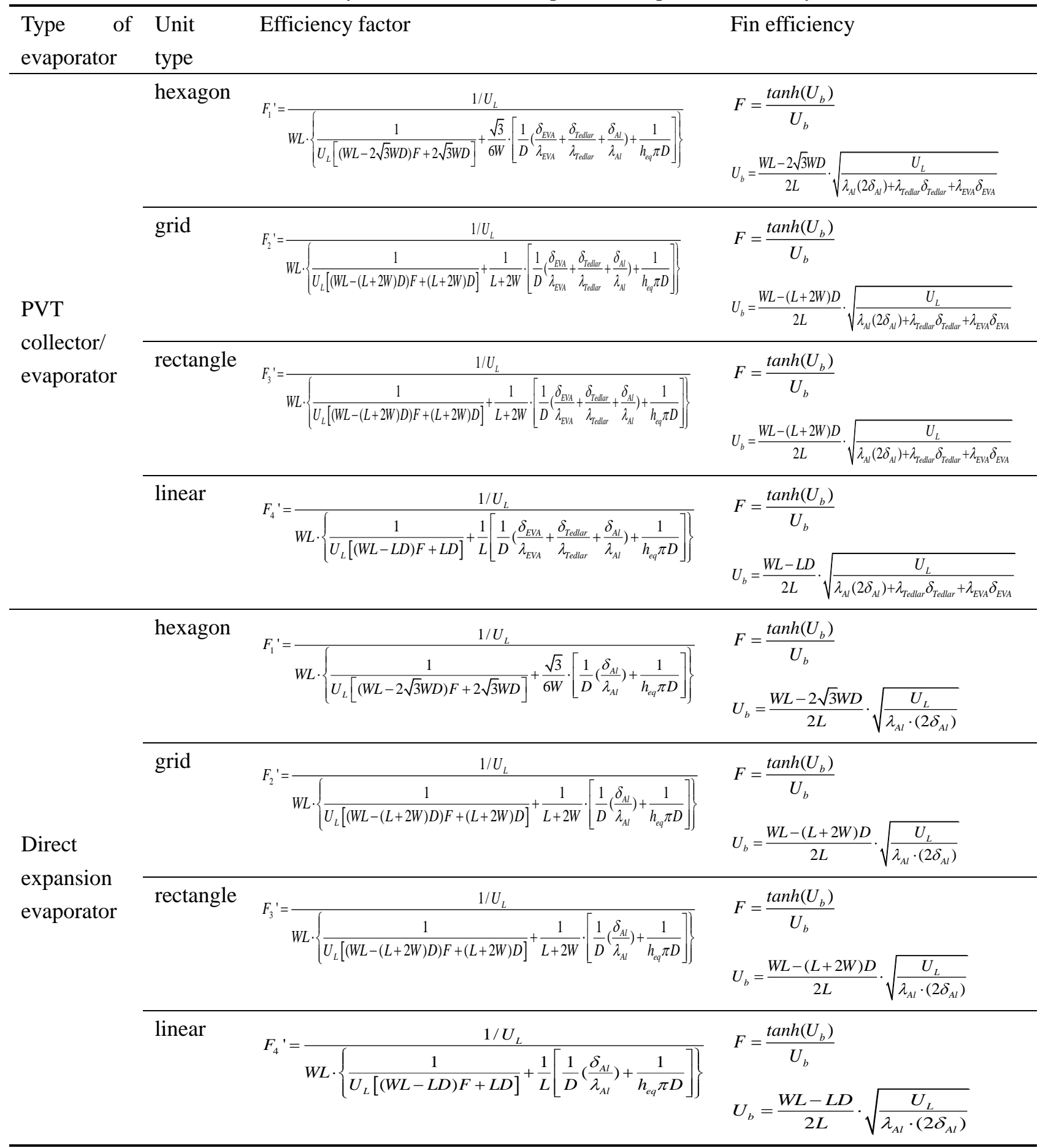

$261 \quad 3.3$ Dimensionless pressure loss coefficient modification

Although the efficiency factor expressions of different types of evaporator units have been given, the direct expansion solar collector is not the same as water or air based solar collector. The refrigerant flows in the evaporator will cause a pressure drop which means it would transfer a certain percentage of kinetic energy to heat. Moreover, it would reduce the heat extract capacity of the fluid from the thermal collector and increase the energy consumption of the compressor. To 
evaluate the influence of pressure drop on efficiency factor, a mathematical model using the CFD (Computational Fluid Dynamics) model has been proposed, and the CFD model of PVT collector/evaporator unit including BLOCK and GRID layouts has shown in Fig. 6.

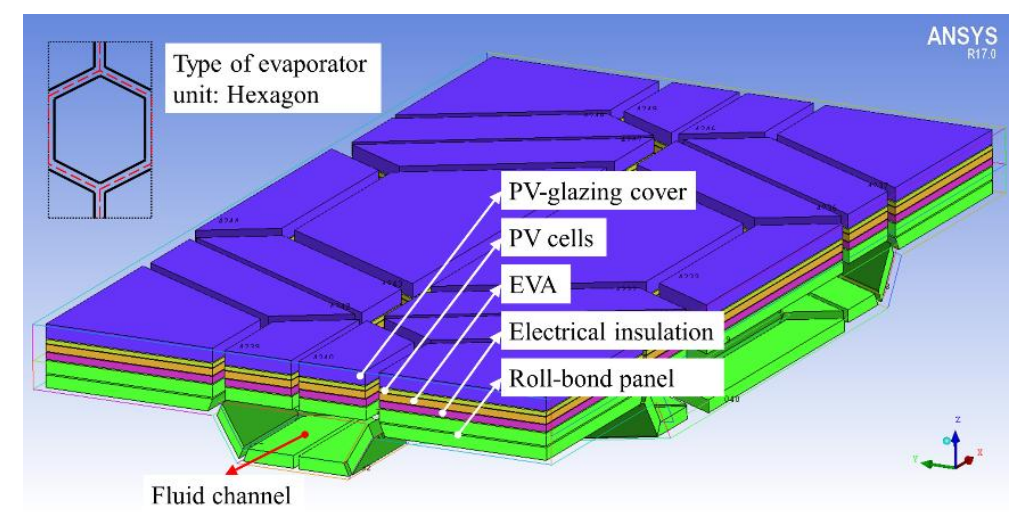

(a)

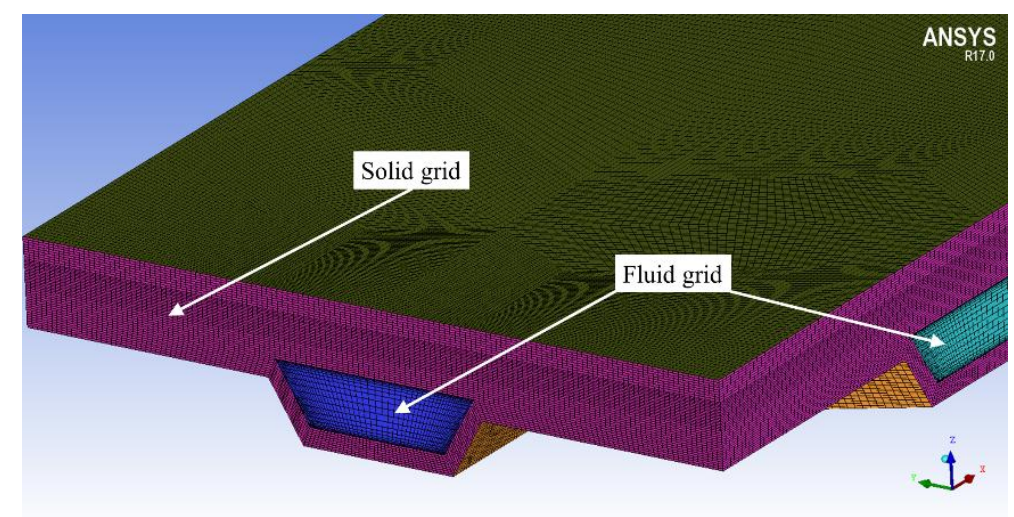

(b)

Fig. 6. (a) The BLOCK layers of solid part for hexagon PVT collector/evaporator unit. (b) The GRID distribution of solid and fluid part for hexagon PVT collector/evaporator unit.

A dimensionless pressure loss coefficient has been added to modify the original expression of the efficiency factor, which can be defined as:

$$
F_{\text {mod }}{ }^{\prime}=\left[1-f\left(P^{\prime}\right) \cdot P^{\prime}\right] \cdot F^{\prime}
$$

$$
P^{\prime}=\frac{P_{\text {loss }}}{P_{\text {ave }}}=\frac{P_{\text {eva }, \text { in }}-P_{\text {eva }, \text { out }}}{1 / 2 \cdot\left(P_{\text {eva }, \text { in }}+P_{\text {eva }, \text { out }}\right)}
$$

where the $P^{\prime}$ is the dimensionless pressure loss; $P_{\text {loss }}$ and $P_{\text {ave }}$ are the pressure loss and average pressure in the evaporator; $P_{\text {eva,in }}$ and $P_{\text {eva,out }}$ are the inlet pressure and outlet pressure of the evaporator; $f\left(P^{\prime}\right)$ is a function of $P^{\prime}$ which is fitting by the CFD model. Through this CFD model, the dimensionless pressure loss could be obtained. Moreover, the difference between unmodified efficiency factor and modified efficiency factor could be used to derivate the function $f\left(P^{\prime}\right)$ expressions of each type unit. The fitting data and function expression of each type of unit are listed in Table. 3 while the simulation pressure is $0.5 \mathrm{Mpa}$. 
Table. 3. Fitting data calculated by the CFD model.

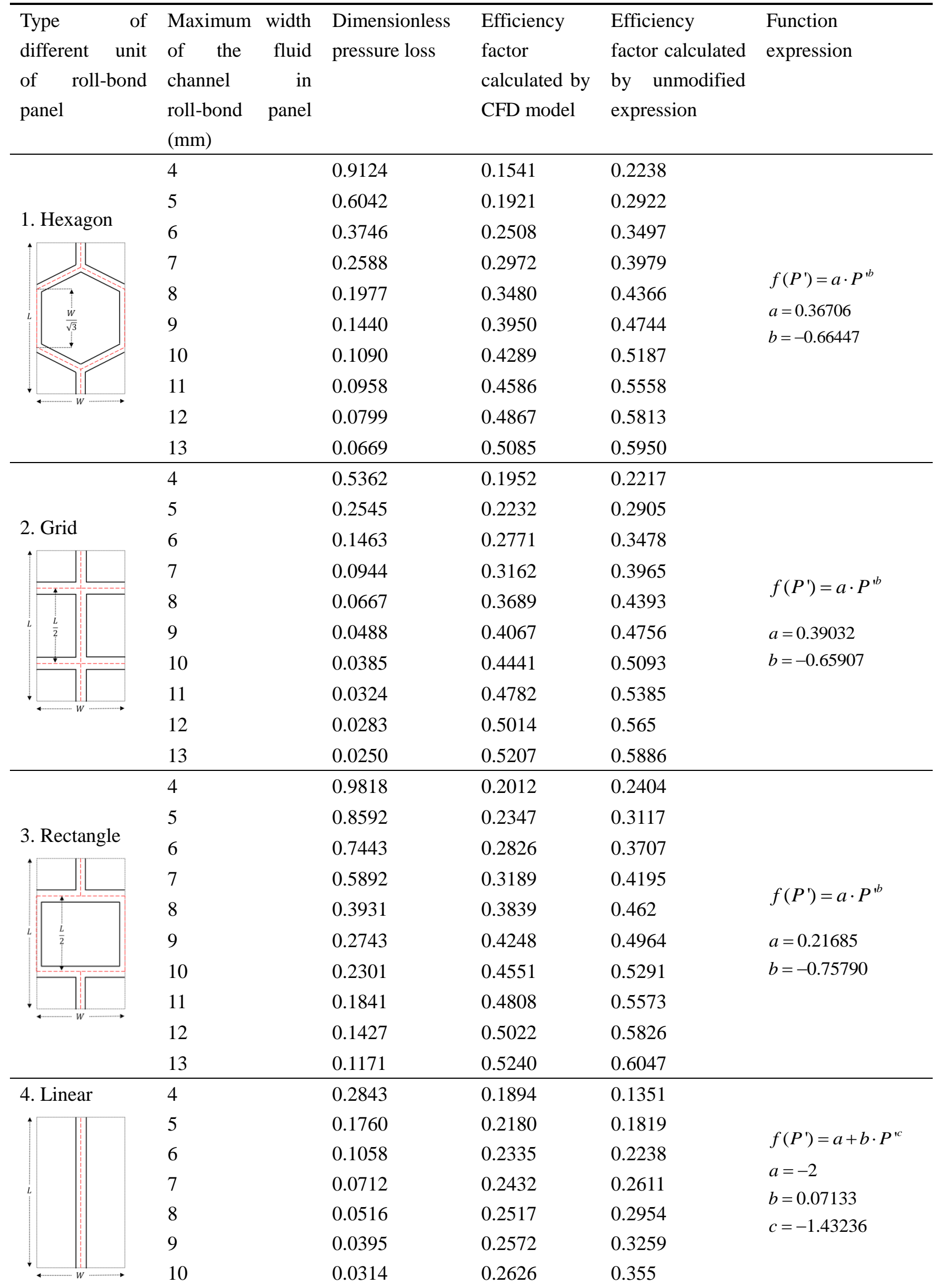




\begin{tabular}{llll}
11 & 0.0257 & 0.2670 & 0.381 \\
12 & 0.0217 & 0.2707 & 0.4052 \\
13 & 0.0186 & 0.2739 & 0.4277 \\
\hline
\end{tabular}

286

287

288

289

290

291

292

293

294

295

296

297

298

299

300

301

302

303

304

305

306

The modified expression of the efficiency factor of different unit types are listed as follows:

Hexagon:

$$
F_{\text {mod }, 1}{ }^{\prime}=\left[1-\left(0.36706 \cdot P^{1^{-0.06447}}\right) \cdot P^{\prime}\right] \cdot F_{1}{ }^{\prime}
$$

Grid:

$$
F_{\text {mod }, 2}{ }^{\prime}=\left[1-\left(0.39032 \cdot P^{1-0.65907}\right) \cdot P^{\prime}\right] \cdot F_{2}{ }^{\prime}
$$

Rectangle:

$$
F_{\text {mod }, 3}{ }^{\prime}=\left[1-\left(0.21685 \cdot P^{-0.7579}\right) \cdot P^{\prime}\right] \cdot F_{3}{ }^{\prime}
$$

Linear:

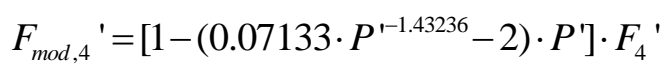

where subscript 1 to 4 represents hexagon, grid, rectangle, and linear type of roll-bond panel unit.

As shown in Fig. 3(b), different direct expansion evaporators may consist of several types of units (combination of hexagon, grid, rectangle, and linear). Thus, the whole panel's efficiency factor can be defined as:

$$
F_{\text {mod }}{ }^{\prime}=\sum_{1}^{n} \frac{S_{n}}{S_{\text {Tot }}} \cdot F_{\text {mod, },}{ }^{\prime}
$$

where the $S_{n}$ and $S_{\text {Tot }}$ are the area of different types of units and area of the whole panel, respectively.

\subsection{Heat removal factor}

The energy balance on the fluid element is shown in Fig. 7. Refer to Eq. (3), the heat removal factor represents the ratio of actual useful energy gain and useful gain if the collector inner surface is equal to the temperature of inlet fluid. Thus, the definition of heat removal factor $F_{R}$ can be expressed as:

$$
F_{R}=\frac{\dot{m} \cdot\left(\chi_{\text {out }}-\chi_{\text {in }}\right) \cdot \Delta H_{r e f}}{W \cdot L \cdot\left[(\tau \alpha) \cdot I \cdot\left(1-\eta_{\mathrm{e}}\right)-U_{L} \cdot\left(T_{\text {in }}-T_{a}\right)\right]}
$$

where $\dot{m}$ is the mass flow rate of refrigerant; $\chi_{\text {in }}$ and $\chi_{\text {out }}$ are the degree of dryness of inlet and outlet refrigerant flow; $\Delta H_{r e f}$ is the latent heat of refrigerant.

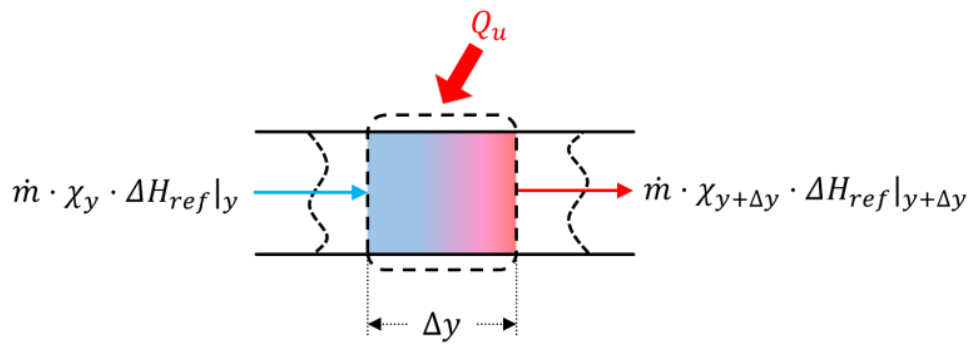

Fig. 7. Energy balance on the fluid element. 
The thermal energy gain by refrigerant of a length $\Delta y$ can be calculated by:

$$
Q_{u}=\left.\dot{m} \cdot \chi_{y+\Delta y} \cdot \Delta H_{r e f}\right|_{y+\Delta y}-\left.\dot{m} \cdot \chi_{y} \cdot \Delta H_{r e f}\right|_{y}
$$

Meanwhile, the thermal energy gain by the thermal collector can be expressed as:

$$
Q_{u}=W \cdot \Delta y \cdot F^{\prime} \cdot\left[(\tau \alpha) \cdot I \cdot\left(1-\eta_{\mathrm{e}}\right)-U_{L} \cdot\left(T_{i n}-T_{a}\right)\right]
$$

where the $F^{\prime}$ and $U_{L}$ are assumed independent of position. Then Eq. (27) is equal to Eq. (28) and this following equation could be obtained:

$$
\dot{m} \cdot \Delta H_{r e f} \cdot \frac{\chi_{y+\Delta y}-\chi_{y}}{\Delta y}=W \cdot F^{\prime} \cdot\left[(\tau \alpha) \cdot I \cdot\left(1-\eta_{\mathrm{e}}\right)-U_{L} \cdot\left(T_{i n}-T_{a}\right)\right]
$$

When $\Delta \mathrm{y}$ approximates to zero, $\chi_{y+\Delta y}-\chi_{y}$ could be replaced by $d \chi, \Delta y$ could be replaced by $d y$ and integrate the formula. Then the following equation could be obtained:

$$
\begin{gathered}
\int_{\text {in }}^{\text {out }} \dot{m} \cdot \Delta H_{r e f} \cdot d \chi=\int_{\text {in }}^{\text {out }} W \cdot F^{\prime} \cdot\left[(\tau \alpha) \cdot I \cdot\left(1-\eta_{\mathrm{e}}\right)-U_{L} \cdot\left(T_{\text {in }}-T_{a}\right)\right] \cdot d y \\
\dot{m} \cdot \Delta H_{r e f} \cdot\left(\chi_{\text {out }}-\chi_{\text {in }}\right)=W \cdot F^{\prime} \cdot\left[(\tau \alpha) \cdot I \cdot\left(1-\eta_{\mathrm{e}}\right)-U_{L} \cdot\left(T_{\text {in }}-T_{a}\right)\right] \cdot L
\end{gathered}
$$

Then submitting $\dot{m} \cdot \Delta H_{\text {ref }} \cdot\left(\chi_{\text {out }}-\chi_{\text {in }}\right)$ into the definition Eq. (26), the heat removal factor can be expressed as:

$$
F_{R}=\frac{\dot{m} \cdot\left(\chi_{\text {out }}-\chi_{\text {in }}\right) \cdot \Delta H_{r e f}}{W \cdot L \cdot\left[(\tau \alpha) \cdot I \cdot\left(1-\eta_{\mathrm{e}}\right)-U_{L} \cdot\left(T_{\text {in }}-T_{a}\right)\right]}=\frac{W \cdot F^{\prime} \cdot\left[(\tau \alpha) \cdot I \cdot\left(1-\eta_{\mathrm{e}}\right)-U_{L} \cdot\left(T_{\text {in }}-T_{a}\right)\right] \cdot L}{W \cdot L \cdot\left[(\tau \alpha) \cdot I \cdot\left(1-\eta_{\mathrm{e}}\right)-U_{L} \cdot\left(T_{\text {in }}-T_{a}\right)\right]}=F^{\prime}
$$

As shown in Eq. (32), the heat removal factor is equal to the efficiency factor for direct expansion evaporator due to the isothermal evaporating process. Thus, only the parameter analysis of the efficiency factor would be conducted in the next few sections.

\subsection{Exergy analysis}

Fig. 8 shows the exergy flow diagram of the PVT module. Considering the PVT module as a single control volume and assuming a steady-state condition, the exergy balance can be expressed as follows:

$$
\sum E x_{\text {in }}=\sum E x_{\text {out }}+\sum E x_{\text {loss }}
$$

where the $E x_{i n}, E x_{\text {out }}$, and $E x_{\text {loss }}$ refer to exergy rate of input, output, and losses, respectively. The total exergy input is consists of two parts: input exergy of the sun $\left(E x_{\text {sun }}\right)$ and input exergy of the refrigerant $\left(E x_{\text {ref,in }}\right)$. The total exergy output is consists of two parts: output electrical exergy $\left(E x_{e}\right)$ and output exergy of the refrigerant $\left(E x_{\text {ref out }}\right)$. The equations could be expressed as:

$$
\begin{gathered}
\sum E x_{\text {in }}=E x_{\text {sun }}+E x_{\text {ref }, \text { in }} \\
\sum E x_{\text {out }}=E x_{e}+E x_{\text {ref }, \text { out }} \\
E x_{\text {sun }}+E x_{\text {ref }, \text { in }}=E x_{e}+E x_{\text {ref }, \text { out }}+E x_{\text {loss }}
\end{gathered}
$$

The input exergy of the sun ( $\left.E x_{\text {sun }}\right)$ could be calculated by (Park et al., 2014): 


$$
E x_{\text {sun }}=A \cdot I \cdot\left(1-\frac{T_{a}}{T_{\text {sun }}}\right)
$$

where the $A$ is the area of PVT module; $I$ is the solar radiation intensity; $T_{a}$ and $T_{\text {sun }}$ are the temperature of the ambient and the sun, respectively. The exergy of the refrigerant which is equal to the thermal exergy $\left(E x_{t h}\right)$ could be calculated as:

$$
E x_{\text {th }}=E x_{\text {ref }, \text { out }}-E x_{\text {ref }, \text { in }}=m_{\text {ref }} \cdot\left(\psi_{\text {out }}-\psi_{\text {in }}\right)
$$

where $m_{\text {ref }}$ is the mass flow rate of the refrigerant; $\Psi_{\text {out }}$ and $\Psi_{\text {in }}$ are the stream exergy per unit mass which could be calculated as:

$$
\begin{gathered}
\psi_{\text {out }}=\left(h_{\text {out }}-h_{a}\right)-T_{a} \cdot\left(s_{\text {out }}-s_{a}\right) \\
\psi_{\text {in }}=\left(h_{\text {in }}-h_{a}\right)-T_{a} \cdot\left(s_{\text {in }}-s_{a}\right)
\end{gathered}
$$

where $h$ and $s$ are the enthalpy and entropy values. Because the electrical energy is a useful available work, the exergy of the PV cells is equal to the electrical power (Chow et al., 2009):

$$
E x_{e}=Q_{e}=A \cdot I \cdot \tau_{c} \cdot \alpha_{p} \cdot \beta_{p} \cdot \eta_{e}
$$

where $\tau_{c}$ is the transmittances of the PV-glazing cover; $a_{p}$ is the absorption ratio of the PV cells; $\beta_{p}$ is the packing factor of PV panels; $\eta_{e}$ is the PV cells electrical efficiency which can be calculated by (Huide et al., 2017):

$$
\eta_{e}=\eta_{r c} \cdot\left[1-\beta_{p v} \cdot\left(T_{p}-T_{r c}\right)\right]
$$

$\eta_{r c}$ is the reference photovoltaic efficiency value of PV cells at $T_{r c}=298 \mathrm{~K}, \eta_{r c}=0.18 ; \beta_{p v}$ is the temperature coefficient ( $1 / \mathrm{K}$ ) of PV cell efficiency, $\beta_{p v}=0.0045$ (Huide et al., 2017).

Therefore, the electrical and thermal exergy efficiencies could be expressed as:

$$
\begin{gathered}
\varepsilon_{e}=\frac{E x_{e}}{E x_{\text {sun }}}=\frac{Q_{e}}{E x_{\text {sun }}} \\
\varepsilon_{\text {th }}=\frac{E x_{\text {th }}}{E x_{\text {sun }}}=\frac{m_{\text {ref }} \cdot\left[\left(h_{\text {out }}-h_{\text {in }}\right)-T_{a} \cdot\left(s_{\text {out }}-s_{\text {in }}\right)\right]}{E x_{\text {sun }}}
\end{gathered}
$$

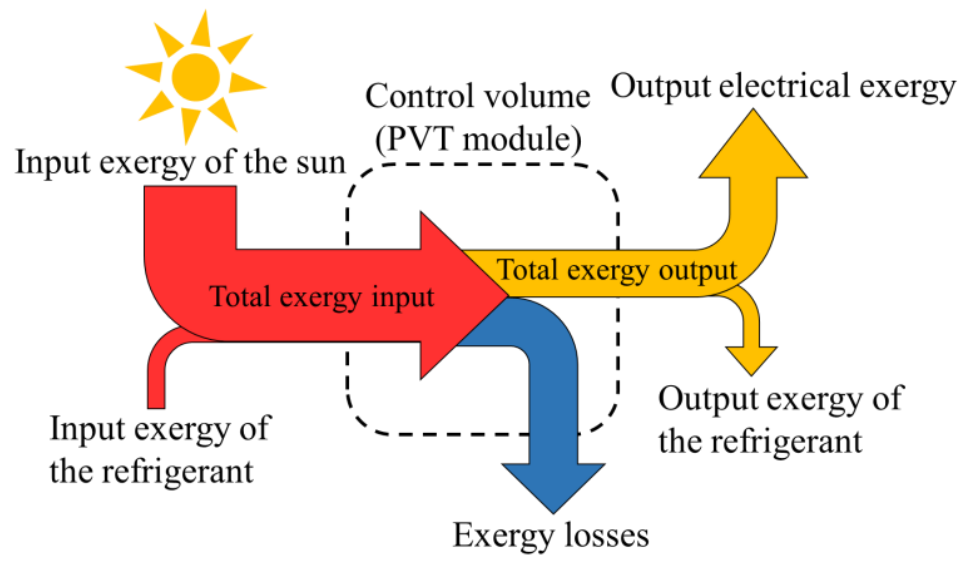

Fig. 8. Exergy flow diagram of the PVT module. 
To ensure the reliability of the proposed mathematic model of efficiency factor, the simulation results should be compared with experimental results. In this section, the experimental results of 20 days have been used to verify the accuracy of the theoretical efficiency factor. Kong et al. (Kong et al., 2018a; Kong et al., 2018b) have conducted a direct expansion solar assisted heat pump system experimentally during summer, autumn, and winter. In their study, a $200 \mathrm{~L}$ water tank and a $2.1 \mathrm{~m}^{2}$ linear type direct expansion evaporator (maximum flow channel is $10 \mathrm{~mm}$ ) have been adopted in their system. The experimental parameters from the literatures have listed in Table. 4. The main point of this paper is the theoretical analysis of the efficiency factor. However, the mathematical model of direct expansion solar assisted heat pump system should be established to simulate the system performance and verify the efficiency factor. As mentioned in section 2.1, the mathematical model of direct expansion solar assisted heat pump has been established in the authors' previous work (Yao et al., 2020), therefore, the content of the mathematical model has not presented in this paper. It needs to be emphasized that the expressions of the efficiency factor in section 3 (calculated by experimental parameters from the literatures) are used to simulate the system performance.

Table. 4. Experimental parameters (Kong et al., 2018a; Kong et al., 2018b).

\begin{tabular}{llll}
\hline \multicolumn{1}{c}{ Parameters } & Nomenclature & Value & Unit \\
\hline Type of the evaporator & {$[-]$} & Linear & {$[-]$} \\
Area of the evaporator & $A$ & 2.1 & $\mathrm{~m}^{2}$ \\
Width of the evaporator & $W_{\text {eva }}$ & 1.0 & $\mathrm{~m}$ \\
Length of the evaporator & $L_{\text {eva }}$ & 2.1 & $\mathrm{~m}$ \\
Maximum width of the fluid channel & $D_{\max }$ & 10 & $\mathrm{~mm}$ \\
Thickness of the fluid channel & $\delta_{\text {channel }}$ & 2.8 & $\mathrm{~mm}$ \\
Thickness of the evaporator & $\delta_{A l}$ & 1.5 & $\mathrm{~mm}$ \\
Material of the evaporator & {$[-]$} & Aluminum & {$[-]$} \\
Refrigerant type & $r e f$ & $\mathrm{R} 134 \mathrm{a}$ & {$[-]$} \\
Volume of water tank & $V_{\text {tank }}$ & 200 & $\mathrm{~L}$ \\
\hline
\end{tabular}

The detailed comparison results of the COP (coefficient of performance) and the efficiency factor have been listed in Table. 5. 20 days of experimental results have been compared with simulated results. In addition, the experimental efficiency factor could be obtained as follows: the total heat transfer rate of the evaporator could be calculated through the COP and the thermal energy stored in the water tank. Then, the heat transfer rate between the evaporator and the ambient could be calculated by the wind speed and panel/ambient temperature as well as the heat absorption rate from solar irradiation of the evaporator. Finally, the experimental efficiency factor could be obtained by the solar radiation intensity, the area of the evaporator, and the heat absorption rate from solar irradiation of the evaporator. The experimental efficiency factor is considered equal to the ratio of the heat absorption rate per square meter $\left(\mathrm{W} / \mathrm{m}^{2}\right)$ of the evaporator and the solar radiation intensity $\left(\mathrm{W} / \mathrm{m}^{2}\right)$.

The experimental COP and simulated COP vary from 3.2 to 6.0 under different conditions, 
and a higher COP could be obtained under high solar radiation intensity, high ambient temperature, and low wind speed. The maximum experimental COP (5.68) is reached in 2017/07/26, while the simulated COP is 5.92, and its relative error is $4.2 \%$. The minimum COP (3.45) occurs in 2017/12/17 when the solar irradiation is low $\left(233 \mathrm{~W} / \mathrm{m}^{2}\right)$, meanwhile, the simulated COP is 3.22 and the relative error is $-6.54 \%$. The average relative error of COP is $4.12 \%$, while the maximum relative error is $-8.12 \%$ which occurs in $2017 / 12 / 29$. On the other hand, the minimum experimental efficiency factor is obtained as 0.4856 due to a high wind speed while the simulation result is 0.5083 , and its relative error is $4.68 \%$. The peak value of the experimental efficiency factor is 0.6932 while the simulated efficiency factor is 0.6534 , and the relative error is $-5.74 \%$. The maximum relative error of the efficiency factor is obtained in $2017 / 11 / 27$ which is $7.46 \%$ while the average relative error of these 20 days results is $3.45 \%$.

Table. 5. Experimental and simulation results of the COP and the efficiency factor.

\begin{tabular}{|c|c|c|c|c|c|c|c|c|c|c|c|}
\hline $\begin{array}{l}\text { Date } \\
\text { (year/month } \\
\text { /day) }\end{array}$ & $\begin{array}{l}\text { Ambient } \\
\text { temperat } \\
\text { ure }\left({ }^{\circ} \mathrm{C}\right)\end{array}$ & $\begin{array}{l}\text { Solar } \\
\text { radiation } \\
\text { intensity } \\
\left(\mathrm{W} / \mathrm{m}^{2}\right)\end{array}$ & $\begin{array}{l}\text { Wind } \\
\text { speed } \\
(\mathrm{m} / \mathrm{s})\end{array}$ & $\begin{array}{l}\text { Temperature } \\
\text { difference } \\
\text { of water } \\
\operatorname{tank}\left({ }^{\circ} \mathrm{C}\right)\end{array}$ & $\begin{array}{l}\text { Operation } \\
\text { time (s) }\end{array}$ & $\begin{array}{l}\text { Experi } \\
\text { mental } \\
\text { COP }\end{array}$ & $\begin{array}{l}\text { Simul } \\
\text { ated } \\
\text { COP }\end{array}$ & $\begin{array}{l}\text { Relative } \\
\text { error of } \\
\operatorname{COP}(\%)\end{array}$ & $\begin{array}{l}\text { Experim } \\
\text { ental } \\
\text { efficienc } \\
\text { y factor }\end{array}$ & $\begin{array}{l}\text { Simulated } \\
\text { efficiency } \\
\text { factor }\end{array}$ & $\begin{array}{l}\text { Relative } \\
\text { error of } \\
\text { efficiency } \\
\text { factor }(\%)\end{array}$ \\
\hline $2017 / 7 / 10$ & 33.3 & 633 & 1.8 & 16.9 & 7320 & 5.59 & 5.28 & -5.52 & 0.6480 & 0.6467 & -0.20 \\
\hline $2017 / 7 / 11$ & 33.5 & 660 & 1.7 & 26.9 & 10740 & 4.43 & 4.50 & 1.62 & 0.6642 & 0.6497 & -2.18 \\
\hline $2017 / 7 / 12$ & 32.2 & 519 & 1.7 & 26.5 & 10500 & 4.41 & 4.33 & -1.72 & 0.6916 & 0.6497 & -6.06 \\
\hline $2017 / 7 / 13$ & 34.0 & 634 & 1.8 & 28.2 & 10260 & 4.85 & 4.77 & -1.62 & 0.6731 & 0.6466 & -3.93 \\
\hline $2017 / 7 / 15$ & 28.1 & 632 & 1.5 & 27.7 & 10560 & 4.55 & 4.61 & 1.38 & 0.6550 & 0.6559 & 0.14 \\
\hline $2017 / 7 / 18$ & 33.9 & 258 & 1.2 & 26.0 & 12540 & 3.78 & 3.70 & -2.20 & 0.6810 & 0.6652 & -2.33 \\
\hline $2017 / 7 / 22$ & 33.1 & 415 & 1.4 & 27.8 & 11280 & 4.34 & 4.09 & -5.70 & 0.6794 & 0.6589 & -3.02 \\
\hline $2017 / 7 / 26$ & 33.7 & 659 & 1.3 & 27.3 & 13560 & 5.68 & 5.92 & 4.20 & 0.6161 & 0.6620 & 7.45 \\
\hline $2017 / 8 / 15$ & 32.7 & 619 & 1.5 & 28.7 & 8040 & 3.63 & 3.88 & 6.84 & 0.6508 & 0.6558 & 0.77 \\
\hline $2017 / 8 / 25$ & 33.3 & 630 & 1.4 & 28.0 & 8700 & 3.71 & 3.89 & 4.92 & 0.6452 & 0.6589 & 2.13 \\
\hline $2017 / 10 / 31$ & 19.6 & 658 & 2.8 & 38.4 & 22980 & 4.61 & 4.82 & 4.64 & 0.5791 & 0.6184 & 6.79 \\
\hline $2017 / 11 / 2$ & 25.0 & 559 & 4.6 & 37.0 & 21360 & 5.09 & 5.16 & 1.42 & 0.5605 & 0.5726 & 2.16 \\
\hline $2017 / 11 / 11$ & 15.2 & 683 & 4.7 & 40.0 & 22260 & 4.54 & 4.25 & -6.28 & 0.5488 & 0.5705 & 3.95 \\
\hline $2017 / 11 / 14$ & 17.3 & 653 & 4.0 & 34.8 & 21420 & 4.46 & 4.36 & -2.21 & 0.5482 & 0.5873 & 7.13 \\
\hline $2017 / 11 / 27$ & 13.2 & 578 & 3.5 & 39.2 & 23700 & 4.23 & 3.95 & -6.56 & 0.5583 & 0.5999 & 7.46 \\
\hline $2017 / 12 / 2$ & 11.9 & 414 & 7.7 & 32.7 & 19800 & 4.33 & 4.02 & -7.21 & 0.4856 & 0.5083 & 4.68 \\
\hline $2017 / 12 / 7$ & 10.8 & 487 & 8.9 & 31.5 & 19500 & 4.93 & 4.90 & -0.57 & 0.4871 & 0.4871 & 0.00 \\
\hline $2017 / 12 / 17$ & 7.9 & 233 & 2.1 & 34.2 & 23640 & 3.45 & 3.22 & -6.54 & 0.6414 & 0.6385 & -0.46 \\
\hline $2017 / 12 / 28$ & 10.7 & 322 & 1.6 & 31.1 & 18900 & 3.88 & 3.76 & -3.16 & 0.6932 & 0.6534 & -5.74 \\
\hline $2017 / 12 / 29$ & 9.9 & 308 & 1.5 & 30.8 & 19920 & 5.37 & 4.93 & -8.12 & 0.6727 & 0.6565 & -2.42 \\
\hline
\end{tabular}

408

409

410

411

412

413

414
In addition, Fig. 9 shows the error analysis of COP and efficiency factor. The green dots represent the simulation results of COP and efficiency factor. Both the relative errors of COP and efficiency factor are within $\pm 10 \%$. Therefore, the proposed expressions of the efficiency factor are considered reliable. Moreover, the efficiency factor could be used to design, optimize, and evaluate the performance of different direct expansion evaporator which employing roll-bond panel. 


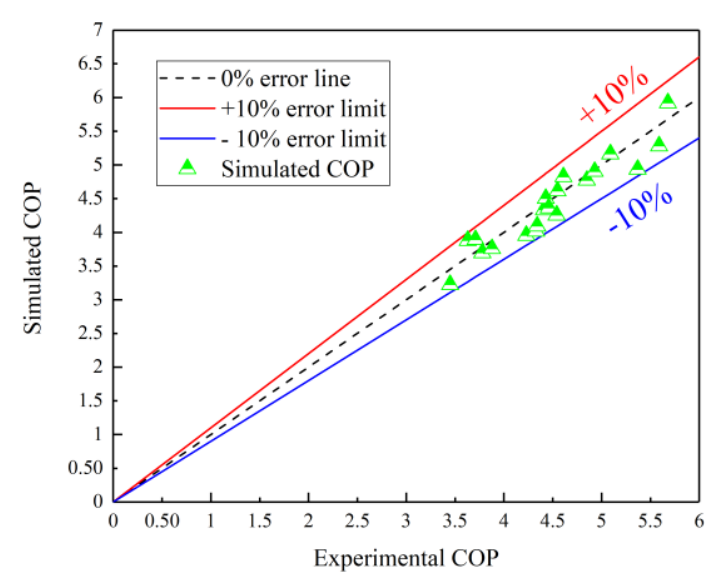

(a)

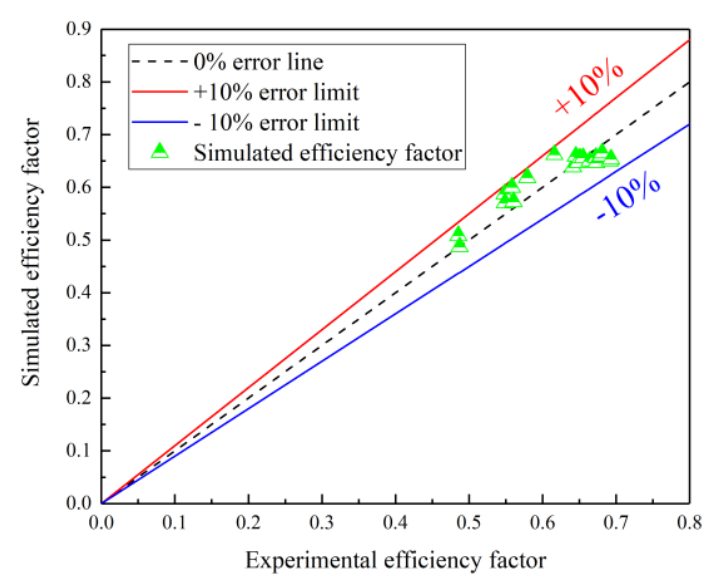

(b)

Fig. 9. Error analysis of (a) simulated COP and experimental COP. (b) simulated efficiency factor and experimental efficiency factor.

\section{Parameter analysis}

\subsection{Different pattern of the fluid channel}

The modified and unmodified efficiency factor and dimensionless pressure loss of four evaporator patterns have shown in Fig. 10, and in this case, the maximum fluid channel width of each type unit is $10 \mathrm{~mm}$. The analysis is conducted under wind speed is $2.5 \mathrm{~m} / \mathrm{s}$, ambient temperature is $25^{\circ} \mathrm{C}$, and PV cells' temperature is $40^{\circ} \mathrm{C}$. The rectangle type has the highest pressure loss due to the fluid channel pattern which would divide the mainstream into two opposite streams. The pressure loss of hexagon type is second caused by the same reason, while the grid and linear types have the lowest pressure loss. However, the separation of the refrigerant in the channel would make the temperature distribution more uniform, which is better for the performance and life of the PV cells. After modification of the dimensionless pressure loss coefficient, the grid type has the highest efficiency factor which means under the same conditions, this kind of evaporator would extract most waste heat from PV panels. The modified efficiency factors under these conditions are $0.521,0.564,0.549$, and 0.342 of hexagon, grid, rectangle, and linear unit types, respectively. Moreover, the rectangle and hexagon types have far better thermal performance than linear type because of a larger area of the fluid channel which means a larger heat transfer area. 


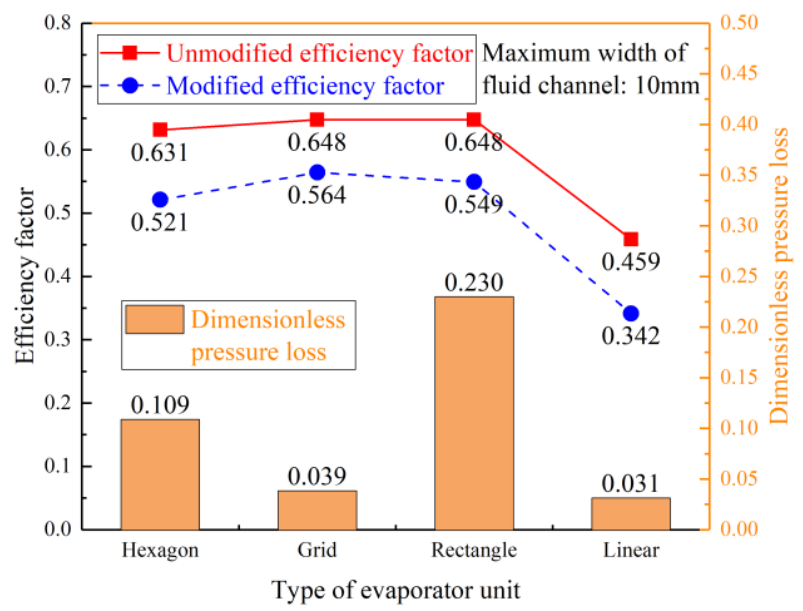

The temperature uniformity of PV cells is also an important index to evaluate the therma performance of PVT collector/evaporator. The working conditions are: solar radiation intensity is $750 \mathrm{~W} / \mathrm{m}^{2}$, wind speed is $2.5 \mathrm{~m} / \mathrm{s}$, the maximum fluid channel width of each type unit is $10 \mathrm{~mm}$. The temperature distributions of cross-section and the front surface of the PVT module have shown in Fig. 11. The fluid inlet is at downside and outlet is at upside while left and right are set as symmetry in Ansys Fluent 17.0. As shown in Fig. 11(a, c), the mainstream from inlet would be forcibly separated into two streams which would cause a significant pressure loss. In the grid and linear type channels, the mainstream would not be forcibly separated into several streams which leads to a lower pressure loss. As shown in Fig. 11(b), there are four fluid branches around the mainstream. Fluid in these branches almost has no velocity but helps to transfer heat from the roll-bond panel, and that is the reason why grid type has a higher thermal efficiency than linear type. Fig. 11(e h) shows the temperature distribution of PVT module front surface and its corresponding maximum temperature difference. The hexagon and rectangle types have a minimum temperature difference which is $0.038{ }^{\circ} \mathrm{C}$ while the linear type is $0.061{ }^{\circ} \mathrm{C}$ and the grid type is $0.135{ }^{\circ} \mathrm{C}$. The hexagon and rectangle type has a better temperature uniformity due to the forced separation of fluid in the channel. However, the accumulation of pressure loss through each unit would cause a significant increase in system energy consumption. Temperature uniformity, thermal efficiency, energy consumption are the three most important indices of PVT collector/evaporator. Considering about above-mentioned indices, the combination of hexagon and grid type would be a better choice than other combinations.

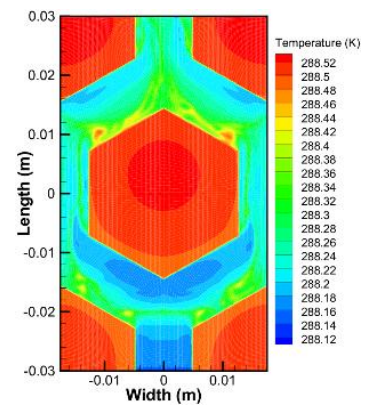

(a) Hexagon

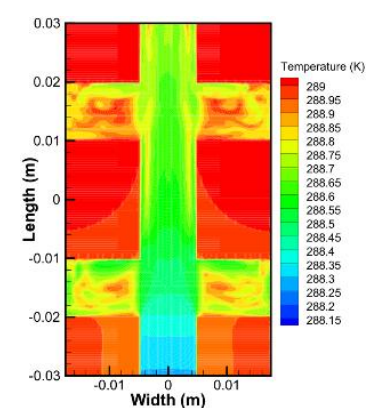

(b) Grid

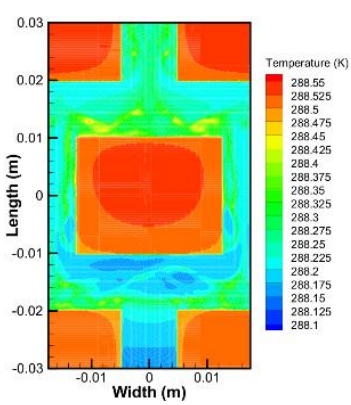

(c) Rectangle

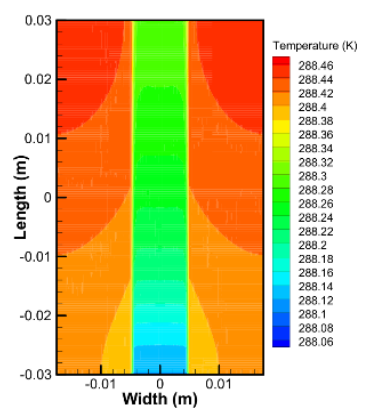

(d) Linear 


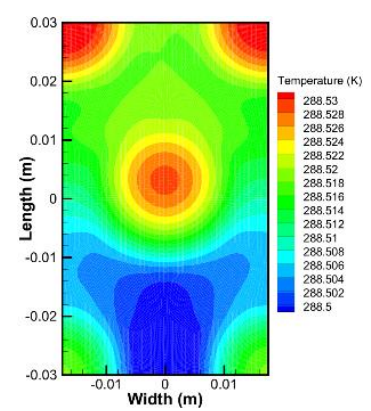

(e) Maximum

temperature

difference: $0.038^{\circ} \mathrm{C}$

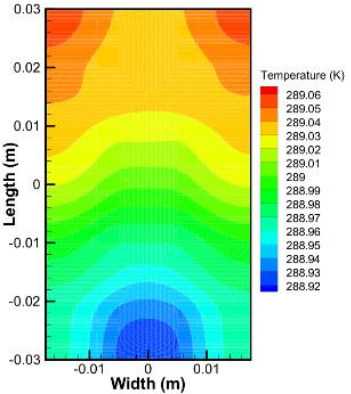

(f) Maximum

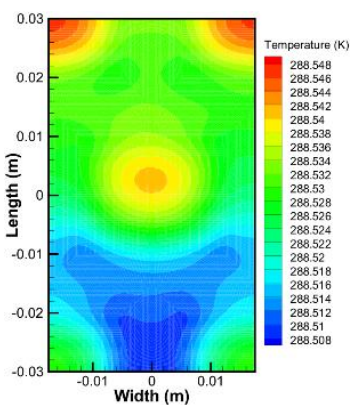

(g) Maximum temperature

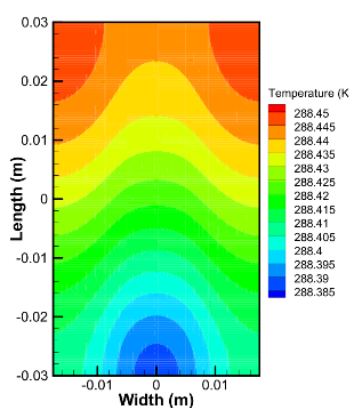

(h) Maximum

temperature difference: $0.061^{\circ} \mathrm{C}$
458

459

460

461

462

463

464

465

466

467

468

469

470

471

472

473

474

475

476

477

478

479

480

481

482

483

484

Fig. 11. (a $\sim \mathbf{d})$ Temperature distribution of cross-section view; $(\mathbf{e} \sim \mathbf{h})$ Temperature distribution of PVT front surface and maximum temperature difference.

Table. 6. Maximum temperature difference and electrical response of each type evaporator unit.

\begin{tabular}{lllll}
\hline Type of evaporator unit & Hexagon & Grid & Rectangle & Linear \\
\hline Maximum temperature difference $\left({ }^{\circ} \mathrm{C}\right)$ & 0.038 & 0.135 & 0.038 & 0.061 \\
Electrical efficiency $(\%)$ & 13.08 & 13.13 & 13.11 & 12.59 \\
Improvement of electrical efficiency $(\%)$ & 15.73 & 16.15 & 15.97 & 11.44 \\
Electrical power $(\mathrm{W})$ & 195.9 & 196.6 & 196.4 & 188.6 \\
\hline
\end{tabular}

Table. 6 presents the maximum temperature difference and electrical response of each type evaporator unit. Under given conditions, the electrical efficiency of a single PV module without thermal collector is $11.30 \%$ while its corresponding electrical power is $168.9 \mathrm{~W}$. Meanwhile, the electrical efficiencies of the hexagon, grid, rectangle, and linear types are $13.08 \%, 13.13 \%$, $13.11 \%$, and $12.59 \%$, respectively. The grid type has the most substantial improvement of electrical efficiency which is $16.15 \%$, while the linear type has the minimum improvement of electrical efficiency which is $11.44 \%$. Moreover, the electrical powers of the hexagon, grid, rectangle, and linear types are $195.9 \mathrm{~W}, 196.6 \mathrm{~W}, 196.4 \mathrm{~W}$, and $188.6 \mathrm{~W}$, respectively.

\subsection{Solar radiation intensity}

The adoption of different types of evaporators would influence the system performance of the direct expansion solar assisted heat pump. In this sub-section, the influence of solar radiation intensity on several system performance indices have been further studied under the working conditions: solar radiation intensity varies from $200 \mathrm{~W} / \mathrm{m}^{2}$ to $1000 \mathrm{~W} / \mathrm{m}^{2}$; wind speed is $2.5 \mathrm{~m} / \mathrm{s}$; ambient temperature is $20^{\circ} \mathrm{C}$; maximum width of the fluid channel is $10 \mathrm{~mm}$.

As shown in Fig. 12(a), different solar radiation intensity would affect the temperature uniformity of the PVT front surface. The maximum temperature differences of the PVT front surface of these four types would increase with the increase of the solar irradiation, which means a higher solar radiation intensity would reduce the temperature uniformity. The hexagon, rectangle, and linear types have almost the same maximum temperature differences when the solar radiation intensity is under $600 \mathrm{~W} / \mathrm{m}^{2}$, while the maximum temperature difference of grid type is much higher than that of the others. Under high solar irradiation conditions, the hexagon and rectangle types perform better at temperature uniformity. For instance, the maximum temperature 
differences of hexagon and rectangle types are $0.0588{ }^{\circ} \mathrm{C}$ and $0.0582{ }^{\circ} \mathrm{C}$ when solar radiation intensity is $1000 \mathrm{~W} / \mathrm{m}^{2}$, respectively, while the maximum temperature differences of grid and linear types are $0.2018{ }^{\circ} \mathrm{C}$ and $0.1174{ }^{\circ} \mathrm{C}$, respectively.

Fig. 12(b d) presents the variation curves of the COP, the mass flow rate of refrigerant, and the compressor power with the variation of solar radiation intensity. A high system COP could be obtained as well as the mass flow rate of refrigerant under high solar radiation intensity. Moreover, the heat pump system using grid type evaporator has better performance than others, for instance, the grid type system has the highest $\mathrm{COP}(6.67)$ when solar radiation intensity is $1000 \mathrm{~W} / \mathrm{m}^{2}$ while the COPs of rectangle, hexagon, and linear type systems are $6.46,5.85$, and 4.67 , respectively. In the meantime, the mass flow rates of refrigerant of grid, rectangle, hexagon, and linear type systems are $5.9 \mathrm{~g} / \mathrm{s}, 5.8 \mathrm{~g} / \mathrm{s}, 6.5 \mathrm{~g} / \mathrm{s}$, and $8.1 \mathrm{~g} / \mathrm{s}$, respectively. As shown in Fig. 12(d), the variations curves of the compressor powers of different systems have the same variation trend, the compressor power increase at first when solar radiation intensity is below $600 \mathrm{~W} / \mathrm{m}^{2}$ and then decrease when the solar radiation intensity exceeds $600 \mathrm{~W} / \mathrm{m}^{2}$. That is because the mass flow rate of refrigerant is low under low solar irradiation conditions, therefore, the compression process would not consume much electricity and lead to a lower compressor power. The evaporating temperature and pressure would increase with the increase of solar irradiation and then lead to a lower compression ratio and finally cause a lower compressor power.
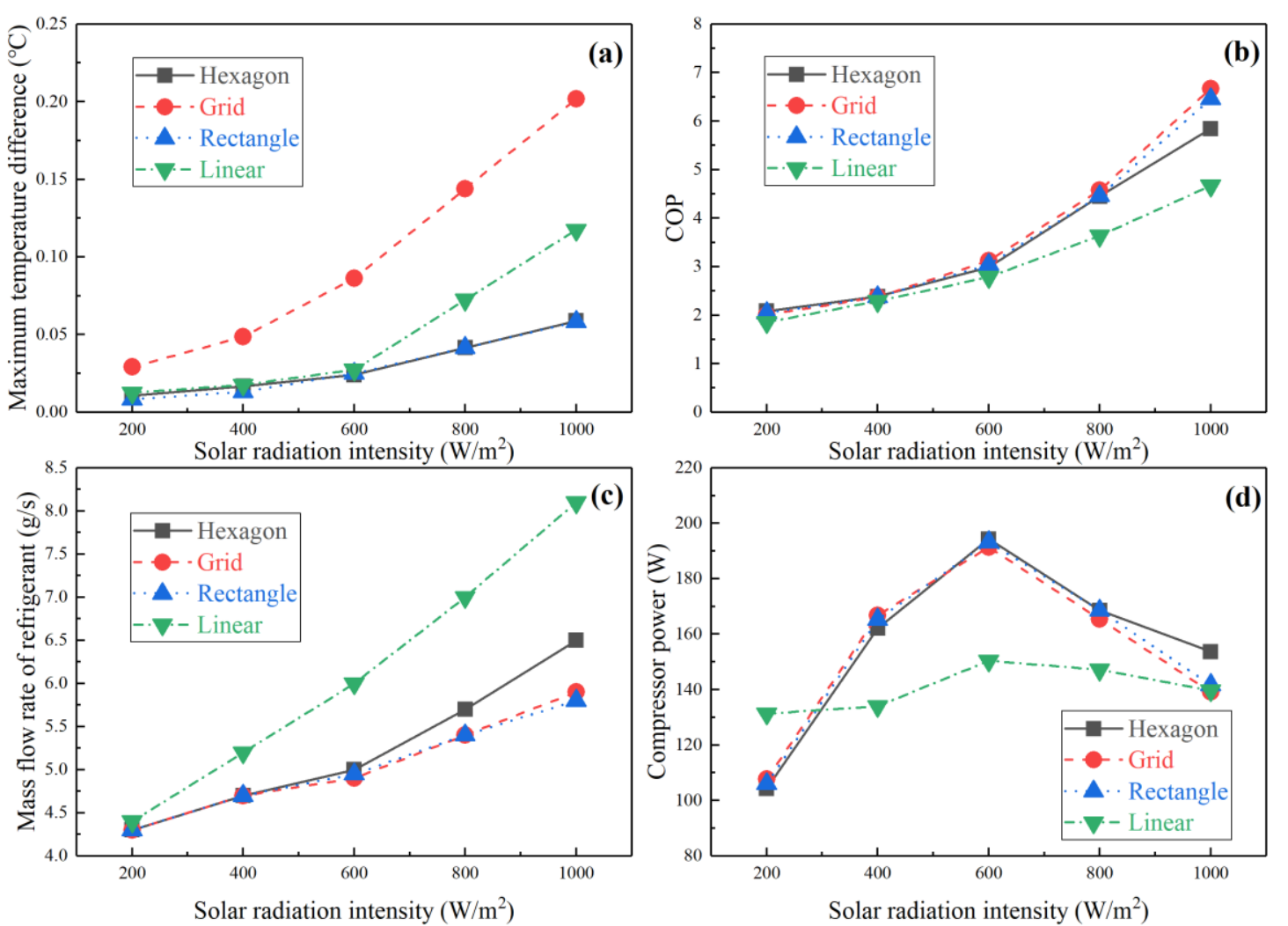

Fig. 12. Influence of solar radiation intensity on (a) maximum temperature difference. (b) COP. (c) mass flow rate of refrigerant. (d) compressor power.

The adoption of solar collector/evaporator would decrease the PV cells' temperature, however, different types of evaporators have different abilities to reduce the PV cells' temperature and improve electrical efficiency. In this regard, the PV cells' temperature and electrical efficiency 
of these four systems are compared with a single PV system. The PV cells' temperatures of a single PV system are $31.8^{\circ} \mathrm{C}, 43.8^{\circ} \mathrm{C}, 55.7^{\circ} \mathrm{C}, 67.9^{\circ} \mathrm{C}$, and $80.4{ }^{\circ} \mathrm{C}$ when solar radiation intensities are $200 \mathrm{~W} / \mathrm{m}^{2}, 400 \mathrm{~W} / \mathrm{m}^{2}, 600 \mathrm{~W} / \mathrm{m}^{2}, 800 \mathrm{~W} / \mathrm{m}^{2}$, and $1000 \mathrm{~W} / \mathrm{m}^{2}$, respectively. Meanwhile, the electrical efficiencies of a single PV system are $13.35 \%, 12.61 \%, 11.87 \%, 11.11 \%$, and $10.34 \%$, respectively.

As shown in Fig. 13(a, b), the linear type evaporator has the worst ability to reduce the PV cells' temperature, and it has the lowest improvement of electrical efficiency, while the others have almost the same performance. For instance, the linear type system reduces $28.2^{\circ} \mathrm{C}$ of the PV cells' temperature and improve $16.8 \%$ of the electrical efficiency compare with a single PV system when the solar radiation intensity is $1000 \mathrm{~W} / \mathrm{m}^{2}$. In the meantime, the temperature drops of grid, rectangle, and hexagon type systems are $39.7^{\circ} \mathrm{C}, 39.3^{\circ} \mathrm{C}$, and $38.8^{\circ} \mathrm{C}$, respectively. Meanwhile, the improvements in electrical efficiency of grid, rectangle, and hexagon type systems are $23.8 \%$, $23.5 \%$, and $23.2 \%$, respectively. Furthermore, the electrical powers of the grid, rectangle, hexagon, and linear type systems are $255.9 \mathrm{~W}, 255.4 \mathrm{~W}, 254.8 \mathrm{~W}$, and $241.7 \mathrm{~W}$, respectively.
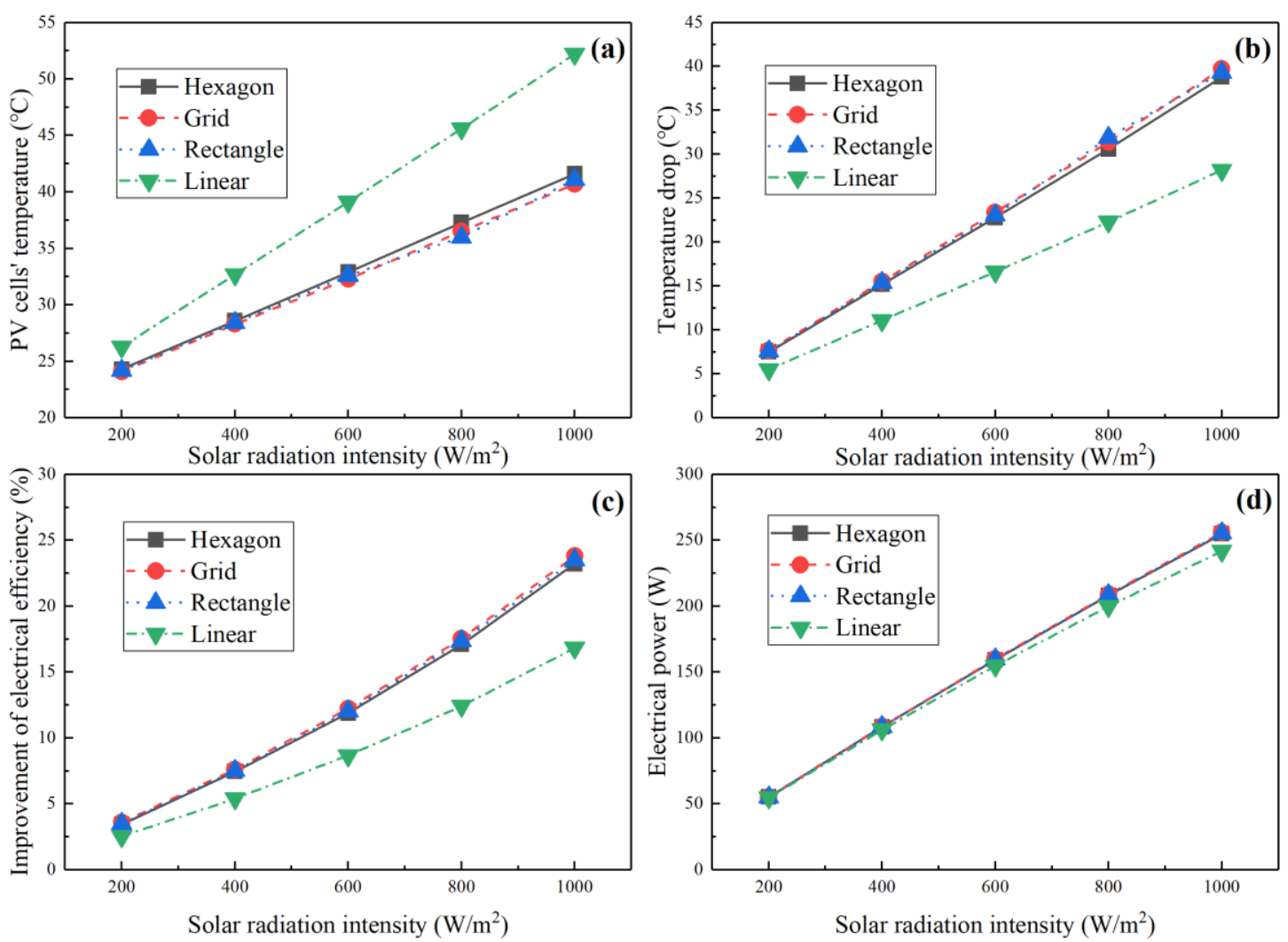

Fig. 13. Influence of solar radiation intensity on (a) PV cells' temperature. (b) temperature drop. (c) improvement of electrical efficiency. (d) electrical power.

Fig. 14(a) shows the variation curves of electrical exergy efficiency and electrical efficiency with the solar radiation intensity. The electrical exergy efficiency as well as electrical efficiency both decrease linearly with the increase of solar irradiation, and the linear type PVT system has the lowest electrical exergy efficiency and electrical efficiency compare with other systems. For instance, the electrical exergy efficiency of the linear type system is $12.73 \%$ when solar radiation intensity is $1000 \mathrm{~W} / \mathrm{m}^{2}$ while the electrical exergy efficiencies of grid, rectangle, and hexagon type systems are $13.48 \%, 13.45 \%$, and $13.42 \%$. As shown in Fig. 14(b), the system using grid type 
evaporator has the highest thermal exergy efficiency and leads to the highest COP, while the system using linear type evaporator has the lowest thermal exergy efficiency under different solar irradiation conditions.

Fig. 14(c) presents the influence of solar radiation intensity on the efficiency factor, and the efficiency factors of all four types of evaporators decreases smoothly with the increase of solar irradiation. The same conclusion could be drawn as sub-section 5.1 that the grid type evaporator has the highest efficiency factor, and the rectangle type evaporator is the second highest, then is the hexagon type evaporator, while the linear type evaporator has the lowest efficiency factor.

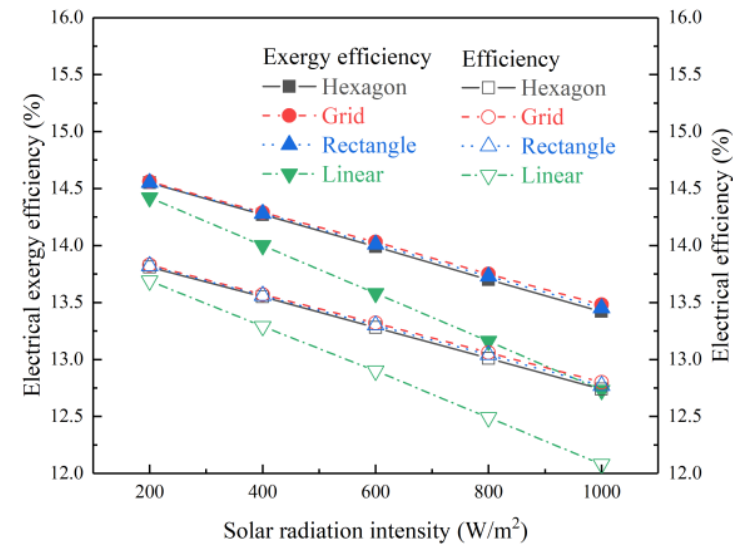

(a)

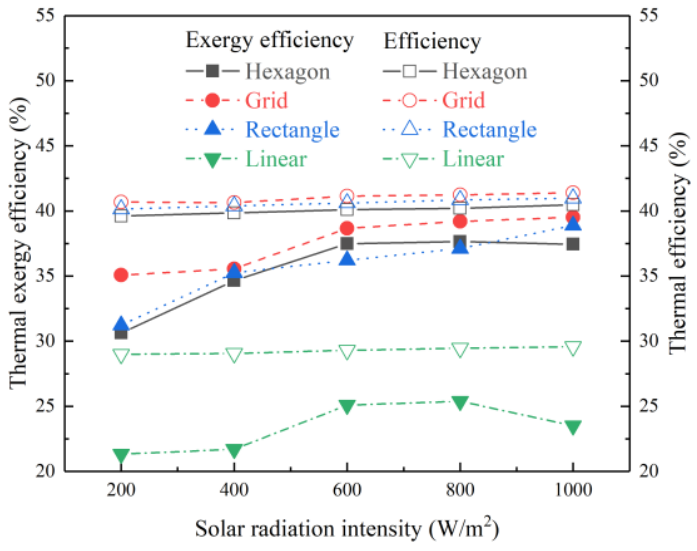

(b)

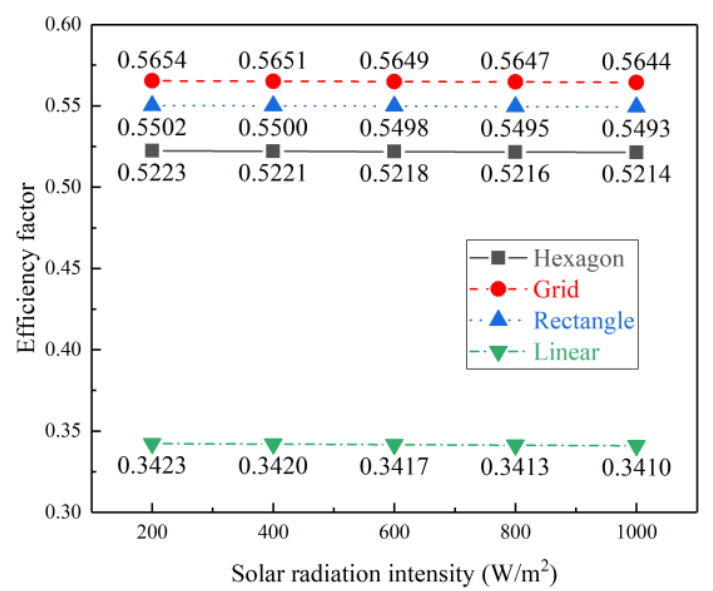

(c)

\subsection{Width of the fluid channel}

The influence of fluid channel width on modified and unmodified efficiency factor and dimensionless pressure loss is shown in Fig. 15. The analysis is conducted under wind speed is 2.5 $\mathrm{m} / \mathrm{s}$, ambient temperature is $25^{\circ} \mathrm{C}$, and PV cells' temperature is $40^{\circ} \mathrm{C}$. The maximum width of the fluid channels varies from $4 \mathrm{~mm}$ to $13 \mathrm{~mm}$ of each type of evaporator unit. If the width is less than $4 \mathrm{~mm}$, the roll-bond panel is useless and meaningless as a thermal collector due to a significant pressure loss, which would cause a high compressor power and reduce the mass flow rate of refrigerant, and finally lead to a poor thermal performance of the evaporator. If the width is wider 
than $13 \mathrm{~mm}$, the roll-bond panel would not be able to withstand the high-pressure refrigerant without destruction. As shown in Fig. 15(a), the efficiency factor increases rapidly from the beginning and smoothly at the end. The linear type has the highest modified efficiency factor than the other three types when the fluid width is $4 \mathrm{~mm}$ due to the minimum dimensionless pressure loss coefficient. However, the modified efficiency factors of the other three types exceed linear type when the width is wider than $6 \mathrm{~mm}$. Moreover, the modified efficiency factor of the grid type is almost two times of linear type when the fluid channel width is $13 \mathrm{~mm}$. The modified efficiency factors at $13 \mathrm{~mm}$ of hexagon, grid, rectangle, and linear type are 182.5\%,170.5\%,131.3\%, and $21.5 \%$ higher than at $4 \mathrm{~mm}$, respectively. A wider width of the fluid channel is better for the PVT collector/evaporator theoretically due to a higher efficiency factor. Nevertheless, a wider width of the fluid channel means more charge of refrigerant in the solar assisted heat pump system, which would cause a higher initial cost due to a larger volume of fluid in the roll-bond evaporator.

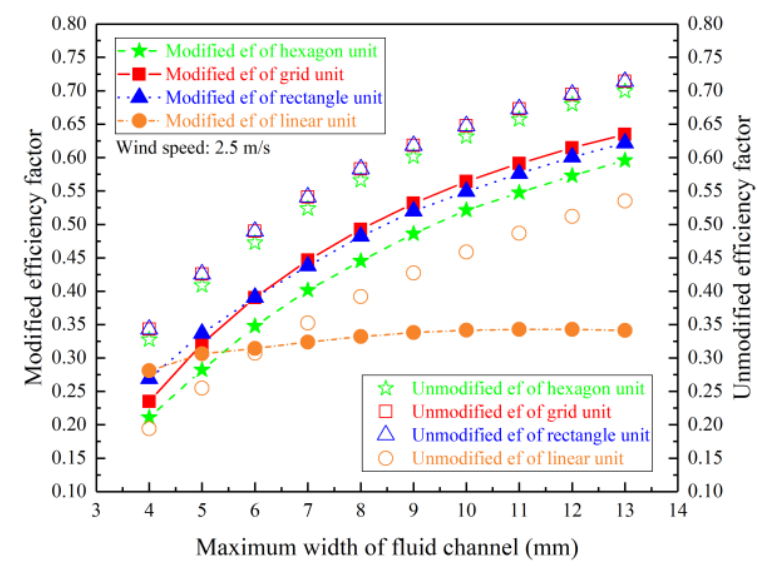

(a)

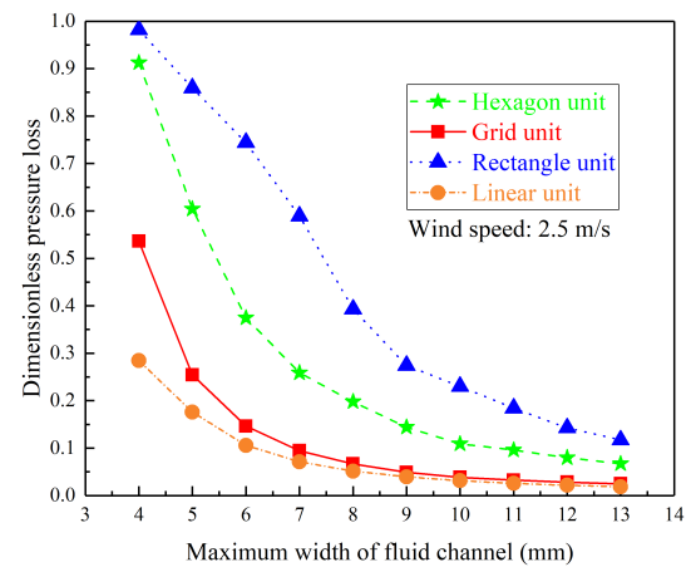

(b)

Fig. 15. Influence of width of the fluid channel on (a) modified and unmodified efficiency factor;

(b) dimensionless pressure loss coefficient.

As shown in Fig. 15(b), different types of evaporator units have the same trend of dimensionless pressure loss. The rectangle type has the highest pressure drop, and hexagon type is the second while the grid type is almost half of it, and the linear type is the last. The pressure drop decreases rapidly from the beginning and smoothly at the end, which has the opposite trend with the efficiency factor. The dimensionless pressure drop at $13 \mathrm{~mm}$ of hexagon, grid, rectangle, and linear type is $7.33 \%, 4.65 \%, 11.92 \%$, and $6.54 \%$ of it at $4 \mathrm{~mm}$. Thus, the fluid channel is not the wider, the better through the above discussion, it has to consider pressure loss, efficiency factor, and initial cost. Due to the significant reduction of pressure loss when fluid channel width increases, the recommendation of fluid channel width is in the range of $8 \mathrm{~mm}$ to $13 \mathrm{~mm}$. If the channel width exceeds $13 \mathrm{~mm}$, the roll-bond panel could not withstand the high-pressure refrigerant during the evaporating process.

\subsection{Area scaling ratio of PVT collector/evaporator unit}

The influence of area scaling ratio which varies from 0.5 to 1.5 on the modified efficiency factor of four types units is shown in Fig. 16. The analysis is conducted under PV cells' temperature is $40^{\circ} \mathrm{C}$ ambient temperature is $25^{\circ} \mathrm{C}$, the maximum width of the fluid channel is 10 $\mathrm{mm}$, and wind speed is $2.5 \mathrm{~m} / \mathrm{s}$. The illustration of the scaling ratio is shown in the downside of 
Fig. 16 which means the length and width of the unit multiple scaling ratio varies from 0.5 to 1.5 while the channel pattern and fluid channel width remain the same. This parameter would reflect the arrangement density of each unit in the same area roll-bond panel. These four variation curves share the same trend which is almost linearly decreased when the scaling ratio increases. The smaller the evaporator unit, the more refrigerant charge of the evaporator which would multiply the initial cost. The maximum modified efficiency factors are obtained when the scaling ratio is 0.5 , which are $0.639,0.685,0.667$, and 0.468 of hexagon, grid, rectangle, and linear type, respectively. Moreover, the modified efficiency factors when scaling ratio is 0.5 are $45.3 \%, 42.9 \%$, $42.9 \%$, and $74.4 \%$ higher than it when scaling ratio is 1.5 of hexagon, grid, rectangle, and linear type, respectively. The modified efficiency factor of the linear type unit would be affected by the scaling ratio most due to the simplest pattern. From the other aspect, the smaller the unit, the worse the pressure withstand capacity, and under a high solar radiation intensity, smaller unit is more vulnerable to break by the high-pressure refrigerant during the evaporating process. Therefore, pressure withstands capacity, efficiency factor, and initial cost should be considered to define the best scaling ratio of an evaporator unit, and the recommendation scaling ration is 0.8 to 1.2 due to the reasons mentioned above.

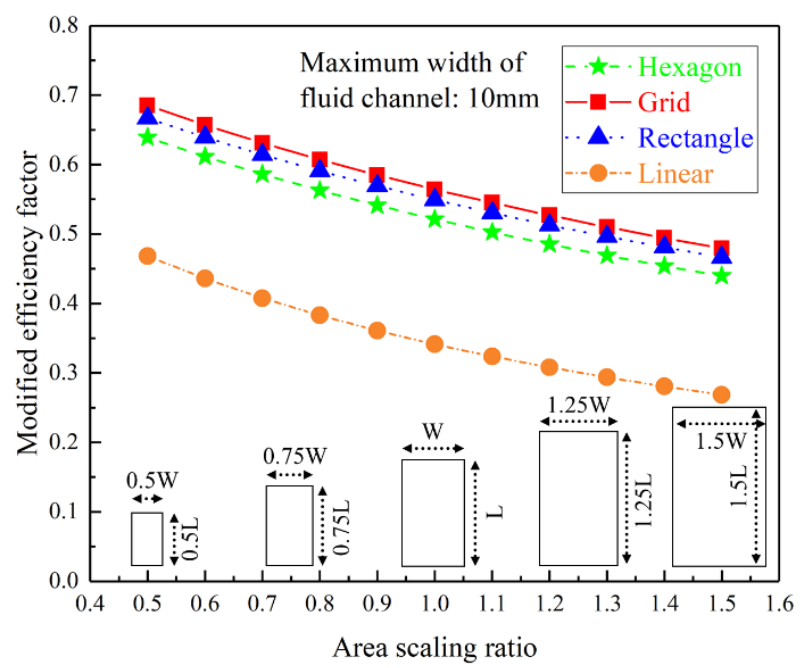

Fig. 16. Influence of area scaling ratio on modified efficiency factor of four types units.

\subsection{Combination of different evaporator unit types}

According to the above discussions, there are six combinations of four unit types have shown in Fig. 17. The hexagon and rectangle types have the best temperature distribution uniformity while these two types have higher pressure loss, which means a higher energy consumption of the compressor. On the opposite, the grid and linear type have the lowest pressure loss but have a worse temperature distribution uniformity. Therefore, a novel combination method has been proposed: the combination of different unit types would be a solution to balance temperature distribution uniformity and pressure loss. Form combination (a) to (f), the pressure loss would decrease as well as temperature distribution uniformity. Thus, the combination choice is not the same for different usage. For instance, if the roll-bond evaporator is used for a direct expansion evaporator solar assisted heat pump system, the temperature distribution uniformity is not the first concern. Thus, the grid type or combination (f) would be the best choice due to a higher efficiency 
factor and a lower compressor energy consumption, which would lead to a higher system COP (coefficient of performance). If the roll-bond evaporator is encapsulated in the PVT module, consider the temperature distribution uniformity to be a higher priority than the pressure loss. Because the temperature distribution uniformity would significantly affect the electrical efficiency and life of the PV cells. Moreover, a more uniformity temperature would increase the stability of the PV cells' current output, which is good for the MPPT solar control device. Thus, combination (b) and (c) would be a better choice for the PVT module considering temperature uniformity than other combinations. To be noted, this novel design method could also be used for different types of PV panels. That is because different kinds of PV panels made by different materials like monocrystalline silicon or polycrystalline silicon and their positions where produce heat are different. Therefore, the evaporator pattern encapsulated in PVT module could be specifically designed and customized for different kinds of PV panels through this design method.

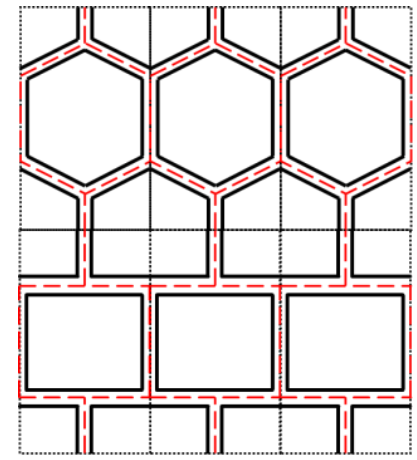

(a) Hexagon-Rectangle

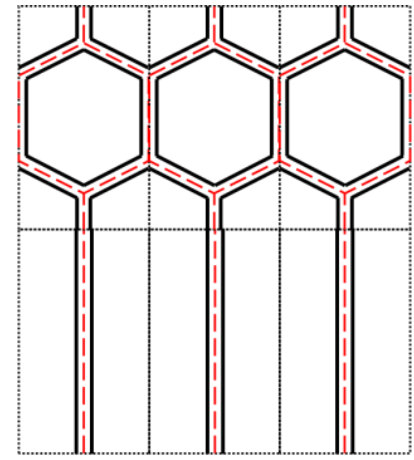

(d) Hexagon-Linear

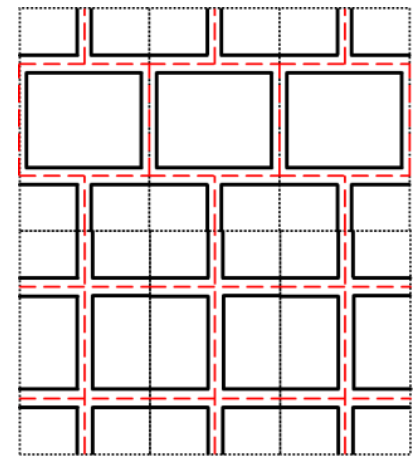

(b) Rectangle-Grid

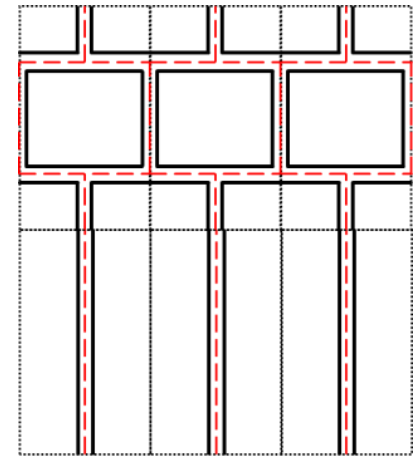

(e) Rectangle-Linear

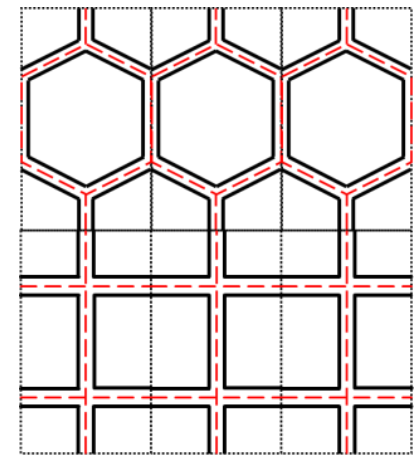

(c) Hexagon-Grid

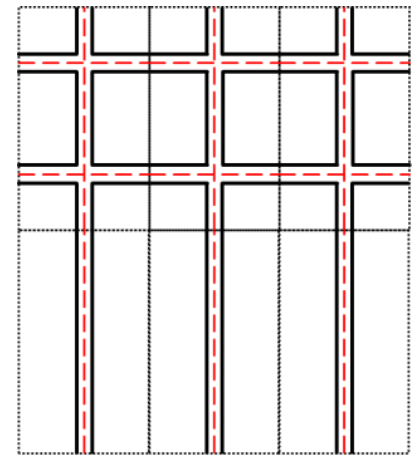

(f) Grid-Linear

Fig. 17. (a f) Different combinations of four unit types.

\section{Conclusions}

Theoretical analysis on the efficiency factor of direct expansion PVT module employing roll-bond collector/evaporator for heat pump application has been conducted in this paper. Aiming to evaluate and design different patterns of roll-bond evaporator which encapsulated in the PVT module, the characteristics of four evaporator unit types have been studied and verified. The main conclusions can be drawn as follows:

(1) Different theoretical efficiency factor expressions of hexagon, grid, rectangle, and linear type units of both PVT module and direct expansion evaporator have given in Table. 2. Moreover, to evaluate the influence of pressure loss on efficiency factor, a mathematical model using the 
CFD model is proposed to modify the efficiency factor which has shown in section 3.3.

(2) Hexagon and rectangle types have better temperature distribution uniformity but higher pressure loss while grid and linear types are the opposite. The dimensionless pressure losses are $0.109,0.039,0.230$ and 0.031 of hexagon, grid, rectangle and linear unit types when the fluid channel width is $10 \mathrm{~mm}$, respectively, while the PV cells' maximum temperature differences are $0.038^{\circ} \mathrm{C}, 0.135^{\circ} \mathrm{C}, 0.038^{\circ} \mathrm{C}$ and $0.061{ }^{\circ} \mathrm{C}$, respectively.

(3) A higher solar radiation intensity would decrease the temperature uniformity of PVT front surface due to a higher temperature difference. The grid type evaporator perform better at reducing the PV cells' temperature (reduce $23.4{ }^{\circ} \mathrm{C}$ when solar irradiation is $600 \mathrm{~W} / \mathrm{m}^{2}$ ) and its corresponding improvement of electrical efficiency is $12.2 \%$ which is $11.9 \%$ for hexagon type, $12.0 \%$ for rectangle type, and $8.7 \%$ for linear type.

(4) The recommendation fluid channel width of the roll-bond panel is $8 \mathrm{~mm}$ to $13 \mathrm{~mm}$, while the recommendation scaling ratio is 0.8 to 1.2 . The modified efficiency factors are $0.521,0.564$, 0.549 , and 0.342 of hexagon, grid, rectangle, and linear types when fluid channel width is $10 \mathrm{~mm}$, respectively.

(5) A novel design method is proposed to specifically design for different kinds of PV panels or direct expansion evaporators. Combinations of the hexagon and grid types or rectangle and grid types are recommended for PVT collector/evaporator, while the combination of grid and linear types or whole grid types are recommended for direct expansion evaporator.

The efficiency factor could be used to analyze and optimize the direct expansion solar collector/evaporator and to simulate the performance of solar assisted heat pump systems. However, the expressions of the modified efficiency of other evaporator patterns could be further studied.

\section{Acknowledgments}

This research work is funded by the International Research Cooperation Program of Shanghai (Grant No. 18160710500).

\section{Nomenclature:}

\section{Symbols}

$A$

W

$L$

$F^{\prime}$

$F_{\text {mod }}$

$F_{R}$

$F$

$\Delta H$

$h$

$S$

$U$

$D$

$T$ area $\left(\mathrm{m}^{2}\right)$

width of roll-bond panel collector/evaporator unit $(\mathrm{m})$

length of roll-bond panel collector/evaporator unit $(\mathrm{m})$

unmodified efficiency factor (-)

modified efficiency factor $(-)$

heat removal factor (-)

fin efficiency (-)

latent heat $(\mathrm{kJ} / \mathrm{kg})$

heat transfer coefficient $\left(\mathrm{W} / \mathrm{m}^{2} \cdot{ }^{\circ} \mathrm{C}\right) /$ enthalpy $(\mathrm{J} / \mathrm{kg})$

entropy $\left(\mathrm{J} / \mathrm{kg} \cdot{ }^{\circ} \mathrm{C}\right)$

heat loss coefficient $\left(\mathrm{W} / \mathrm{m}^{2} \cdot{ }^{\circ} \mathrm{C}\right)$

equivalent width of the fluid channel (m)

temperature $(\mathrm{K})$ 


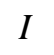

$Q$

$v$

$m$

$P^{\prime}$

$P$

Ex

667

668 Greek symbols

$\delta$

$\tau$

$a$

$\beta$

$\varepsilon$

$\kappa$

$\sigma$

$\eta$

$\chi$

$\Psi$

669

670 Subscripts

$\begin{array}{ll}p & \text { PV cells } \\ e & \text { electrical } \\ c & \text { PV-glazing cover }\end{array}$

EVA

eva

ref

cv

$c d$

$r d$

Al

a

$L$

$u$

Tot

$n$

$e q$

in

out

sun solar radiation intensity $\left(\mathrm{W} / \mathrm{m}^{2}\right)$

heat transfer rate $(\mathrm{W})$

wind speed $(\mathrm{m} / \mathrm{s})$

mass flowrate $(\mathrm{kg} / \mathrm{s})$

dimensionless pressure loss (-)

pressure $(\mathrm{Pa})$

exergy rate (W)

thickness (m)

transmittance (-)

absorption ratios (-)

packing factor (-)

emissivity (-) / exergy efficiency (-)

thermal conductivity $\left(\mathrm{W} / \mathrm{m} \cdot{ }^{\circ} \mathrm{C}\right)$

Stefan-Boltzmann constant (-)

efficiency (-)

dryness (-)

stream exergy per unit mass $(\mathrm{W} / \mathrm{kg})$

EVA (Ethylene Vinyl Acetate) grease

evaporator

refrigerant

convection

conduction

radiation

aluminum roll-bond panel pipe

ambient

lost

useful

total

number

equivalent

inlet

outlet

sun

References:

672 Bliss, R.W., 1959. The derivations of several "Plate-efficiency factors" useful in the design of flat-plate

673 solar heat collectors. Solar Energy 3(4), 55-64. 
Caetano, N.S., Mata, T.M., Martins, A.A., Felgueiras, M.C., 2017. New Trends in Energy Production and Utilization. Energy Procedia 107, 7-14.

Cai, J., Ji, J., Wang, Y., Zhou, F., Yu, B., 2017. A novel PVT-air dual source heat pump water heater system: Dynamic simulation and performance characterization. Energy Conversion and Management 148, 635-645.

Chauhan, A., Tyagi, V.V., Anand, S., 2018. Futuristic approach for thermal management in solar PVThermal systems with possible applications. Energy Conversion and Management 163, 314-354.

Chauhan, A., Tyagi, V.V., Anand, S., 2019. Minimum entropy generation and its validation against Hottel Whillier model for PVT and FPC collectors. Solar Energy 188, 143-157.

Chow, T.T., Pei, G., Fong, K.F., Lin, Z., Chan, A.L.S., Ji, J., 2009. Energy and exergy analysis of photovoltaic-thermal collector with and without glass cover. Applied Energy 86(3), 310-316.

Del Amo, A., Martínez-Gracia, A., Bayod-Rújula, A.A., Cañada, M., 2019. Performance analysis and experimental validation of a solar-assisted heat pump fed by photovoltaic-thermal collectors. Energy $169,1214-1223$.

Duffie, J., Beckman, W.A., Worek, W., 1994. Solar Engineering of Thermal Process. Journal of Solar Energy Engineering-transactions of The Asme - J SOL ENERGY ENG 116.

Hc, H., Bb, W., 1942. Performance of flat-plate solar-heat collectors. Trans. ASME (Am. Soc. Mech. Eng.); (United States) 64.

Hottel, H., Whillier, A., 1955. Evaluation of flat-plate solar collector performance. Trans. Conf. Use of Solar Energy; () 3 (Thermal Processes) Part 2.

Huang, W., Ji, J., Xu, N., Li, G., 2016. Frosting characteristics and heating performance of a direct-expansion solar-assisted heat pump for space heating under frosting conditions. Applied Energy 171, 656-666.

Huide, F., Xuxin, Z., Lei, M., Tao, Z., Qixing, W., Hongyuan, S., 2017. A comparative study on three types of solar utilization technologies for buildings: Photovoltaic, solar thermal and hybrid photovoltaic/thermal systems. Energy Conversion and Management 140, 1-13.

Kamel, R.S., Fung, A.S., Dash, P.R.H., 2015. Solar systems and their integration with heat pumps: A review. Energy and Buildings 87, 395-412.

Keček, D., Mikulić, D., Lovrinčević, Ž., 2019. Deployment of renewable energy: Economic effects on the Croatian economy. Energy Policy 126, 402-410.

Kong, X., Sun, P., Dong, S., Jiang, K., Li, Y., 2018a. Experimental performance analysis of a direct-expansion solar-assisted heat pump water heater with R134a in summer. International Journal of Refrigeration 91, 12-19.

Kong, X., Sun, P., Li, Y., Jiang, K., Dong, S., 2018b. Experimental studies of a variable capacity direct-expansion solar-assisted heat pump water heater in autumn and winter conditions. Solar Energy 170, 352-357.

Kuang, Y.H., Sumathy, K., Wang, R.Z., 2003. Study on a direct - expansion solar - assisted heat pump water heating system. International Journal of Energy Research 27, 531-548.

Kuik, O., Branger, F., Quirion, P., 2019. Competitive advantage in the renewable energy industry: Evidence from a gravity model. Renewable Energy 131, 472-481.

Mellor, A., Alonso Alvarez, D., Guarracino, I., Ramos, A., Riverola Lacasta, A., Ferre Llin, L., Murrell, A.J., Paul, D.J., Chemisana, D., Markides, C.N., Ekins-Daukes, N.J., 2018. Roadmap for the next-generation of hybrid photovoltaic-thermal solar energy collectors. Solar Energy 174, 386-398.

Mohanraj, M., Belyayev, Y., Jayaraj, S., Kaltayev, A., 2018. Research and developments on solar 
assisted compression heat pump systems - A comprehensive review (Part A: Modeling and modifications). Renewable and Sustainable Energy Reviews 83, 90-123.

P. Hartnett, J., M. Rohsenow, W., 1973. Handbook of Heat Transfer.

Paolo Frankl, S., 2010. Technology Roadmap: Solar Photovoltaic Energy.

Park, S.R., Pandey, A.K., Tyagi, V.V., Tyagi, S.K., 2014. Energy and exergy analysis of typical renewable energy systems. Renewable and Sustainable Energy Reviews 30, 105-123.

Pietrosemoli, L., Rodríguez-Monroy, C., 2019. The Venezuelan energy crisis: Renewable energies in the transition towards sustainability. Renewable and Sustainable Energy Reviews 105, 415-426.

Saffarian, M.R., Moravej, M., Doranehgard, M.H., 2020. Heat transfer enhancement in a flat plate solar collector with different flow path shapes using nanofluid. Renewable Energy 146, 2316-2329.

Sporn, P., Ambrose, E.R., 1955. The heat pump and solar energy proceedings of the world symposium on applied. Solar Energy 11, 1-5.

Stojanović, B., Akander, J., 2010. Build-up and long-term performance test of a full-scale solar-assisted heat pump system for residential heating in Nordic climatic conditions. Applied Thermal Engineering 30(2-3), 188-195.

Sun, X., Dai, Y., Novakovic, V., Wu, J., Wang, R., 2015. Performance Comparison of Direct Expansion Solar-assisted Heat Pump and Conventional Air Source Heat Pump for Domestic Hot Water. Energy Procedia 70, 394-401.

Tsai, H.-L., 2015. Modeling and validation of refrigerant-based PVT-assisted heat pump water heating (PVTA-HPWH) system. Solar Energy 122, 36-47.

Wolf, M., 1976. Performance analyses of combined heating and photovoltaic power systems for residences. Energy Conversion 16(1), 79-90.

Yao, J., Xu, H., Dai, Y., Huang, M., 2020. Performance analysis of solar assisted heat pump coupled with build-in PCM heat storage based on PVT panel. Solar Energy 197, 279-291.

Zhang, P., Rong, X., Yang, X., Zhang, D., 2019. Design and performance simulation of a novel hybrid PVT-air dual source heat pump system based on a three-fluid heat exchanger. Solar Energy 191, 505-517.

Zhang, X., Zhao, X., Smith, S., Xu, J., Yu, X., 2012. Review of R\&D progress and practical application of the solar photovoltaic/thermal (PVT) technologies. Renewable and Sustainable Energy Reviews 16(1), 599-617.

Zhou, C., Liang, R., Zhang, J., Riaz, A., 2019. Experimental study on the cogeneration performance of roll-bond-PVT heat pump system with single stage compression during summer. Applied Thermal Engineering 149, 249-261.

Zhou, J., Ma, X., Zhao, X., Yuan, Y., Yu, M., Li, J., 2020. Numerical simulation and experimental validation of a micro-channel PVT modules based direct-expansion solar heat pump system. Renewable Energy 145, 1992-2004. 
Conflict of Interest
We declare that there are no conflicts of interest in the work we submitted.

Conflict of Interest
We declare that there are no conflicts of interest in the work we submitted.

\section{conflict of Interest Statement}

Conflict of Interest
We declare that there are no conflicts of interest in the work we submitted.

.

(1)

(1)

(1)

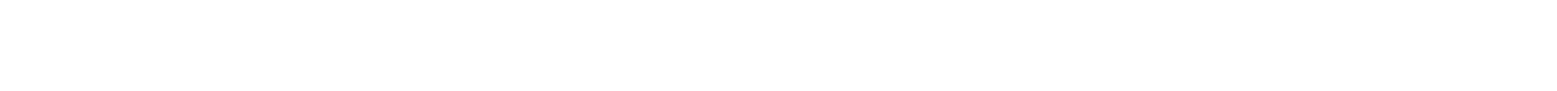
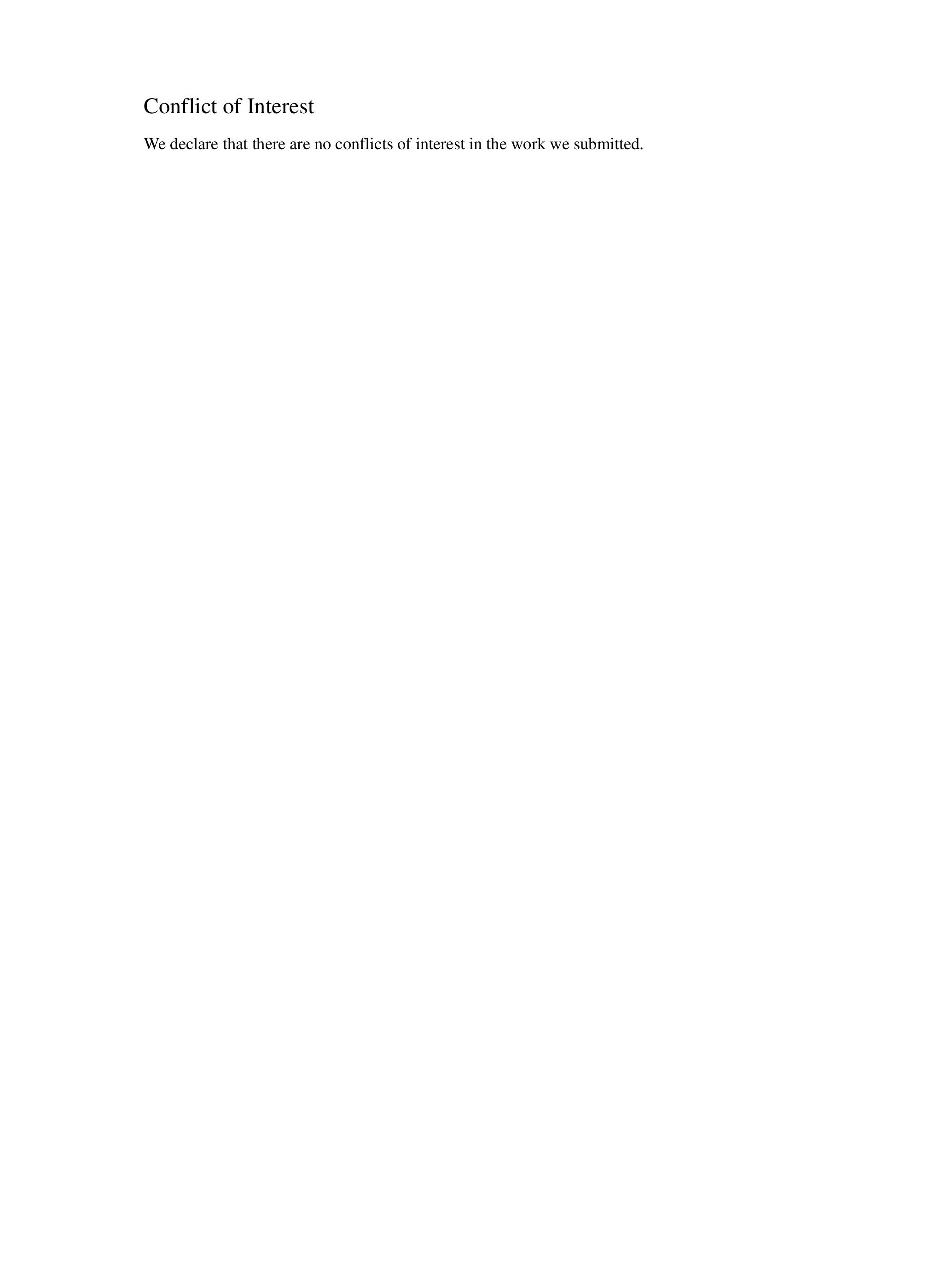